\title{
Global Wellness
}

\section{Tourism Economy}

NOVEMBER 2018

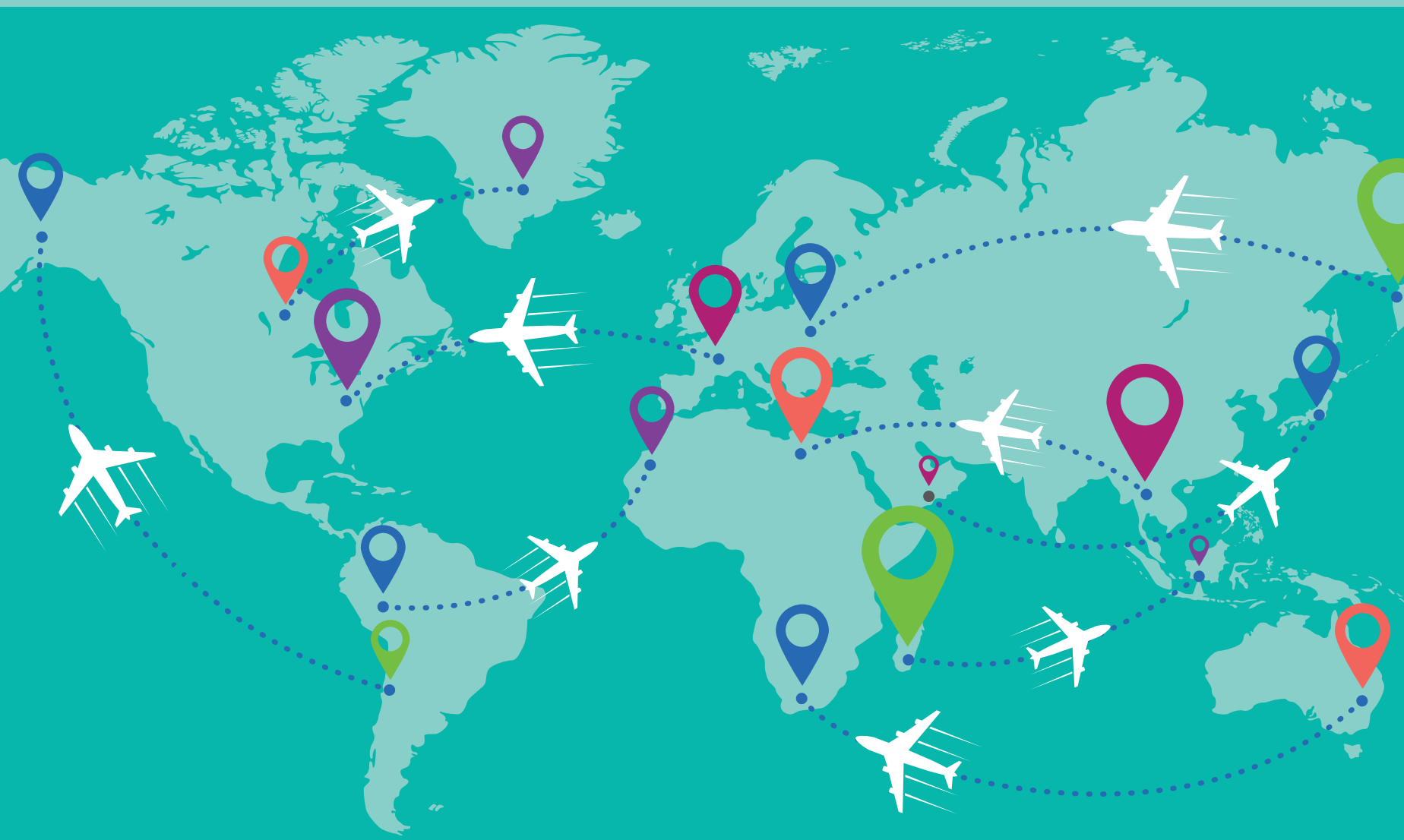

\section{GLOBAL WELLNESS}





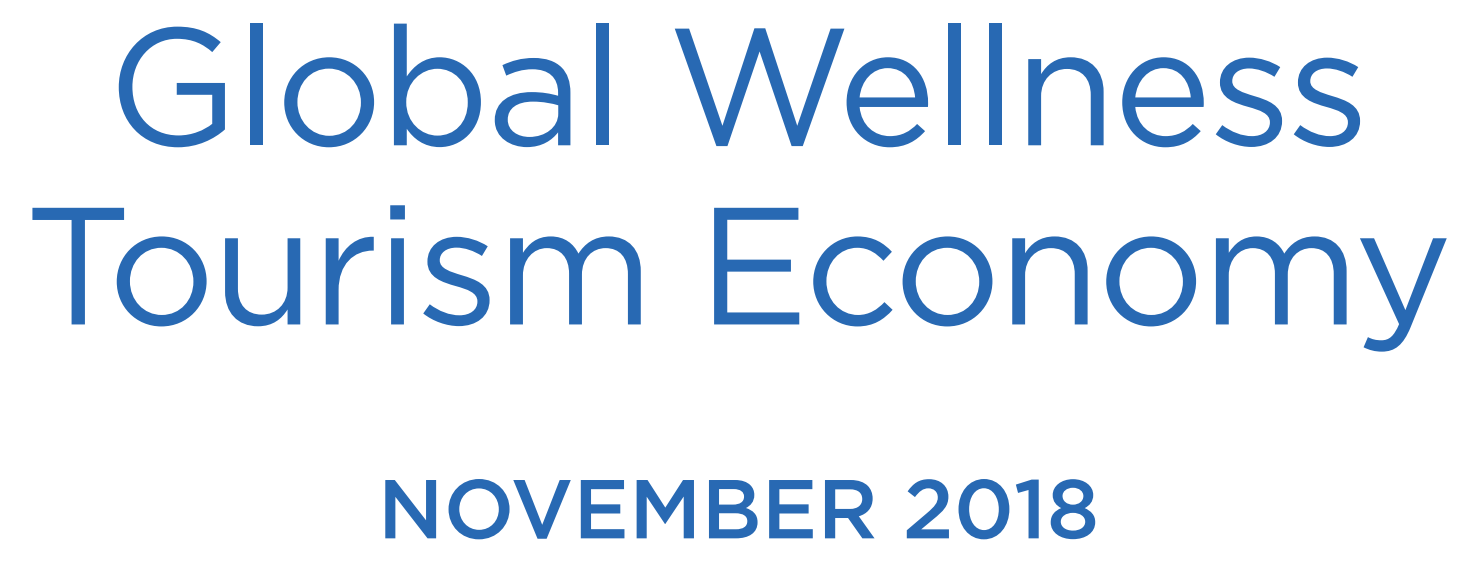

GLOBAL WELLNESS

INSTITUTE $^{\text {TM }}$

EMPOWERING WELLNESS WORLDWIDE 


\section{Copyright $\odot 2018$ by the Global Wellness Institute}

Quotation of, citation from, and reference to any of the data, findings, and research methodology from this report must be credited to "Global Wellness Institute, Global Wellness Tourism Economy, November 2018." For more information, please contact research@globalwellnessinstitute. org or visit www.globalwellnessinstitute.org. 
Full Report

Preface 


\section{ABOUT THE AUTHORS}

\section{ABOUT THE GLOBAL WELLNESS INSTITUTE}

The Global Wellness Institute (GWI), a 501(c)(3) non-profit organization, is considered the leading global research and educational resource for the global wellness industry and is known for introducing major industry initiatives and regional events that bring together leaders and visionaries to chart the future. GWI positively impacts global health and wellness by advocating for both public institutions and businesses that are working to help prevent disease, reduce stress, and enhance overall quality of life. Its mission is to empower wellness worldwide.

www.globalwellnessinstitute.org

\section{ABOUT THE AUTHORS}

The Global Wellness Tourism Economy report was prepared by Ophelia Yeung and Katherine Johnston, Senior Research Fellows at the Global Wellness Institute. Together, they have four decades of experience leading research and strategy development for businesses, universities, research institutions, and multilateral and government organizations under the auspices of SRI International, a Silicon Valley-based technology and innovation company. Since 2008, Ms. Yeung and Ms. Johnston have worked with the team at what has become the Global Wellness Institute to pioneer groundbreaking research on the global wellness economy and its subsectors. They were assisted in this research by Tonia Callender, GWI Research Fellow. 


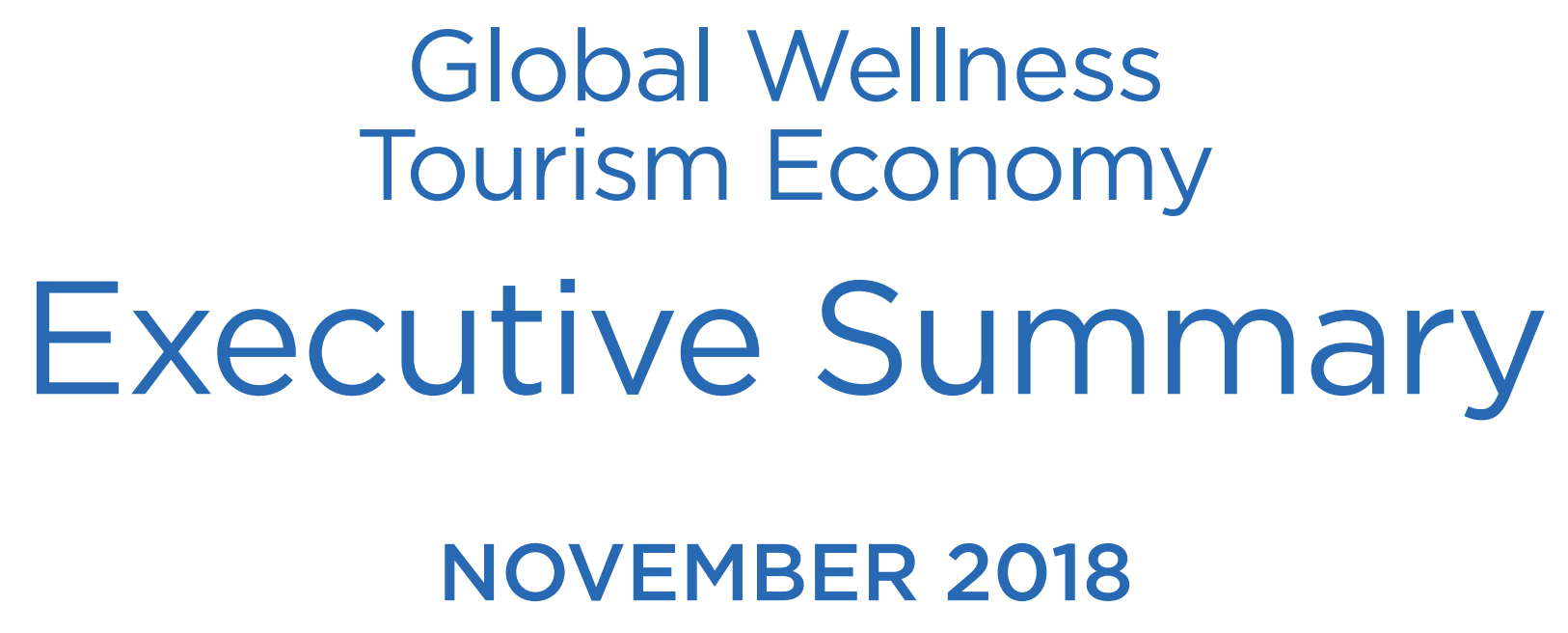

NOVEMBER 2018

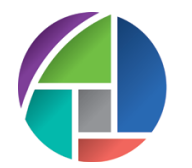

GLOBAL WELLNESS

INSTITUTE $^{\text {TM }}$

EMPOWERING WELLNESS WORLDWIDE 



\section{Wellness tourism is travel associated with the pursuit of maintaining or enhancing one's personal wellbeing. $\mathrm{GWI}$ estimates wellness tourism is a $\$ 639$ billion global market in 2017, growing more than twice as fast as general tourism.}

In 2013, the Global Wellness Institute (GWI) unveiled the inaugural edition of the Global Wellness Tourism Economy report - a landmark study that defined the parameters and characteristics of the emerging wellness tourism sector, estimated its global size, and highlighted its far reaching economic impacts. Since then, this tourism segment has accelerated around the world. This updated Global Wellness Tourism Economy report revisits the framework and definition presented in the inaugural report and provides new data and insights on global, regional, and country-level developments.

Estimated at $\$ 639.4$ billion in 2017 , wellness tourism is a fast-growing tourism segment that has been growing by $6.5 \%$ annually from 2015-2017 (more than twice the growth rate for general tourism). Travelers made 830 million wellness trips in 2017, which is 139 million more than in 2015. Growth has been driven by an expanding global middle class, growing consumer desire to adopt a wellness lifestyle, rising interest in experiential travel, and increasing affordability of flights and travel options. Across regions, Europe remains the destination for the largest number of wellness trips, while North America leads in wellness tourism expenditures. Asia has made the most gains in the number of wellness trips and wellness tourism expenditures, with demand stimulated by strong economies and an expanding middle class.

Wellness Tourism by Region, 2017

Number of wellness tourism trips and expenditures (inbound and domestic)

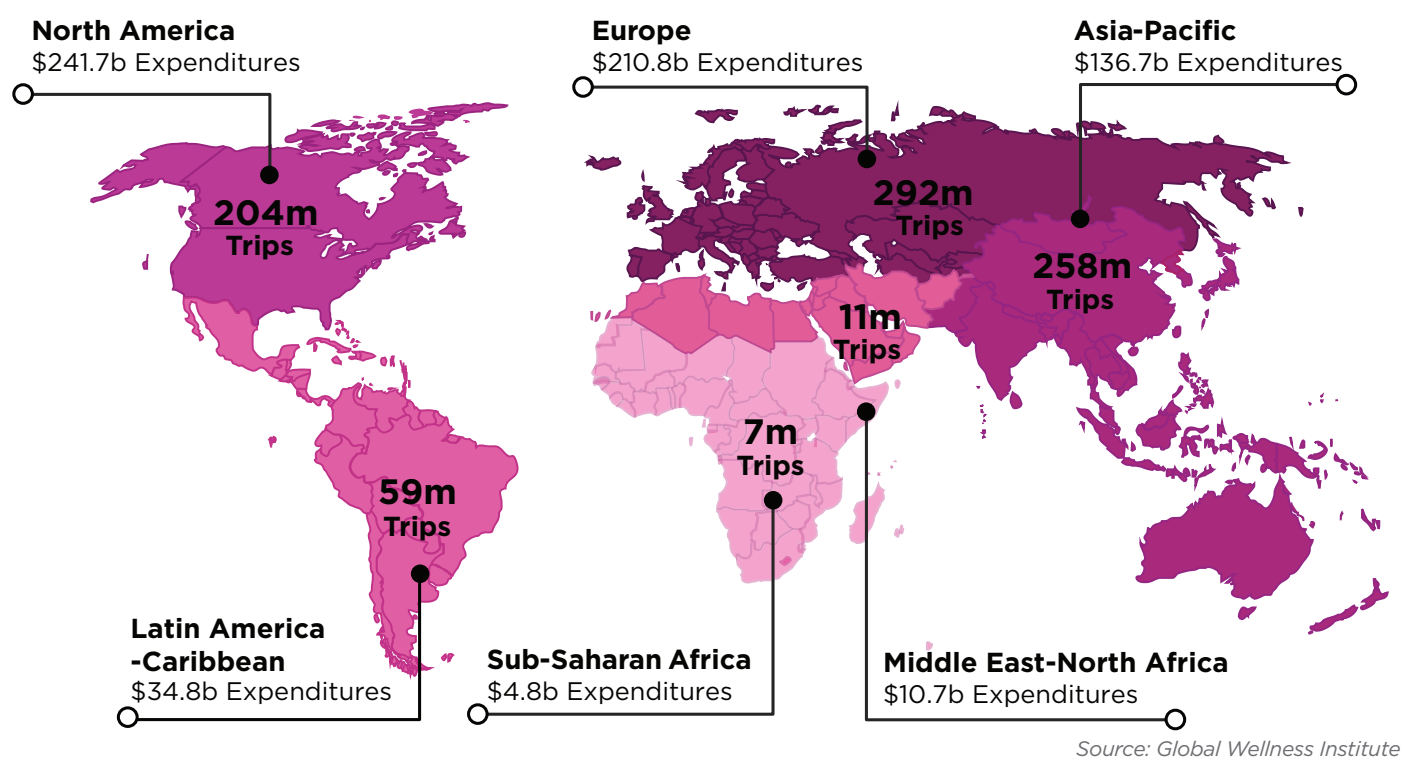




\section{Secondary wellness travelers account for the bulk of wellness tourism trips and growth: $89 \%$ of trips and $86 \%$ of expenditures.}

The wellness tourism market includes two types of travelers: primary wellness travelers, who are motivated by wellness to take a trip or choose their destination based on its wellness offerings (e.g., someone visiting a wellness resort or participating in a yoga retreat); and secondary wellness travelers, who seek to maintain wellness or engage in wellness activities during any kind of travel (e.g., someone who visits a gym, gets a massage, or prioritizes healthy food when they take a trip). The bulk of wellness tourism is done by secondary wellness travelers, who account for $89 \%$ of wellness tourism trips and $86 \%$ of expenditures in 2017 . Secondary wellness tourism also continues to grow at a faster rate than primary wellness tourism, at $10 \%$ compared to $8 \%$ annually, from 2015-2017.

\section{Domestic wellness travel dwarfs international wellness travel, but international wellness trips have been growing faster.}

Globally, domestic travel accounts for $82 \%$ of total wellness tourism trips and $65 \%$ of expenditures. International wellness trips represent a proportionally larger share of expenditures because the average level of spending for an international trip is much higher. International wellness tourism trips have also been growing at a faster pace ( $12 \%$ annually) than domestic wellness tourism trips (9\% annually) from 2015-2017.

\section{Secondary and Domestic Wellness Travel Lead In Trips and Expenditures}

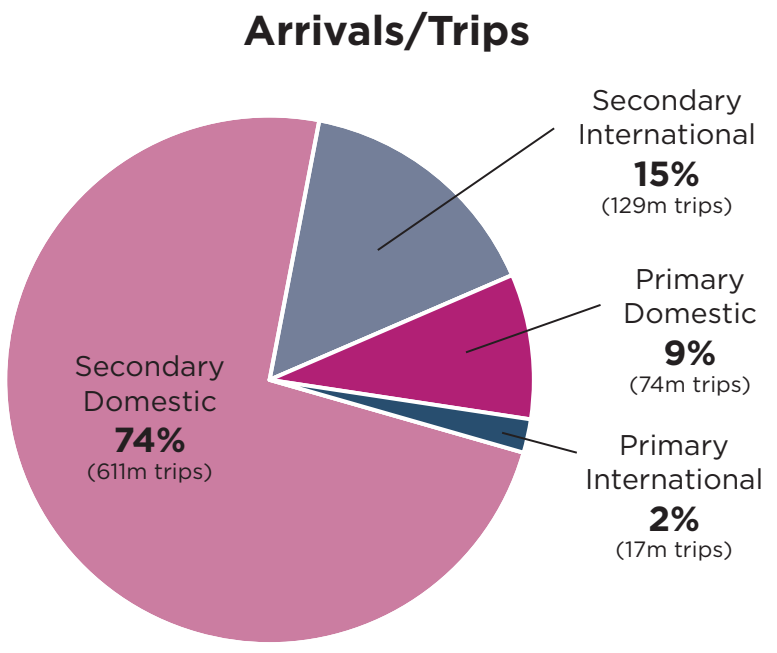

Receipts/Expenditures

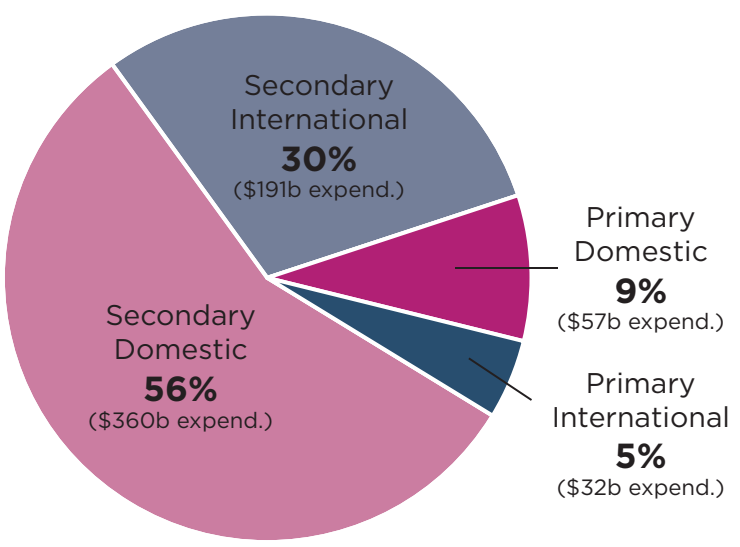

Note: Figures may not sum to total due to rounding. Source: Global Wellness Institute 


\section{Wellness tourism is high-yield tourism.}

Wellness travelers spend more per trip than the average tourist, and this holds true for both domestic and international travelers. In 2017, international wellness tourists on average spent $\$ 1,528$ per trip, $53 \%$ more than the typical international tourist. The premium for domestic wellness tourists is even higher. At $\$ 609$ per trip, they spend $178 \%$ more than the typical domestic tourist.

\section{Wellness Tourism Spending Premiums, 2017}

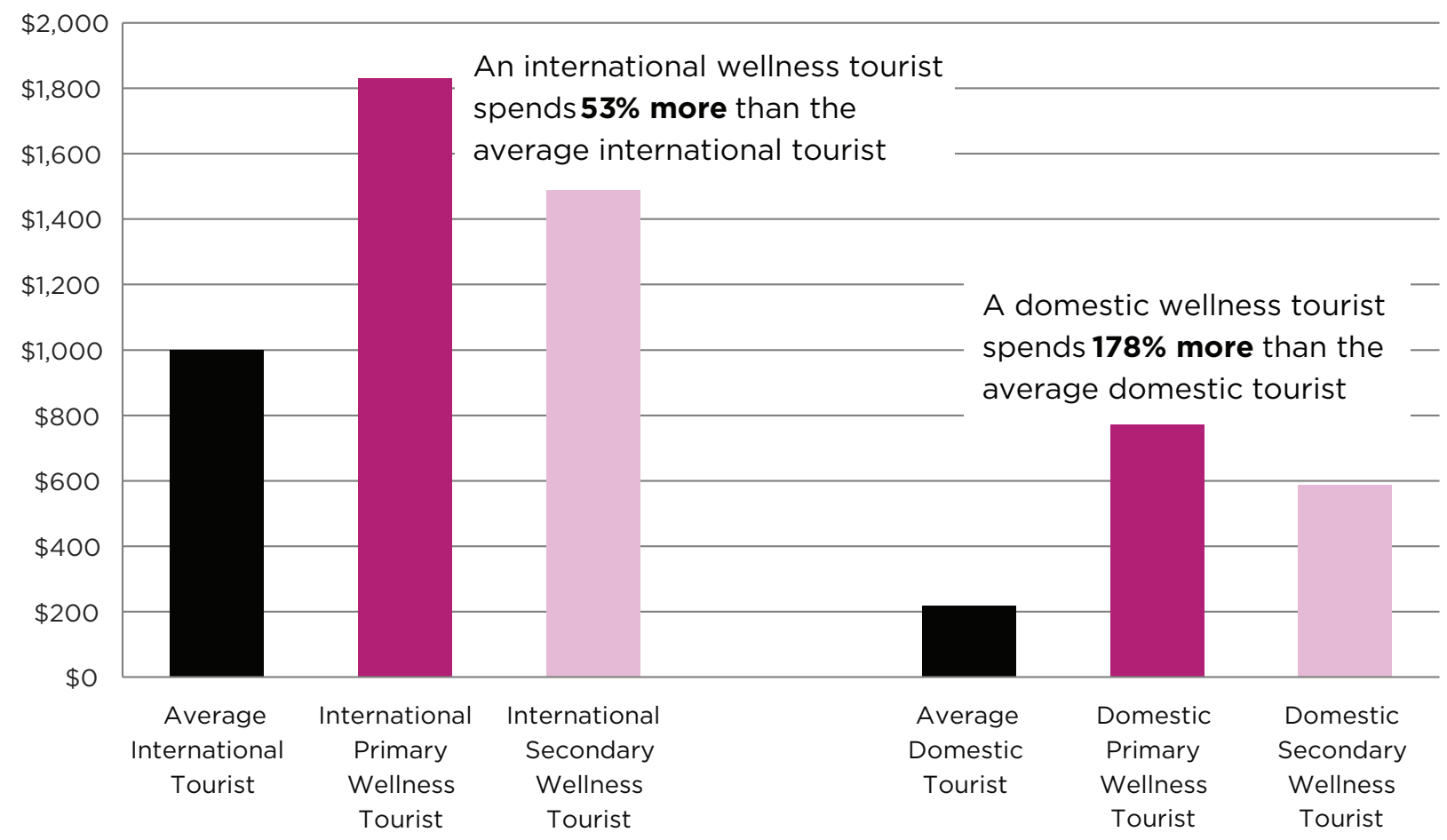




\section{Wellness tourism creates opportunities for wellness and all tourism and hospitality-related businesses.}

The $\$ 639.4$ billion spent globally by wellness travelers is distributed among many segments of the tourism industry, from food and lodging, to activities, excursions, shopping, and other services. Within each segment, some expenditures may include wellness-focused activities (such as visiting a hot spring, getting a massage, or taking a meditation or fitness class), while other expenditures may be "generic" (such as transportation, general food and lodging, or buying souvenirs). As more consumers incorporate wellness into their lifestyles, there are many opportunities for all businesses to infuse wellness into their offerings and capture spending by wellness travelers.

\section{Wellness Tourism Industry in 2017}

\begin{tabular}{|c|c|c|c|}
\hline $\begin{array}{c}\text { In-Country } \\
\text { Transport } \\
\mathbf{\$ 1 0 9 . 9 b}\end{array}$ & $\begin{array}{l}\text { Hotels/Motels } \\
\text { Resorts } \\
\text { Campgrounds }\end{array}$ & $\begin{array}{l}\text { Lodging } \\
\$ 130.5 b\end{array}$ & $\begin{array}{l}\text { Destination Spas } \\
\text { Health Resorts } \\
\text { Ashrams | Retreats }\end{array}$ \\
\hline $\begin{array}{c}\text { Airlines, Rental Cars } \\
\text { Public Transit, } \\
\text { Trains, Taxis }\end{array}$ & $\begin{array}{l}\text { Restaurants } \\
\text { Bars } \\
\text { Snack Shops }\end{array}$ & $\begin{array}{l}\text { Food \& Beverage } \\
\mathbf{\$ 1 1 1 . 5 b}\end{array}$ & $\begin{array}{c}\text { Spa Cuisine } \\
\text { Healthy Cuisine } \\
\text { Organic Cuisine }\end{array}$ \\
\hline $\begin{array}{c}\text { Other Services } \\
\mathbf{\$ 8 9 . 5 b}\end{array}$ & $\begin{array}{l}\text { Souvenirs | Gifts } \\
\text { Clothing | Art }\end{array}$ & $\begin{array}{l}\text { Shopping } \\
\$ 98.3 b\end{array}$ & $\begin{array}{l}\text { Fitness Wear I Spa Products } \\
\text { Healthy Foods I Vitamins }\end{array}$ \\
\hline $\begin{array}{c}\text { Telecom, Insurance, } \\
\text { Travel Agencies, } \\
\text { Concierges }\end{array}$ & $\begin{array}{l}\text { Museums } \\
\text { Tours | Theater }\end{array}$ & $\begin{array}{c}\text { Activities \& Excursions } \\
\$ 99.7 b\end{array}$ & $\begin{array}{l}\text { Spas | Bathing | Fitness } \\
\text { Meditation | Life Coaching }\end{array}$ \\
\hline Generic & & We & ness-Specific \\
\hline
\end{tabular}

Data combine both inbound/international and domestic wellness tourism spending, and also include both primary and secondary wellness trips.

Source: Estimates by the Global Wellness Institute, based on tourism industry data from Euromonitor International. 


\section{Wellness tourism will continue its growth momentum as more consumers adopt wellness as a key decision driver.}

GWI projects that wellness tourism will grow at an average annual rate of $7.5 \%$ through 2022 , considerably faster than the $6.4 \%$ annual growth forecasted for overall global tourism. We expect that global wellness tourism expenditures will reach over $\$ 919$ billion in 2022, representing $18 \%$ of the global tourism market. Correspondingly, we project wellness tourism trips to grow by $8.1 \%$ annually to 1.2 billion trips in 2022 . This growth forecast is well-aligned with the expected growth across many sectors that focus on wellness and holistic health (e.g., fitness/mind-body, healthy eating, organic food, etc.), as more consumers adopt wellness as a dominant lifestyle value and decision driver.

Over half of the projected growth in wellness tourism expenditures (and three-quarters of the growth in wellness trips) through 2022 will take place in Asia-Pacific, Latin America-Caribbean, Middle East-North Africa, and Sub-Saharan Africa, driven by a dramatic increase in both domestic tourism and intra-regional wellness tourism in these markets.

\section{Wellness Tourism Growth Projections, 2017-2022}

\begin{tabular}{|c|c|c|c|}
\hline & \multicolumn{2}{|c|}{$\begin{array}{l}\text { Projected Expenditures } \\
\text { (US } \$ \text { billions) }\end{array}$} & \multirow{2}{*}{$\begin{array}{l}\text { Projected Average Annual } \\
\text { Growth Rate } \\
2017-2022\end{array}$} \\
\hline & 2017 & 2022 & \\
\hline North America & $\$ 241.7$ & $\$ 311.3$ & $5.2 \%$ \\
\hline Europe & $\$ 210.8$ & $\$ 275.0$ & $5.5 \%$ \\
\hline Asia-Pacific & $\$ 136.7$ & $\$ 251.6$ & $13.0 \%$ \\
\hline Latin America-Caribbean & $\$ 34.8$ & $\$ 54.7$ & $9.5 \%$ \\
\hline Middle East-North Africa & $\$ 10.7$ & $\$ 18.7$ & $11.8 \%$ \\
\hline Africa & $\$ 4.8$ & $\$ 8.1$ & $11.1 \%$ \\
\hline Total Wellness Tourism Industry & $\$ 639.4$ & $\$ 919.4$ & $7.5 \%$ \\
\hline
\end{tabular}

Source: Global Wellness Institute estimates, based upon tourism industry data from Euromonitor International, economic data from the IMF, and GWI's data and projection model 


\section{Wellness, hospitality, and travel businesses are converging.}

Since wellness tourism burst into mainstream consumer consciousness a few years ago, the industry has evolved rapidly. Businesses and governments are investing in developing new strategies, products, experiences, and destinations. Wellness, hospitality, and travel are converging in diverse and unprecedented ways, as businesses experiment with new partnerships and business models to help travelers incorporate wellness into every aspect of their trips.

Fly healthy and fly well. Recognizing that air travel can be unhealthy and stressful, airports and airlines are promoting health and wellness programs for their customers. Collaborations among airports, airlines, and wellness businesses are taking many forms: high-end spas, fitness centers, and wellness classes in terminals and airline lounges; in-flight meditation, wellness programming, and sleep aides; healthier food options; and even healthier/biophilic airport design.

Healthy hotels go mainstream. As wellness travel becomes more mainstream, many hotels are incorporating wellness into their design, amenities, services, and programming. Wellness features may include bedding and lighting that promote better sleep, windows and shades that block out light and noise, in-room fitness equipment and videos, healthy snacks and menus at restaurants, or on-site spas and gyms. Acquisitions, partnerships, and collaborations between hospitality companies and fitness, spa, and other wellness brands are increasingly common. An emerging trend is the adoption of wellness architecture, biophilic design, and sustainability elements into the entire design of the property.

Engineering wellness travel experiences. Consumers increasingly view vacations as an opportunity to experience wellness in new ways, and businesses from cruise lines to tour operators and event organizers are engineering diverse new wellness travel experiences. A number of cruise lines are partnering with wellness industry experts and service providers to raise the quality and sophistication of their wellness offerings or to create wellness-themed voyages.

Wellness products and brands travel with their customers. As wellness routines become a daily lifestyle for many consumers, products and brands are following their customers on their travels to help them continue these routines wherever they go (e.g., Westin partnering with Peloton). Some retail and product companies like Lululemon and Free People are extending their wellnessminded brands into experiences, such as offering wellness retreats for their customers.

A new nexus of travel, work, and wellness. For those who want to experience a country for a longer duration than the standard vacation, companies such as Roam, Outsite, The Remote Experience, and others are offering a combination of coworking, coliving, and travel, enabling people to experience other countries and cultures while working and living with like-minded individuals for a week, a month, or longer. Many provide on-site wellness/fitness amenities, yoga classes, meditation, and other community events.

Clearly, the rise of wellness tourism is enticing new entrants into the market, as well as new forms of competition and partnerships. The integration of business areas along a continuum from hospitality to wellness and healthy lifestyles will continue to gather momentum. We expect more experimentation in different types of integration within this continuum in the future, as different players in the travel, hospitality, spa, fitness, and retail worlds identify what drives their core customers and seek out new ways to distinguish themselves from competitors in this evolving landscape.

viii | Global Wellness Institute 


\section{Destination marketing becomes more authentic and place- based.}

Since GWI began studying wellness tourism, the number of countries that actively market some form of wellness tourism at the national level has grown from 65 in 2013 to more than 100 in 2018. Importantly, the nature and focus of wellness tourism marketing and development has become more targeted and authentic. Thermal/mineral springs have seen the biggest growth in marketing and development focus, both in countries with longstanding hot spring bathing traditions (across Europe, Latin America, and Asia), as well as in countries with undeveloped geothermal assets (e.g., Kenya, Rwanda, Ethiopia, Saudi Arabia, Cambodia, India).

A small but growing number of destinations are developing a truly authentic and place-based wellness tourism product and brand - from the state of Kerala, India, which branded itself as the "Land of Ayurveda" over two decades ago, to neighboring countries such as Sri Lanka, Nepal, and Bhutan, each promoting wellness tourism experiences that link wellness with yoga, Ayurveda, meditation, spirituality, pilgrimage, indigenous medicine, faith healing, and happiness. Other examples include Costa Rica's new "Wellness Pura Vida" tourism campaign, and Beverly Hills' (U.S.) "City of Wellth" tourism campaign to redefine luxury as less about materialism and more about health, purpose, and happiness.

\section{Wellness tourism brings wide-ranging impacts to destinations and their people.}

As wellness tourism evolves, it is becoming recognized as an opportunity to bring wideranging benefits to local economies and populations. As such, wellness tourism development is increasingly integrated with regional economic planning and community development. Austria's Tirol region has leveraged wellness tourism to develop a broader "Cluster Wellness Tirol” network, which now includes more than 100 businesses in telemedicine, food, nutrition, spa equipment and technology, workplace wellness, and other wellness-related fields. Costa Rica's "Wellness Pura Vida" strategy (currently under development) aims to engage local communities in the planning process and to use wellness tourism development as a catalyst for social and economic growth in seven regions across the country. Rochester, Minnesota’s 20-year, \$5.6 billion Destination Medical Center initiative builds on the world-class reputation of the Mayo Clinic and its massive medical tourism industry (3 million+ visitors per year). Plans include a "heart of the city" urban district where hospitality intersects with healthcare, with healthy design and extensive wellness lifestyle and leisure amenities that will benefit thousands of Mayo Clinic employees/residents alongside the visitors to the clinic and their families. 


\section{In the future, the wellness of travel will increasingly link to the wellness of the place and how we contribute to it.}

As more consumers adopt wellness as part of their value system, they will increasingly filter their travel experiences through a holistic wellness lens, and they will increasingly become interested in the wellbeing of the people in the places that they visit. That is one reason why a high-end resort hotel such as The Breakers Palm Beach (U.S.) puts their employee wellness at the center of their brand and their guest experience, or why Westin Hotels \& Resorts is expanding its wellness offerings to organize activities that allow guests to give back to the places they are visiting. Recognizing that the wellness of a place is the DNA of its authentic wellness offering, more destinations, regions (such as Wellness Valley in Romagna, Italy and the state of Colorado in the United States), and countries (such as Costa Rica and Bhutan) are prioritizing the wellbeing of their residents and their environment to create their own unique wellness value proposition and brand.

In a holistic wellness framework, being well and doing good are closely connected; we cannot be truly well if our communities and the environment around us are not well. Research from the rapidly expanding fields of happiness, compassion, and altruism suggests that we are more likely to attain a deeper and lasting sense of peace and wellbeing by focusing on others, through helping, giving, and forming deeper connections. In recent years, wellness travel has also been evolving from a focus on being experiential to being transformative. We predict that future wellness travelers will increasingly link personal transformation with the connections they make during travel and their impacts on the people and the places that they touch. Wellness travel will become a more meaningful two-way exchange between the travelers and the destination, instead of a one-sided consumptive and commercial transaction. This consumer evolution, along with the development of wellness tourism, can play an important role in mitigating the negative impacts of over-tourism in some popular destinations and regions. 


\section{Global Wellness Tourism Economy Full Report}

NOVEMBER 2018

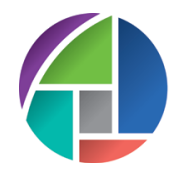

GLOBAL WELLNESS

INSTITUTE $^{\text {TM }}$

EMPOWERING WELLNESS WORLDWIDE 

In 2013, the Global Wellness Institute (GWI) unveiled the inaugural edition of the Global Wellness Tourism Economy report - a landmark study that defined the parameters and characteristics of the emerging wellness tourism sector, estimated its global size, and highlighted its far reaching economic impacts. In the subsequent five years, GWl's definition and market data for wellness tourism have been widely adopted, cited, and used by the global tourism community, tourism promotion organizations, businesses, and governments.

More importantly, the awareness of and demand for wellness tourism have risen dramatically around the world. Hardly mentioned as a tourism category just five years ago, wellness tourism is now recognized as one of the fastest growing tourism niches, with promises to expand the overall tourism "pie" while mitigating some of the challenges facing many destinations with respect to mass tourism and seasonal fluctuations.

This updated Global Wellness Tourism Economy report revisits the framework and definition presented in the inaugural report and provides new data and insights on global, regional, and country-level developments. We highlight the key points that you should know about wellness tourism, whether you are currently working in the field or a newcomer to this space. As tourism evolves continuously to keep pace with global consumer demand for all things experiential and wellness-related, we also share our thinking on the forces that will shape the massive and fastmoving wellness tourism sector in the coming years.

\section{Research Scope and Methodology}

The definitions, conceptual framework, and estimation models for the global wellness tourism economy are developed by the authors under the auspices of the Global Wellness Institute (GWI), consistent with the data and methodologies used in GWI's prior studies. The data presented in this report are for the year 2017. The analysis is based on extensive primary and secondary research conducted from January to September 2018, including literature reviews, data research, and expert interviews.

Country-level wellness tourism data are developed by the authors using our proprietary databases and economic models for wellness tourism, cross-referenced with in-house data and research on the global spa, thermal/mineral springs, workplace wellness, and wellness lifestyle real estate industries. To arrive at our estimates, we also draw from the general international and domestic travel and tourism industry data published by Euromonitor International, and we consult numerous public and private data sources including: World Travel \& Tourism Council, World Tourism Organization (UNWTO), World Bank, International Monetary Fund, World Health Organization, International Labour Organization; global travel promotion and booking websites; and numerous country-specific and industryspecific organizations, databases, publications, websites, and media sources. 
4 | Global Wellness Institute 


\section{THE RISE OF WELLNESS TOURISM}

\section{Infusing wellness into travel is an imperative.}

Travel can be bad for our physical and mental health. Crowds, delays, airport security checks, luggage, and many other travel hassles can cause tremendous stress, especially when coupled with jet lag, poor sleep, missed exercise routines, unhealthy food, alcohol, and sun exposure. All too often we return from a trip feeling like we need another vacation in order to recover. A recent Columbia University study of business travelers found that frequent and extensive travel is associated with many physical and behavioral health risk factors, including obesity, high blood pressure, lack of physical activity, smoking, alcohol dependence, trouble sleeping, anxiety, and depression.

In spite of the modern rigors of travel, the act of travel itself has long been considered a wellnessenhancing activity. Since ancient times, people have used travel as a means for rejuvenation and healing. Romans traveled to baths, hot springs, and seaside resorts for treatments, healthier climates, purification, and spiritual rituals. For centuries, pilgrims from around the world have visited the Dead Sea for its therapeutic properties, while Chinese, Japanese, and Koreans have traveled to hot springs for relaxation and community. Russia's first resort spa was constructed in Karelia nearly 300 years ago, in the era of Peter the Great.

Today, many of us look forward to travel as an adventure and as an opportunity to rejuvenate and de-stress. Several years ago, when we conducted a survey that asked consumers what they do to maintain/enhance their personal wellness, respondents selected "take a vacation" as one of their top five activities. ${ }^{2}$ In a recent survey of Millennials sponsored by Expedia, four in ten respondents said that their main motivation for their most recent holiday was to reduce stress. ${ }^{3}$ As more and more people pay attention to their health, they increasingly want to keep up with their healthy habits when they travel. And a growing segment of travelers are taking trips specifically focused on maintaining and improving their personal health and wellbeing. This shift is driving the growth of wellness tourism.

\footnotetext{
${ }^{1}$ Rundle, A.G., Revenson, T.A., and Friedman, M. (2018). Business Travel and Behavioral and Mental Health. Journal of Occupational \& Environmental Medicine, 60(7), 612-616. See also: Rundle, A. (2018). Just How Bad Is Business Travel for Your Health? Here's the Data. Harvard Business Review. https://hbr.org/2018/05/just-howbad-is-business-travel-for-your-health-heres-the-data\#article-top.

2 This survey was conducted by the authors as part of an SRI International/Global Spa Summit study of 1,077 consumers worldwide in 2010. See: SRI International/Global Spa Summit (2010). Spas and the Global Wellness Market: Synergies and Opportunities.

$342 \%$ of younger Millennials and $36 \%$ of older Millennials (across eight countries) selected "to reduce stress" in response to the question "Thinking about the last time you went on holiday, what were your main motivations?" See: Expedia and Future Foundation (2016). Millennial Traveller Report: Why Millennials will shape the next 20 years of travel.
} 


\title{
Holistic health and prevention are already at the center of consumer decision-making.
}

\begin{abstract}
Wellness tourism is about much more than where people visit and what they do while on a trip - it is an extension of the values and lifestyle of the traveler. Consumer interest in a lifestyle of health and sustainability used to be the domain of a small, educated, niche group of early adopters who have catalyzed many sectors including organic and local foods; yoga and meditation; solar panels and recycling; and niche tourism movements like ecotourism and sustainable tourism. But these preferences have rapidly gone mainstream over the span of the last ten years, as consumers try to stave off chronic disease and deteriorating mental health associated with our increasingly sedentary, unhealthy, digitized, and stressful lifestyles. All around the world, more people are incorporating elements of health, prevention, self-actualization, experience, and mindfulness into their daily lives - from what they eat to how they relax and exercise, and from their work environments to the design of their homes and communities. It is not a surprise that people now expect to continue their healthy lifestyles and wellness routines when they are away from home.
\end{abstract}

The wellness industry is well-positioned to help consumers reclaim travel as an opportunity for rest and relaxation, rejuvenation, discovery, joy, and self-actualization - all elements of living a well life. It is important to note that the wellness tourism market is not limited to people traveling to destination spas, wellness centers, and yoga retreats. People concerned about their health and wellbeing will increasingly incorporate their wellness priorities into decision-making for any kind of leisure or business trip, and they will expect the market to meet their needs. This study explores and quantifies the size of these opportunities for the tourism industry on a global basis. 


\section{Wellness tourism is the powerful intersection of two large and growing industries: the $\$ 2.6$ trillion tourism industry and the $\$ 4.2$ trillion wellness industry.}

As one of the world's largest industries, travel and tourism directly supports more than 118 million jobs and contributes 3.2\% to global GDP (or $\$ 2.6$ trillion in 2017, according to the World Travel \& Tourism Council). ${ }^{4}$ The rise of the global middle class - alongside the modern human need for rest and relaxation, adventure, and new experiences - continues to fuel a tourism industry whose worldwide growth has surpassed that of many major industries such as manufacturing, financial services, and retail.

As mentioned above, demographic and lifestyle trends are driving an exponential growth of consumer interest in all things related to wellness. The Global Wellness Institute (GWI) estimates the size of the global wellness economy to be $\$ 4.2$ trillion in 2017 , encompassing wellness tourism; wellness real estate; workplace wellness; spas; thermal/mineral springs; fitness \& mind-body; healthy eating, nutrition, \& weight-loss; traditional \& complementary medicine; preventive \& personalized medicine and public health; and personal care, beauty, \& anti-aging.

Importantly, both tourism and the overall wellness economy are projected to grow at a faster rate than the global economy. Wellness tourism is clearly positioned at an important intersection between these two giants, and many stakeholders - including the hospitality industry, wellness businesses, and residents and governments of destination countries and regions - stand to benefit from this opportunity.

${ }^{4}$ World Travel \& Tourism Council (2018). Travel \& Tourism Economic Impact 2018: World. London, UK: WTTC. 
8 | Global Wellness Institute 


\section{FIVE KEY THINGS TO KNOW ABOUT WELLNESS TOURISM}

\section{What is wellness tourism?}

In a sense, people who take any kind of vacation for leisure, rest, and relaxation are improving their wellness as part of tourism. However, this broad definition is not particularly useful for governments and businesses seeking to target consumers and to develop and promote this sector. Therefore, the Global Wellness Institute (GWI) has established a definition that captures the motivations and characteristics of people engaging in wellness tourism, so that businesses and other stakeholders can understand and tap into its vast opportunities.

GWI defines wellness tourism as travel associated with the pursuit of maintaining or enhancing one's personal wellbeing.

With so much unwellness embedded in today's travel, wellness tourism brings the promise of combating those negative qualities and turning travel into an opportunity to maintain and improve our holistic health.

\section{Wellness Travel Can Improve Rather Than Harm Your Health}

\section{Unwell Travel}

Q11) Unhealthy \& over-eating

(1)

Travel stress

Excessive drinking

Poor sleeping

Disruption of fitness routine

\section{Wellness Travel}

Rest \& rejuvenation

Disease prevention \& management

0 Extend \& discover healthy lifestyles

Authentic \& transformative experiences

Meaning, connection, \& joy

Source: Global Wellness Institute

This definition of wellness tourism is derived from GWI's definition of wellness: the active pursuit of activities, choices, and lifestyles that lead to a state of holistic health. This is consistent with the World Health Organization's definition of health as a state of complete physical, mental, and social wellbeing. ${ }^{5}$ It goes beyond mere freedom from disease or infirmity and emphasizes the proactive maintenance and improvement of health and wellbeing.

${ }^{5}$ Constitution of the World Health Organization: Principles, http://www.who.int/about/mission/en/. 
One way to understand wellness is to consider health as a continuum that extends from illness to a state of optimal wellbeing. ${ }^{6}$ On one end, patients with poor health engage the medical paradigm to treat illnesses; they interact reactively and episodically with doctors and clinicians who provide care. On the opposite end, people focus proactively on prevention and maximizing their vitality. They adopt attitudes and lifestyles that prevent disease, improve health, and enhance their quality of life and sense of wellbeing. In other words, wellness is proactive, preventive, and driven by selfresponsibility. Wellness tourism is the extension of this consumer value and worldview.

\section{Poor Health

\section{Medical Paradigm}

\section{Wellness Paradigm}

Feel Better

Thrive

\begin{tabular}{lr}
\hline Treat \& cure illness & Maintain \& improve health \\
\hline Corrective & Preventive \\
\hline Episodic & Holistic \\
\hline Clinical-responsibility & Individual responsibility \\
\hline Compartmentalized & Integrated into life \\
\hline
\end{tabular}

Source: Global Wellness Institute

${ }^{6}$ The continuum concept is adapted from Dr. Jack Travis' Illness-Wellness Continuum. Travis is one of the pioneers of the modern wellness movement in the late 1970 s. 


\section{Wellness tourism is not medical tourism.}

Wellness tourism is often conflated with medical tourism - not only by consumers, but in destination marketing. This confusion is caused by an incomplete understanding of these markets and inconsistent usage of terminologies by destinations, government organizations, and promotion agencies. Sometimes the term "health tourism" is also used as a catch-all to describe many types of medical and wellness services and activities - from open heart surgery and dental care to destination spas and yoga retreats - causing further confusion.

In fact, these two sectors operate largely in separate domains and meet different consumer needs. Referring to the health continuum that we discussed above, medical tourism primarily addresses the "poor health" end of the market, with patients traveling to another place for specific medical treatments or enhancements. Top medical tourism procedures include cosmetic surgery, orthopedic surgery, cardiac surgery, and dental procedures. Patients and their families are attracted by the availability, better quality, and/or price of care at the destinations. Therefore, successful medical tourism depends upon the status of a country's broader medical sector, along with appropriate government regulations, patient safeguards, training standards, insurance frameworks, travel and visa restrictions, and other issues that drive the patient's experience and treatment outcomes.

Wellness tourism attracts consumers who are at the opposite end of the wellness continuum - those seeking activities and destinations that extend their wellness lifestyle and help them proactively maintain and improve their health and wellbeing. The appeal and success of wellness tourism depends on an entirely different set of factors, business models, customer mindsets, human resources, and industry culture, and it is more closely aligned with leisure, recreation, and hospitality.

\section{Understanding the Difference Between Wellness Tourism and Medical Tourism}

\section{REACTIVE}

PROACTIVE

\section{Medical Tourism}

\section{Wellness Tourism}

Travel to receive treatment for a diagnosed disease, ailment, or condition, or to seek enhancement.
Travel to maintain, manage, or improve health and wellbeing.

Motivated by desire for lower cost of care, higher quality care, better access to care, and/or care not available at home.

Activities are reactive to illnesses, medically necessary, invasive, and/or overseen by a doctor.

Motivated by desire for healthy living, disease prevention, stress reduction, management of poor lifestyle habits, and/or authentic experiences.

Activities are proactive, voluntary, non-invasive, and non-medical in nature.

Source: Global Wellness Institute 
To be sure, there is some overlap between medical tourism and wellness tourism. For example, some top-end destination spas and many traditional health resorts across Europe offer treatments that can be both curative and preventive in nature, and that are typically administered by licensed medical professionals. These include DNA testing, executive checkups, acupuncture, detoxes and cleanses, hydrotherapy, and complementary and holistic medicine services. But in general, the types of visitors, activities, services, businesses, and regulations involved are very different between medical tourism and wellness tourism, even though they may share a dependence on a region's basic tourism and hospitality infrastructure and amenities.

Overall, we do not recommend that destinations merge these two types of tourism in their marketing and development strategies because it can cause customer confusion. Over-emphasizing their convergence may risk diluting the appeal of both segments. From a wellness tourism perspective, travelers may not enjoy destinations that are full of recovering or sick patients. From a medical tourism perspective, highlighting spa, wellness, and leisure offerings may weaken the destination's image as lacking in medical rigor and quality. However, both types of tourism depend upon a strong hospitality infrastructure (e.g., flight connections, accommodations, ground transportation, etc.) to flourish, so a general attention to basic tourism infrastructure will clearly benefit both sectors. 


\section{Who are the wellness travelers?}

There is a common misconception that wellness travelers are a small, elite, and wealthy group of leisure tourists who visit destination spas, health resorts, or yoga and meditation retreats. In fact, wellness travelers comprise a much broader and more diverse group of consumers with many motivations, interests, and values. GWI identifies two types of wellness travelers:

Primary wellness traveler: A traveler whose trip or destination choice is primarily motivated by wellness.

Secondary wellness traveler: A traveler who seeks to maintain wellness while traveling or who participates in wellness experiences while taking any type of trip for leisure or business.

\section{Distinguishing Primary and Secondary Wellness Travelers}

\section{Primary Wellness Tourists}

- Visiting a destination spa (such as Canyon Ranch, Rancho La Puerta, Chiva Som, Ananda, Gwinganna, SHA Wellness, Lanserhof, etc.)

- Vacationing at a hot springs resort for a long weekend

- Staying at an ashram for a meditation retreat

- Taking a weekend spa trip for rejuvenation and stress reduction

- Traveling to a wellness center for a full-scale executive health checkup

- Taking a wellness cruise

- Staying at an eco-spa or jungle spa resort for a week

- Participating in a yoga retreat that includes healthy food and meditation in a natural setting

\section{Secondary Wellness Tourists}

- A business or leisure traveler who actively seeks out healthy accommodations, food, and fitness options during a trip

- A family that spends a day at a hot springs bathing establishment as part of a holiday trip

- A vacationer at a beach resort who wants to visit the spa and salon a few times during the trip

- A cruise tourist who specifically selects a ship with extensive spa, beauty, and fitness amenities

- An adventure tourist who visits an eco-spa after a long day of hiking or biking

- A tour group traveler who gets a Thai massage or reflexology treatment, or visits a hammam, as part of the tour experience 
By this definition, people who travel to a wellness resort, yoga retreat, or boot camp are primary wellness travelers. These are typically very committed wellness consumers who proactively maintain a healthy lifestyle, seek mental/spiritual balance, and/or are socially and environmentally conscious. When these same consumers travel for business and other purposes, they are likely to incorporate their own wellness values into their decisions about hotels, restaurants, activities, etc., and so they are also likely to be secondary wellness travelers on most trips. On the other hand, secondary wellness travelers also encompass a much broader cross-section of consumers who have varying degrees of interest in wellness and are inclined to express them in many different ways during travel.

Importantly, primary and secondary wellness travel can be done by the same person on different trips, and these two types of wellness travel reinforce one another. Over time, some secondary wellness travelers will decide to take a primary wellness trip, as their interest in and experience with wellness grows. For example, a person who visits a day-use hot spring during a family vacation (secondary wellness travel) may later be motivated to plan a weekend getaway staying at a hot spring resort (primary wellness travel).

Rising incomes and education levels, alongside growing concerns with chronic diseases and environmental issues, are driving accelerated consumer interest in wellness. As more people integrate holistic health and the prevention of disease into their lifestyles and their travel, we expect rising interest in both primary and secondary wellness travel, as well as the increasing crossover of secondary wellness travelers into primary wellness travel experiences. 


\section{Every destination has something unique to offer wellness travelers.}

Because wellness is multidimensional - spanning the physical, mental, social, emotional, spiritual, and environmental spheres - wellness travel is also multifaceted. It encompasses a large and diverse set of activities and pursuits, including preventive health services, spa, beauty, fitness, personal growth, nature, and much more. This in turn creates opportunities for all kinds of businesses and providers.

\section{Holistic Values Drive Activities and Choices of Wellness Travelers}

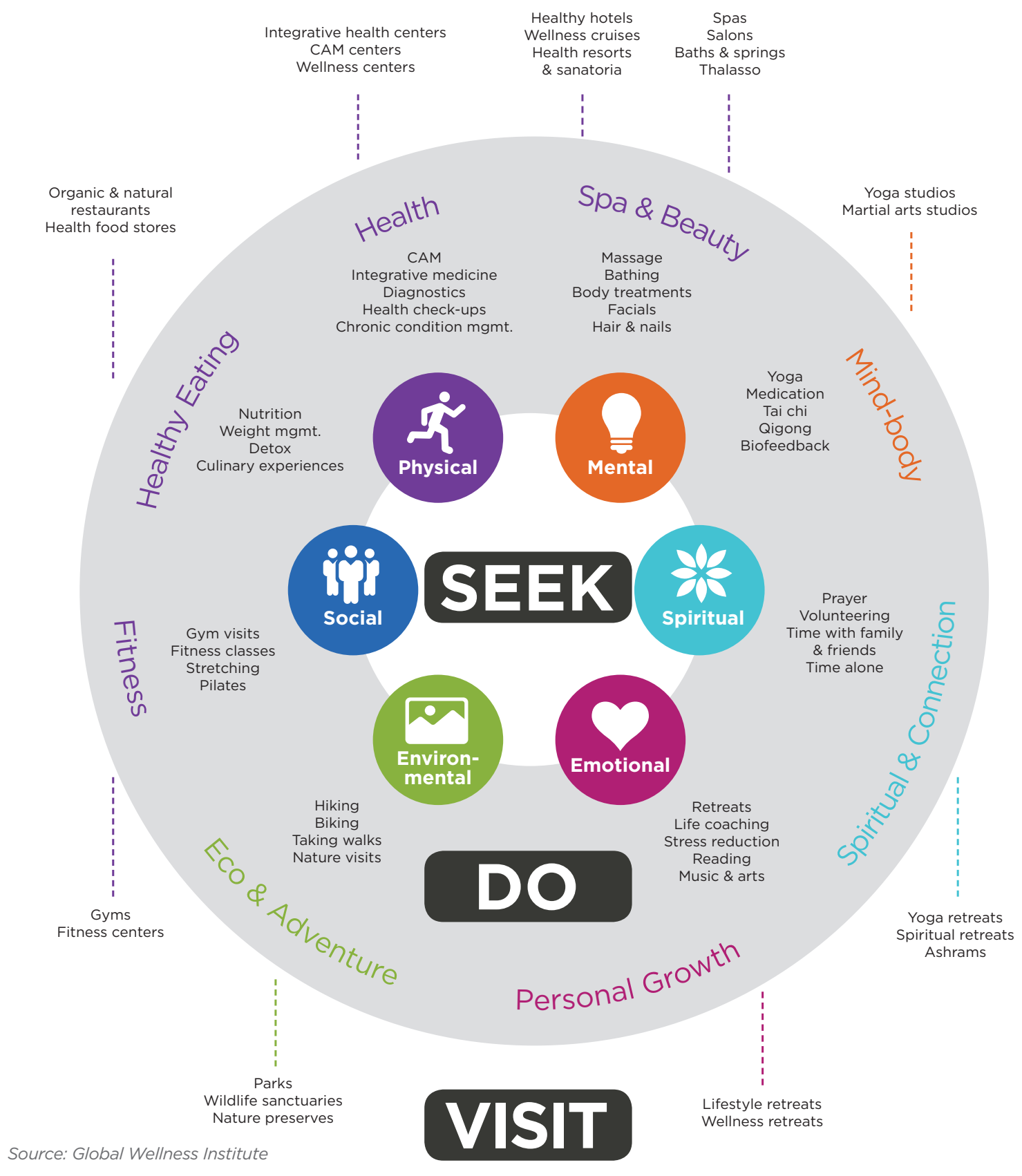


Like other forms of specialty travel, wellness travel is not a cookie-cutter experience. Every destination has its own distinct flavors in relation to wellness, linked with its local culture, natural assets, foods, etc. Some travelers may be satisfied with a generic massage, exercise class, or smoothie. The more discerning and sophisticated wellness travelers - especially those in the Millennial generation - are interested in what the destination offers that is different from someplace else. These unique and authentic experiences can be built upon indigenous healing practices; ancient/spiritual traditions; native plants and forests; special muds, minerals, and waters; vernacular architecture; street vibes; local ingredients and culinary traditions; history and culture; etc. Because each destination is different, there is always something unique to offer wellness travelers.

\section{Every Destination Has Something Unique to Offer}

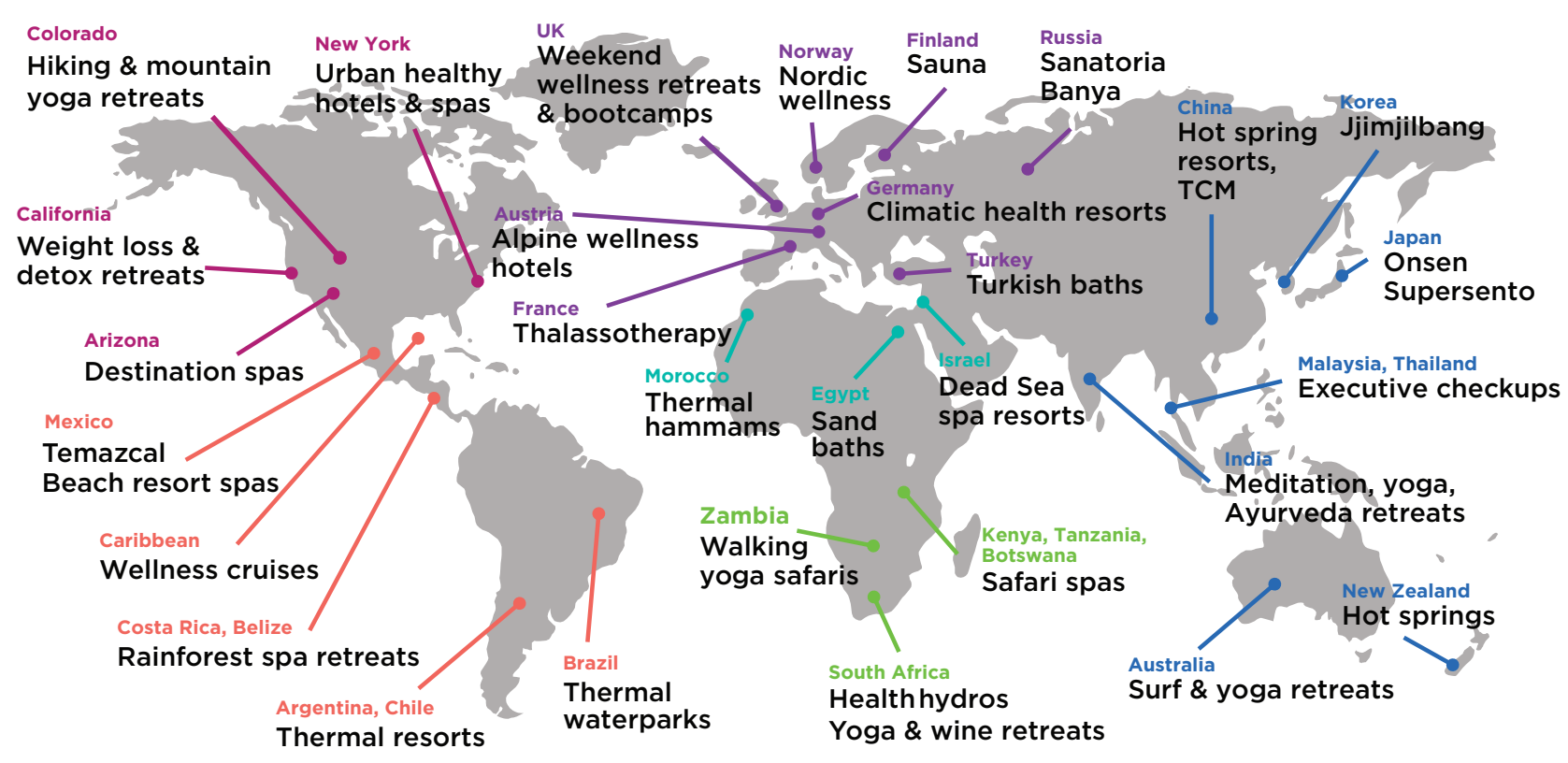




\section{Wellness tourism brings benefits to businesses and stakeholders beyond the wellness sectors.}

The wellness tourism economy is much larger than a narrowly-defined set of typical wellness businesses, such as spas, wellness retreats, thermal/mineral springs, and boot camps. Wellness travelers (especially secondary wellness travelers) are looking to continue their wellness lifestyle during travel, and this lifestyle may encompass healthy eating, exercise/fitness routines, mindbody practices, nature experiences, connections with local people and culture, etc., thereby creating opportunities for businesses such as yoga studios, gyms and fitness centers, heathy food stores/markets, events, arts and crafts, museums, and many others.

In addition to wellness experiences, all wellness tourists need transportation, food, and lodging, and they will likely seek out shopping or entertainment. All of these business - whether they are wellness-specific or not - benefit from wellness tourism and are part of the wellness tourism economy. There are numerous opportunities to infuse wellness into all kinds of amenities and services, which can help businesses differentiate, provide more value, and capture higher spending by wellness travelers. Examples include: airport spas that target wellness travelers in transit; wellness-centered hotels for those who want better sleep and regular fitness routines; specialty restaurants serving healthy, organic, or local cuisine; transportation companies that use clean fuels or low-/zero-emission vehicles; or gift shops that sell products that are connected to unique local wellness traditions.

Wellness tourism may help destinations mitigate the negative impacts of mass tourism or overtourism. Because wellness travelers tend to be high-spenders and favor experiences that are authentic and unique, there is less pressure for destinations to engage in a "race to the bottom" strategy that competes on price and quantity.

Wellness tourism also provides destinations with an opportunity to reduce the seasonality of visitor flows. For example, ski destinations can attract wellness travelers interested in hiking and other outdoor activities in the summertime, while beach destinations can appeal to travelers who are looking for a more tranquil environment to destress or take a retreat in the wintertime. 
There are many stakeholders who can collaborate to develop and benefit from wellness tourism, including many government players involved in tourism, economic, social, health, and environmental development. Collaboration of communities, private businesses, and public-sector stakeholders across these sectors will be critical for destinations and regions to develop wellness tourism successfully and to maximize the positive economic and social impacts.

\section{Many Stakeholders Can Collaborate and Benefit from Wellness Tourism}

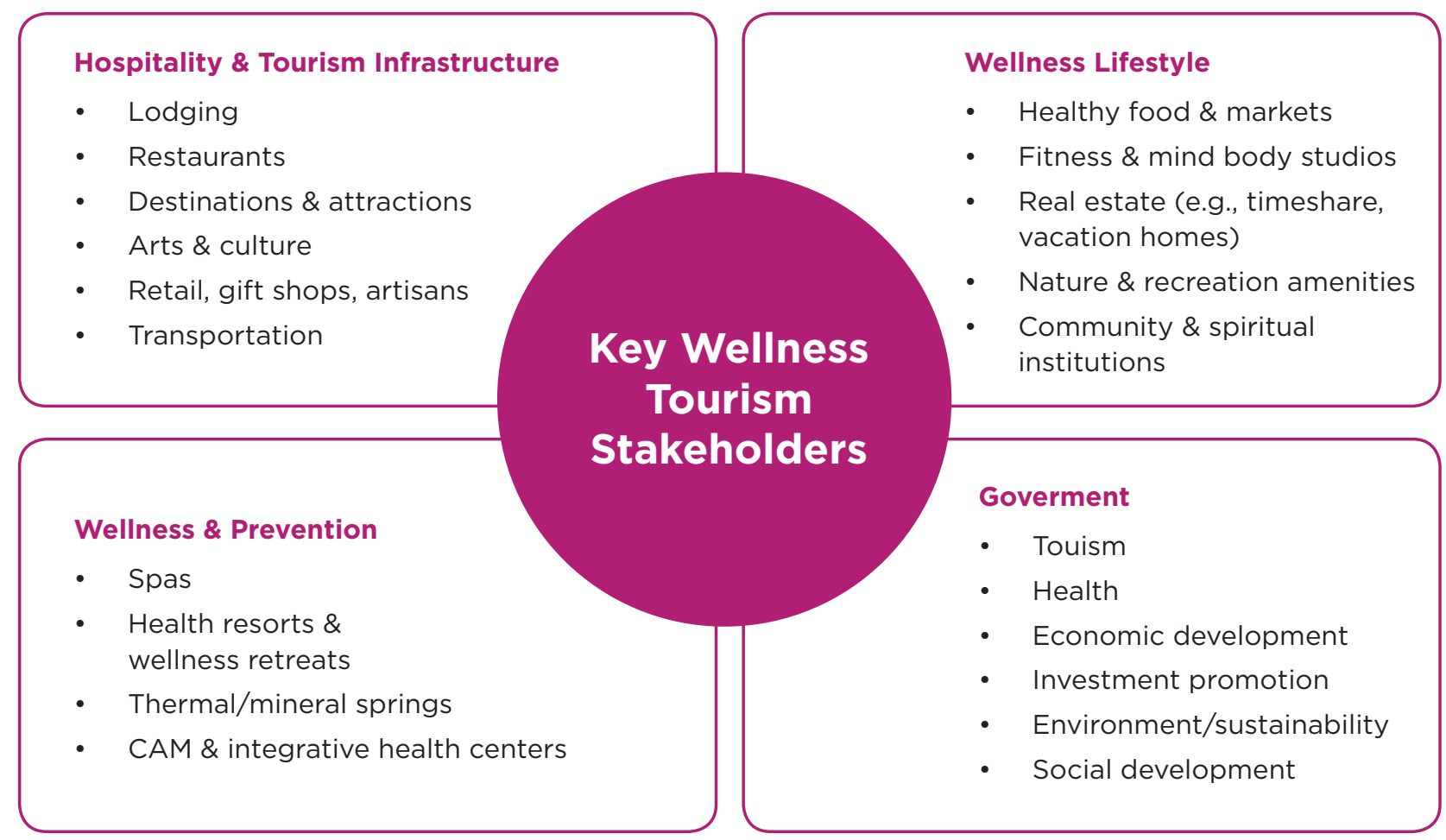

Source: Global Wellness Institute 


\section{Measuring Wellness Tourism}

GWI measures wellness tourism by aggregating the trip expenditures of people who are defined as wellness tourists. These expenditures include lodging, food and beverage, activities and excursions, shopping, in-country transportation (travel within the country) ${ }^{7}$, and other services (e.g., concierge, telecommunications, travel agent services, travel insurance, etc.).

We include expenditures made by both international and domestic travelers:

International wellness tourism expenditures: All receipts earned by a country from inbound wellness tourists visiting from abroad, with an overnight stay.

Domestic wellness tourism expenditures: All expenditures in a country made by wellness tourists who are traveling within their own country, with an overnight stay.

Within each of the international and domestic tourism segments, we estimate the portion of trips and expenditures that are represented by wellness tourists, including both the primary and secondary wellness tourism segments:

Primary wellness tourist: A tourist whose trip or destination is primarily motivated by wellness.

Secondary wellness tourist: A tourist who seeks to maintain wellness while traveling, or who participates in wellness experiences while taking any type of trip, for leisure or business.

Finally, we aggregate the spending of primary and secondary wellness tourists, both international/inbound and domestic, across 212 countries, to arrive at the size of the global wellness tourism industry.

\footnotetext{
${ }_{7}^{7}$ Following the convention for calculation of international tourism statistics, we exclude international airfare from the calculation of wellness tourism. The international airfare paid by international tourists does not necessarily accrue to the country he/she is visiting. Therefore, expenditures on international airfare are typically not included in the tourism receipts reported by individual countries, but instead are covered in a different line item in balance of payment statistics.
} 
20 | Global Wellness Institute 


\section{THE WELLNESS TOURISM ECONOMY}

\section{At $\$ 639$ billion, wellness tourism is a significant and fast- growing segment of global tourism, growing more than twice as fast as general tourism.}

In the 2013 Wellness Tourism Economy inaugural study, GWI defined wellness tourism as travel associated with the pursuit of maintaining or enhancing one's personal wellbeing, and we measured the size of global wellness tourism for the first time. Fast forward five years, wellness tourism is now widely recognized as a fast-growing, high-opportunity tourism niche segment. GWI estimates that wellness tourism expenditures reached $\$ 639.4$ billion in 2017 , as compared to $\$ 563.2$ billion in 2015. The sector's 6.5\% annual growth rate from 2015-2017 is more than double the $3.2 \%$ annual growth rate for general tourism. Wellness travelers made 830 million international and domestic wellness trips in 2017, which is 139 million more than in 2015. Wellness trips account for $6.6 \%$ of all tourism trips but represent $16.8 \%$ of total tourism expenditures. This is because wellness travelers tend to spend much more per trip than the average traveler.

Europe remains the region with the largest number of wellness trips. North America continues to lead in wellness tourism expenditures because average spending per trip is higher. In the past five years, Asia has made the most gains in the number of wellness trips and wellness tourism expenditures, with demand stimulated by strong economies and an expanding middle class.

\section{Wellness Tourism Trips and Expenditures by Region, 2015 and 2017}

\begin{tabular}{l|r|r|r|r} 
& \multicolumn{2}{c|}{$\begin{array}{c}\text { Number of Trips } \\
\text { (millions) }\end{array}$} \\
& \multicolumn{2}{c|}{$\begin{array}{c}\text { Expenditures } \\
\text { (US\$ billions) }\end{array}$} \\
\hline North America & 2015 & 2017 & 2015 & 2017 \\
\hline Europe & 186.5 & 204.1 & $\$ 215.7$ & $\$ 241.7$ \\
\hline Asia-Pacific & 249.9 & 291.8 & $\$ 193.4$ & $\$ 210.8$ \\
\hline Latin America-Caribbean & 193.9 & 257.6 & $\$ 111.2$ & $\$ 136.7$ \\
\hline Middle East-North Africa & 46.8 & 59.1 & $\$ 30.4$ & $\$ 34.8$ \\
\hline Africa & 8.5 & 11.0 & $\$ 8.3$ & $\$ 10.7$ \\
\hline Total Wellness Tourism Industry & $\mathbf{6 9 1 . 0}$ & $\mathbf{8 3 0 . 0}$ & $\$ 563.2$ & $\$ 639.4$ \\
\hline
\end{tabular}

Note: These figures combine both international/inbound and domestic wellness tourism spending, and also include both primary and secondary wellness trips. Figures may not sum to total due to rounding.

Source: Estimates by the Global Wellness Institute, based on tourism industry data from Euromonitor International 
Wellness tourism is heavily concentrated in several major countries across North America, Europe, and Asia-Pacific. The United States alone accounts for over one-third of global revenues. The top five countries (United States, Germany, China, France, Japan) represent 59\% of the global market, and the top twenty countries represent $84 \%$. Since 2013 , China has continued to move up in the rankings for wellness tourism expenditures (and is now in the top three). India has moved into the top ten, while Malaysia has entered the top twenty for the first time (supplanting Russia).

\section{Top Twenty Wellness Tourism Destination Markets, 2017}

\begin{tabular}{|c|c|c|c|c|}
\hline & $\begin{array}{c}\text { Number of Trips } \\
\text { (millions) }\end{array}$ & $\begin{array}{l}\text { Direct } \\
\text { Employment } \\
\text { (millions) }\end{array}$ & $\begin{array}{l}\text { Expenditures } \\
\text { (US } \$ \text { billions) }\end{array}$ & $\begin{array}{l}\text { Rank in } \\
2017\end{array}$ \\
\hline United States & 176.5 & 1.88 & $\$ 226.0$ & 1 \\
\hline Germany & 66.1 & 1.13 & $\$ 65.7$ & 2 \\
\hline China & 70.2 & 1.78 & $\$ 31.7$ & 3 \\
\hline France & 32.4 & 0.31 & $\$ 30.7$ & 4 \\
\hline Japan & 40.5 & 0.18 & $\$ 22.5$ & 5 \\
\hline Austria & 16.8 & 0.16 & $\$ 16.5$ & 6 \\
\hline India & 56.0 & 3.74 & $\$ 16.3$ & 7 \\
\hline Canada & 27.5 & 0.29 & $\$ 15.7$ & 8 \\
\hline United Kingdom & 23.2 & 0.20 & $\$ 13.5$ & 9 \\
\hline Italy & 13.1 & 0.15 & $\$ 13.4$ & 10 \\
\hline Mexico & 18.7 & 0.49 & $\$ 12.8$ & 11 \\
\hline Switzerland & 9.7 & 0.10 & $\$ 12.6$ & 12 \\
\hline Thailand & 12.5 & 0.53 & $\$ 12.0$ & 13 \\
\hline Australia & 10.0 & 0.11 & $\$ 10.5$ & 14 \\
\hline Spain & 18.8 & 0.10 & $\$ 9.9$ & 15 \\
\hline South Korea & 19.6 & 0.13 & $\$ 7.2$ & 16 \\
\hline Indonesia & 8.3 & 1.31 & $\$ 6.9$ & 17 \\
\hline Malaysia & 8.3 & 0.18 & $\$ 5.0$ & 18 \\
\hline Turkey & 9.1 & 0.05 & $\$ 4.4$ & 19 \\
\hline Brazil & 10.5 & 0.13 & $\$ 4.1$ & 20 \\
\hline
\end{tabular}

Note: These figures combine both international/inbound and domestic wellness tourism spending, and also include both primary and secondary wellness trips.

Source: Estimates by the Global Wellness Institute, based upon tourism industry data from Euromonitor International 


\section{Wellness tourism growth is distributed across the world.}

The rapid growth of wellness tourism around the world has been stimulated by a rising global middle class, growing consumer desire to adopt a wellness lifestyle, rising interest in experiential travel, and increasing affordability of flights and travel options. The developing markets in AsiaPacific, Latin America-Caribbean, Middle East-North Africa, and Sub-Saharan Africa have posted robust growth in recent years. While these regions represented only $40 \%$ of wellness trips in 2017, they accounted for $57 \%$ of the increase in trips since 2015. China and India are both growth leaders, adding over 21 million and 17 million wellness trips respectively (inbound and domestic) from 2015-2017. Wellness tourism also continues to grow steadily across the leading developed markets, including the United States and several major European countries.

\section{Leading Growth Markets for Wellness Tourism Trips, 2015-2017}

\begin{tabular}{|c|c|c|}
\hline & $\begin{array}{c}\text { Number of Wellness } \\
\text { Arrivals/Trips Added from 2015-2017 } \\
\text { (millions) }\end{array}$ & $\begin{array}{l}\text { Average Annual Growth } \\
\text { Rate from 2015-2017 }\end{array}$ \\
\hline China & 21.9 & $20.6 \%$ \\
\hline India & 17.3 & $20.3 \%$ \\
\hline United States & 15.4 & $4.7 \%$ \\
\hline Germany & 7.5 & $6.2 \%$ \\
\hline Spain & 5.2 & $17.5 \%$ \\
\hline Mexico & 3.3 & $10.3 \%$ \\
\hline Malaysia & 3.3 & $28.6 \%$ \\
\hline Vietnam & 3.2 & $22.8 \%$ \\
\hline Chile & 3.2 & $29.3 \%$ \\
\hline Thailand & 2.7 & $13.1 \%$ \\
\hline Japan & 2.7 & $3.5 \%$ \\
\hline Italy & 2.7 & $12.2 \%$ \\
\hline Indonesia & 2.7 & $21.5 \%$ \\
\hline United Kingdom & 2.6 & $6.1 \%$ \\
\hline Russia & 2.3 & $8.4 \%$ \\
\hline Czech Republic & 2.2 & $18.1 \%$ \\
\hline Austria & 2.2 & $7.3 \%$ \\
\hline Canada & 2.2 & $4.2 \%$ \\
\hline Poland & 2.0 & $14.7 \%$ \\
\hline Brazil & 1.9 & $10.4 \%$ \\
\hline France & 1.8 & $2.8 \%$ \\
\hline South Korea & 1.6 & $4.5 \%$ \\
\hline Australia & 1.5 & $8.3 \%$ \\
\hline Slovakia & 1.4 & $36.9 \%$ \\
\hline Philippines & 1.1 & $31.1 \%$ \\
\hline
\end{tabular}

Note: These figures combine both international/inbound and domestic wellness tourism spending, and also include both primary and secondary wellness trips. Source: Estimates by the Global Wellness Institute, based upon tourism industry data from Euromonitor International 


\section{Secondary wellness travelers account for the bulk of wellness tourism trips and growth: $89 \%$ of trips and $86 \%$ of expenditures.}

Wellness travelers comprise a broad and diverse group of consumers with many motivations, interests, and values. As elaborated in Chapter II, GWI defines and measures two major segments:

Primary wellness travelers: A traveler whose trip or destination choice is primarily motivated by wellness.

Secondary wellness travelers: A traveler who seeks to maintain wellness while traveling or who participates in wellness experiences while taking any type of trip for leisure or business.

The bulk of wellness travel is done by secondary wellness tourists - i.e., those who seek wellness experiences during their travel, when wellness is not the primary motivation for their trip or destination. Secondary wellness tourism accounted for $89 \%$ of wellness tourism trips and $86 \%$ of wellness tourism expenditures in 2017. Secondary wellness tourism also continues to grow at a faster rate than primary wellness tourism; secondary wellness tourism trips grew by $10 \%$ annually from 2015-2017, while primary trips grew by $8 \%$ annually.

Since secondary wellness travelers are defined as people whose primary trip motivation is not wellness, travelers in other niche categories, including ecotourism, sports/adventure tourism, cultural/arts tourism, and other segments, can also be secondary wellness travelers. Travelers across these niche segments are similar to demographics and interests to wellness tourists, and GWI predicts that wellness tourism will increasingly overlap with these other tourism niches over time, helping drive a continued strong growth trajectory.

\section{Secondary Wellness Travel Leads in Trips and Expenditures}
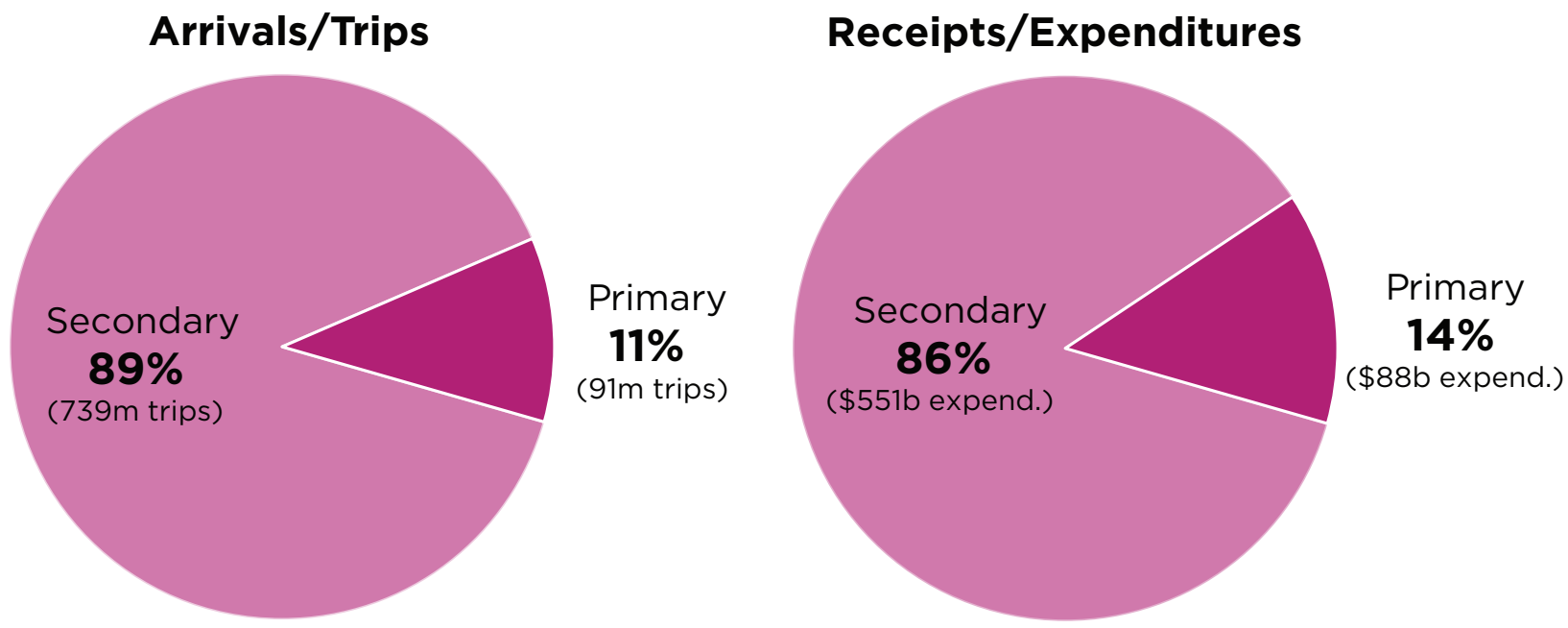

Note: These figures combine both international/inbound and domestic wellness tourism spending. Source: Estimates by the Global Wellness Institute, based upon tourism industry data from Euromonitor International 


\section{Domestic wellness travel dwarfs international wellness travel, but international wellness trips have been growing faster.}

For most people, it is easier and cheaper to travel domestically than overseas, especially for shorter trips. Worldwide, there are more than eight times as many domestic trips taken as international trips each year (11.2 billion domestic trips versus 1.3 billion international trips in 2017). ${ }^{8}$ Likewise, wellness travel is much more likely to be domestic travel rather than international travel. This is especially the case in very large countries like the United States, Canada, or China, where traveling internationally is much more expensive and time consuming. It is less true in Europe, where crossborder travel is easy and not much different from traveling state-to-state within the United States.

Globally, domestic travel accounts for $82 \%$ of total wellness tourism trips and $65 \%$ of expenditures. International wellness trips account for a proportionally larger share of expenditures because the average level of spending for an international trip is much higher. International wellness tourism trips have also been growing at a faster pace ( $12 \%$ annually) than domestic wellness tourism trips (9\% annually) from 2015-2017.

\section{Domestic Wellness Travel Leads in Trips and Expenditures}

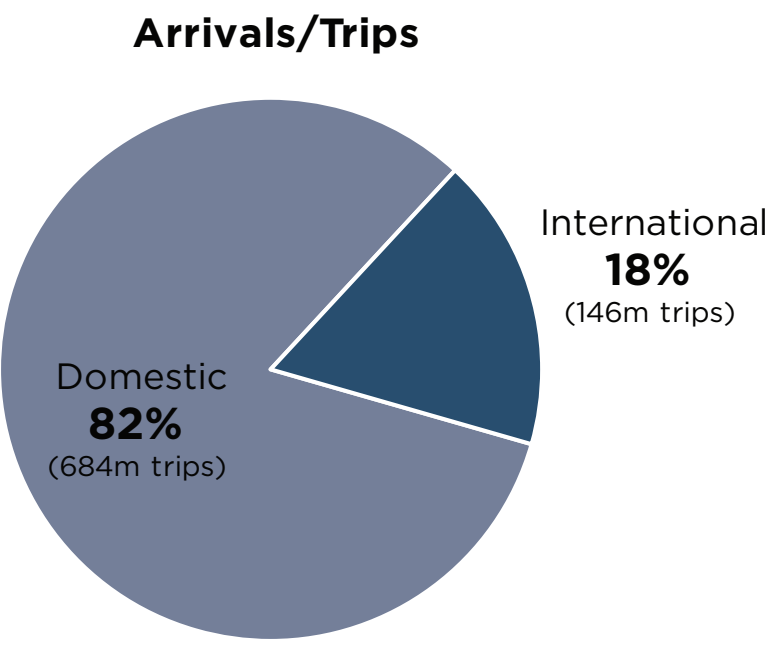

\section{Receipts/Expenditures}

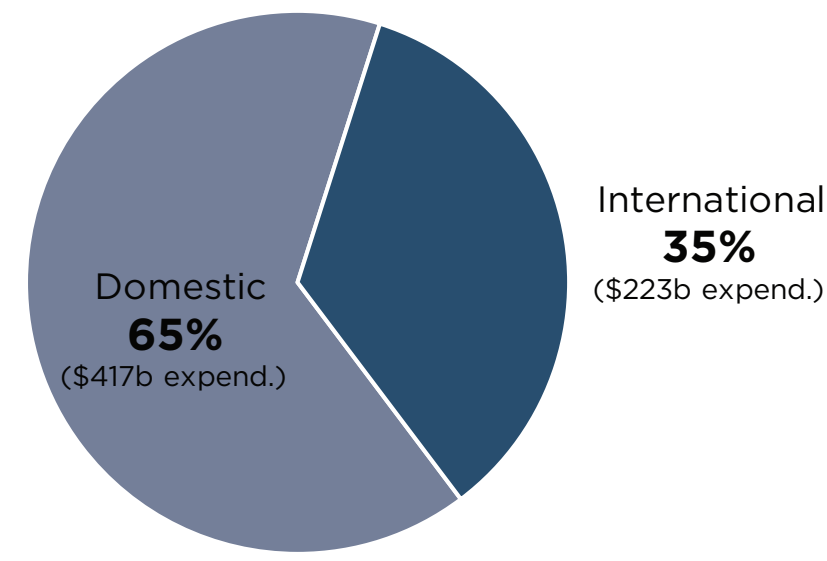

Countries with the Most DOMESTIC

Wellness Tourism Trips
Countries with the Most INBOUND/

INTERNATIONAL Wellness Tourism Trips
1. United States
2. China
3. Germany
4. India
5. Japan 


\section{Wellness tourism is high-yield tourism.}

Wellness travelers spend more per trip than the average tourist, and this holds true for both domestic and international travelers. In 2017, international wellness tourists on average spent $\$ 1,528$ per trip, $53 \%$ more than the typical international tourist. The premium for domestic wellness tourists is even higher, at $\$ 609$ per trip and $178 \%$ more than the typical domestic tourist. This is because wellness travelers are typically more affluent, educated, and well-traveled, and they tend to be early adopters who will try out new and novel experiences.

\section{Wellness Tourism Spending Premiums, 2017}

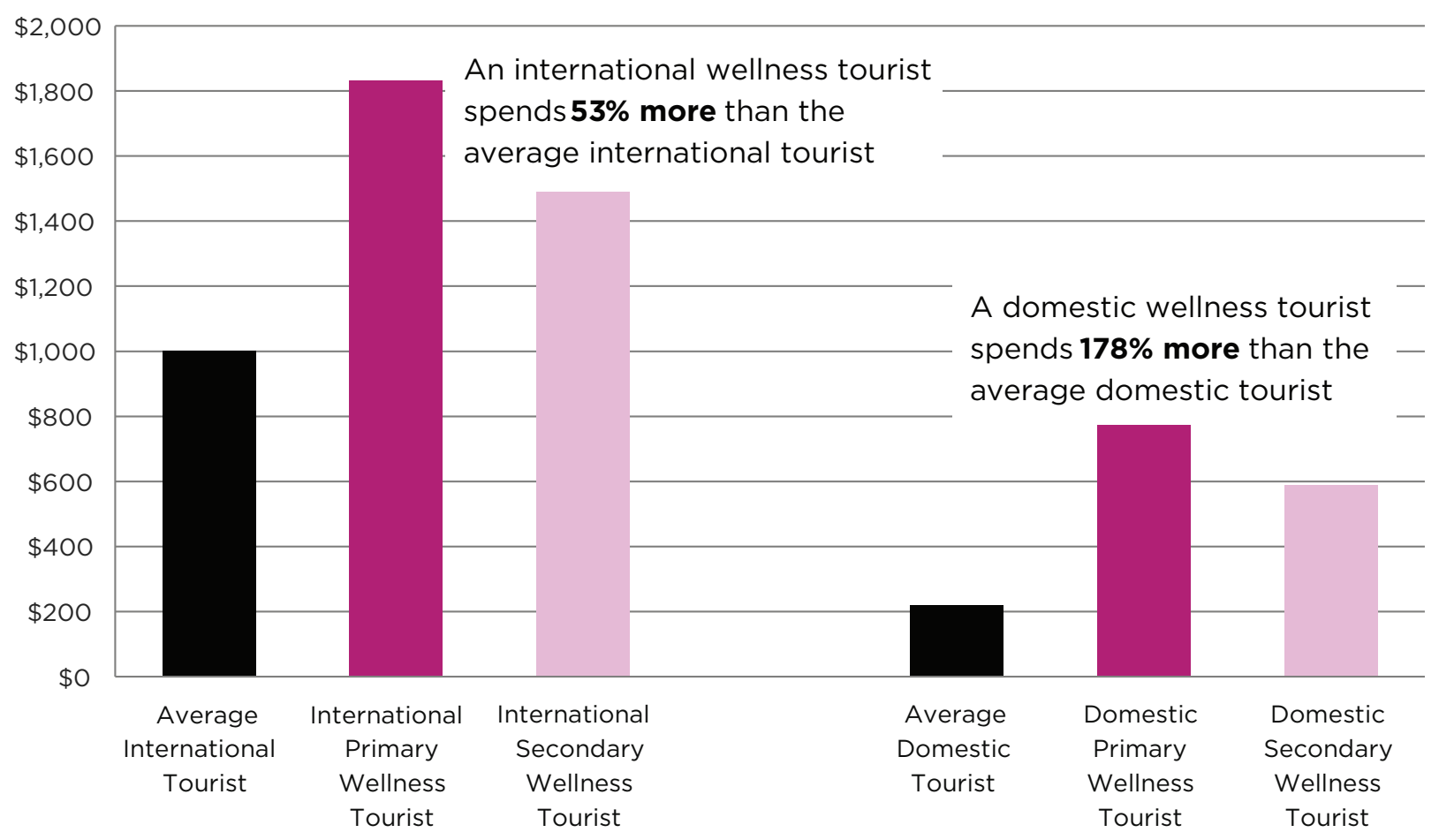

Source: Estimates by the Global Wellness Institute, based upon tourism industry data from Euromonitor International

There is wide variation in the wellness tourism premiums across different countries, as spending patterns are affected by many factors, including the nature of the country's wellness tourism offerings, the types of visitors and source countries, and the balance of secondary versus primary wellness tourism trips taken in that country. The table below illustrates the wellness tourism spending premiums in the twenty largest wellness tourism markets (by expenditures). Among these largest markets, the international wellness trip premium ranges from $20 \%-74 \%$, while the domestic trip premium ranges widely from $28 \%-162 \%$. 


\section{Wellness Tourism Spending Premiums in the Top Twenty Largest Destination Markets, 2017}

\begin{tabular}{|c|c|c|c|c|}
\hline & \multicolumn{2}{|c|}{$\begin{array}{l}\text { Average Spending per INBOUND/ } \\
\text { INTERNATIONAL Trip }\end{array}$} & \multicolumn{2}{|c|}{$\begin{array}{l}\text { Average Spending per } \\
\text { DOMESTIC Trip }\end{array}$} \\
\hline & Wellness Trips & Average Trip & Wellness Trip & Average Trip \\
\hline United States & $\$ 3,812$ & $\$ 2,689$ & $\$ 1,139$ & $\$ 716$ \\
\hline Germany & $\$ 1,901$ & $\$ 1,180$ & $\$ 902$ & $\$ 536$ \\
\hline China & $\$ 2,226$ & $\$ 1,417$ & $\$ 232$ & $\$ 146$ \\
\hline France & $\$ 1,166$ & $\$ 759$ & $\$ 889$ & $\$ 554$ \\
\hline Japan & $\$ 2,192$ & $\$ 1,436$ & $\$ 488$ & $\$ 307$ \\
\hline Austria & $\$ 1,189$ & $\$ 780$ & $\$ 831$ & $\$ 524$ \\
\hline India & $\$ 2,937$ & $\$ 1,941$ & $\$ 58$ & $\$ 36$ \\
\hline Canada & $\$ 1,052$ & $\$ 731$ & $\$ 527$ & $\$ 291$ \\
\hline United Kingdom & $\$ 1,535$ & $\$ 883$ & $\$ 405$ & $\$ 229$ \\
\hline Italy & $\$ 1,325$ & $\$ 907$ & $\$ 953$ & $\$ 642$ \\
\hline Mexico & $\$ 801$ & $\$ 493$ & $\$ 577$ & $\$ 450$ \\
\hline Switzerland & $\$ 2,070$ & $\$ 1,227$ & $\$ 731$ & $\$ 457$ \\
\hline Thailand & $\$ 1,885$ & $\$ 1,206$ & $\$ 191$ & $\$ 120$ \\
\hline Australia & $\$ 2,992$ & $\$ 2,490$ & $\$ 866$ & $\$ 487$ \\
\hline Spain & $\$ 1,547$ & $\$ 1,004$ & $\$ 240$ & $\$ 148$ \\
\hline South Korea & $\$ 2,054$ & $\$ 1,307$ & $\$ 205$ & $\$ 126$ \\
\hline Indonesia & $\$ 1,184$ & $\$ 793$ & $\$ 251$ & $\$ 115$ \\
\hline Malaysia & $\$ 1,109$ & $\$ 717$ & $\$ 267$ & $\$ 102$ \\
\hline Turkey & $\$ 891$ & $\$ 537$ & $\$ 271$ & $\$ 159$ \\
\hline Brazil & $\$ 1,572$ & $\$ 1,188$ & $\$ 366$ & $\$ 243$ \\
\hline
\end{tabular}




\section{Wellness tourism creates opportunities for wellness and all tourism and hospitality-related businesses.}

The $\$ 639.4$ billion spent globally by wellness travelers is distributed among many segments of the tourism industry, from food and lodging, to activities, excursions, shopping, and other services. Within each segment, some expenditures may include wellness-focused activities (such as visiting a hot spring, getting a massage, or taking a meditation or fitness class), while other expenditures may be generic (such as transportation, general food and lodging, or buying souvenirs). As more consumers incorporate wellness into their lifestyles, there are many opportunities for the "generic" businesses to infuse wellness into their offerings, which can help them differentiate, provide more value, and capture higher spending by wellness travelers. For example, mainstream hotel brands are now promoting wellness features such as in-room exercise equipment and special beds and lighting that help people sleep better. Airports are offering in-transit gyms, spas, and walking circuits around their terminals, and airlines are promoting in-flight meditation and stretching apps. Museums offer yoga and meditation classes right in their art galleries, while gift shops stock products connected to unique local wellness traditions and stories.

\section{Wellness Tourism Industry in 2017}

\begin{tabular}{|c|c|c|c|}
\hline $\begin{array}{l}\text { In-Country } \\
\text { Transport } \\
\mathbf{\$ 1 0 9 . 9 b}\end{array}$ & $\begin{array}{l}\text { Hotels/Motels } \\
\text { Resorts } \\
\text { Campgrounds }\end{array}$ & $\begin{array}{l}\text { Lodging } \\
\$ 130.5 b\end{array}$ & $\begin{array}{l}\text { Destination Spas } \\
\text { Health Resorts } \\
\text { Ashrams | Retreats }\end{array}$ \\
\hline $\begin{array}{l}\text { Airlines, Rental Cars } \\
\text { Public Transit, } \\
\text { Trains, Taxis }\end{array}$ & $\begin{array}{l}\text { Restaurants } \\
\text { Bars } \\
\text { Snack Shops }\end{array}$ & $\begin{array}{c}\text { Food \& Beverage } \\
\$ \mathbf{\$ 1 1 . 5 b}\end{array}$ & $\begin{array}{l}\text { Spa Cuisine } \\
\text { Healthy Cuisine } \\
\text { Organic Cuisine }\end{array}$ \\
\hline $\begin{array}{c}\text { Other Services } \\
\mathbf{\$ 8 9 . 5 b}\end{array}$ & $\begin{array}{l}\text { Souvenirs | Gifts } \\
\text { Clothing | Art }\end{array}$ & $\begin{array}{l}\text { Shopping } \\
\$ 98.3 b\end{array}$ & $\begin{array}{l}\text { Fitness Wear | Spa Products } \\
\text { Healthy Foods I Vitamins }\end{array}$ \\
\hline $\begin{array}{c}\text { Telecom, Insurance, } \\
\text { Travel Agencies, } \\
\text { Concierges }\end{array}$ & $\begin{array}{l}\text { Museums } \\
\text { Tours | Theater }\end{array}$ & $\begin{array}{c}\text { Activities \& Excursions } \\
\$ 99.7 \mathbf{b}\end{array}$ & $\begin{array}{c}\text { Spas | Bathing | Fitness } \\
\text { Meditation | Life Coaching }\end{array}$ \\
\hline Generic & & We & ness-Specific \\
\hline
\end{tabular}




\section{Spa tourism remains a significant and high-growth segment within wellness tourism.}

While wellness tourism is much broader than spa tourism, spas represent a core business within the wellness tourism market. In 2017, spa tourism represented $\$ 309.1$ billion in expenditures, with 450.0 million spa-related trips taken. Spa tourism expenditures have grown by $8 \%$ annually since 2015 .

\section{Spa Tourism Represents About $48 \%$ of Global Wellness Tourism Expenditures}

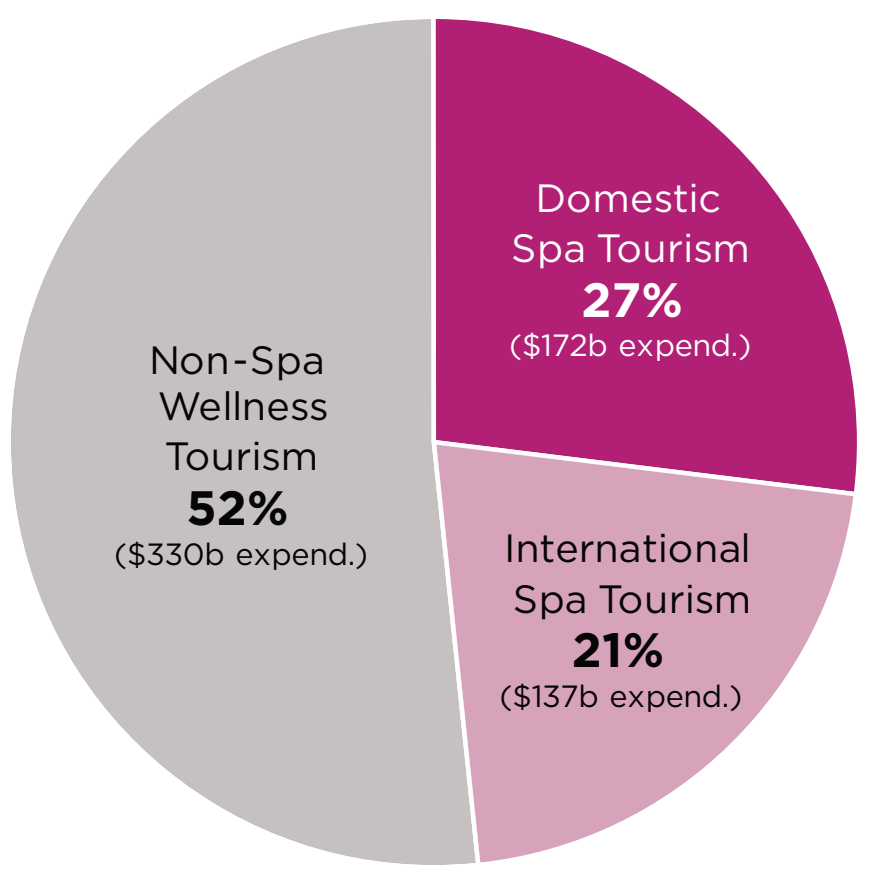

Source: Global Wellness Institute 


\section{Wellness tourism will continue its growth momentum.}

When GWI first started measuring wellness tourism five years ago, we predicted that the wellness tourism market would grow twice as quickly as overall tourism, and that has turned out to be correct. Wellness tourism expenditures have grown at a rapid $7.8 \%$ average annual rate over the last five years, increasing from $\$ 438.6$ billion in 2012 to $\$ 639.4$ billion in 2017 . During this same five-year period, overall tourism expenditures grew by only $3.0 \%$ annually. ${ }^{9}$

We project that this trend will continue into the next five years. Primary wellness travelers will become increasingly sophisticated and discerning with respect to their trip intentions and requirements - whether it means going deeper into certain wellness modalities (for example, following a yoga or fitness "guru"), pursuing a holistic experience that incorporates authenticity and local flavors, or pushing the boundary on transformative journeys. Secondary wellness travelers, who represent the bulk of wellness trips, will also grow as more people incorporate their wellness lifestyles and values into their travel. The aspects of travel that touch wellness will continue to expand beyond the conventional spheres - such as healthy rooms, fitness facilities/ programming, massages, and healthy food - and will extend to new and different opportunities to be stimulated or destress, immerse in local cultures, connect with nature, delve deeper into our selves, or foster personal growth.

\section{Wellness Tourism Growth Projections, 2017-2022}

\begin{tabular}{l|r|r|r} 
& \multicolumn{1}{c|}{$\begin{array}{c}\text { Projected Expenditures } \\
\text { (US\$ billions) }\end{array}$} & $\begin{array}{c}\text { Projected Average Annual } \\
\text { Growth Rate }\end{array}$ \\
\cline { 2 - 4 } & \multicolumn{1}{c|}{$\mathbf{2 0 1 7}$} & \multicolumn{1}{c}{$\mathbf{2 0 2 2}$} & \multicolumn{2}{|c|}{$\mathbf{2 0 1 7 - 2 0 2 2}$} \\
\hline North America & $\$ 241.7$ & $\$ 311.3$ & $5.2 \%$ \\
\hline Europe & $\$ 210.8$ & $\$ 275.0$ & $5.5 \%$ \\
\hline Asia-Pacific & $\$ 136.7$ & $\$ 251.6$ & $13.0 \%$ \\
\hline Latin America-Caribbean & $\$ 34.8$ & $\$ 54.7$ & $9.5 \%$ \\
\hline Middle East-North Africa & $\$ 10.7$ & $\$ 18.7$ & $11.8 \%$ \\
\hline Africa & $\$ 4.8$ & $\$ 8.1$ & $11.1 \%$ \\
\hline Total Wellness Tourism Industry & $\$ 639.4$ & $\$ 919.4$ & $\mathbf{7 . 5 \%}$ \\
\hline
\end{tabular}

Source: Global Wellness Institute estimates, based upon tourism industry data from Euromonitor International, economic data from the IMF, and GWI's data and projection model

\footnotetext{
${ }_{9}^{9}$ These figures combine both inbound/international and domestic tourism expenditures. General tourism industry data and projections are drawn from Euromonitor International.
} 
GWI projects that wellness tourism will grow at an average annual rate of $7.5 \%$ through 2022 , considerably faster than the $\mathbf{6 . 4 \%}$ annual growth forecasted for overall global tourism. We expect that global wellness tourism expenditures will reach over $\$ 919$ billion in 2022, representing $18 \%$ of the global tourism market. Correspondingly, we project wellness tourism trips to grow by $8.1 \%$ annually to 1.2 billion trips in 2022 . This growth forecast is well-aligned with the expected growth across many sectors that focus on wellness and holistic health (e.g., fitness/mind-body, healthy eating, organic food, etc.), as more consumers adopt wellness as a dominant lifestyle value and decision driver. Over half of the projected growth in wellness tourism expenditures (and three-quarters of the growth in wellness trips) through 2022 will take place in Asia-Pacific, Latin America-Caribbean, Middle East-North Africa, and Sub-Saharan Africa, driven by a dramatic increase in both domestic tourism and intra-regional wellness tourism in these markets. 
32 | Global Wellness Institute 


\section{EMERGING BUSINESS MODELS AND THE FUTURE OF WELLNESS TOURISM}

\section{Wellness, hospitality, and travel businesses are converging.}

Since wellness tourism burst into mainstream consumer consciousness a few years ago, the industry has evolved rapidly. Businesses and governments are investing in developing new strategies, products, experiences, and destinations. Wellness, hospitality, and travel are converging in diverse and unprecedented ways, as businesses experiment with new partnerships and business models to offer expanded services and programming that will help travelers incorporate wellness into every aspect of their trips.

\section{Fly healthy and fly well.}

Recognizing that air travel can be an unhealthy and stressful experience, airports and airlines are promoting health and wellness programs for customers combating long travel times, disrupted sleep, cramped spaces, and stress. Collaborations among airports, airlines, and wellness businesses are taking many forms:

- At airport terminals and airline lounges around the world, travelers can now find yoga classes, spas, quiet relaxation areas, nap pods, healthier foods, VR technology, and even therapy dogs. In Singapore, travelers at Changi Airport can relax in fitness lounges, high-end spas, and a rooftop pool and jacuzzi; visit outdoor flower gardens; or even try the meditative art of woodcarving. In Switzerland, Zurich provides rentals of inline skates, bicycles, and Nordic walking poles to encourage travelers to exercise in the conservation area just outside the airport. Qatar's Hamad Airport has a Vitality, Wellbeing, and Fitness Centre with a pool, hydrotherapy services, and showers. The American Heart Association is partnering with airports across the United States to map out guided walking circuits throughout airport terminals. Many airports are also experimenting with biophilic and healthy design approaches, such as adding natural daylight, plant walls, outdoor and indoor green spaces, and natural and locally-sourced materials.

- In-flight services on many airlines now include health-conscious cuisine, wellness programming, and sleep and relaxation products. Lufthansa provides its passengers with specially-designed sleep masks, while Qantas, Hawaiian Airlines, Cathay Pacific, and other airlines offer in-flight meditation and wellness programming as part of their in-flight entertainment packages.

- Partnerships between the airline industry and wellness industries have led to expanded health and wellness offerings. American Express is partnering with Exhale to open airport spas. Singapore Airlines is working with Canyon Ranch to ease the stress of its long-haul flights with offerings focusing on sleep, cuisine, and guided stretching. Qantas has partnered with Bodhi Wellness Spa to provided guided stretching and meditation at its new lounge in Perth. Delta Airlines recently offered a promotion with Equinox, allowing customers to visit Equinox gyms or access online classes via their smart device if they had recently flown on the airline. 
- Established wellness enterprises are expanding their markets and services to travel venues. Be Relax Spa has expanded its operations and offerings (new juice bars) to nearly two dozen airports on three continents. Sleep pod companies such as Izzzleep in Mexico and NapCity in the Americas and Germany offer specialized sleep services. New airport facilities and programs by fitness newcomers such as Roam Gym and FlyFit have expanded the choices for fitness enthusiasts with time to spare during transit.

- Social media and a variety of apps are enabling savvy air travelers to find the health and wellness services they need. The Sanctifly App provides an efficient way to search airports for healthy choices, including gyms, spas, and pools. LoungeBuddy helps users find the airport lounge with their desired services and allows them to use their phone to book a space. For those seeking tips from seasoned travelers, blogs such as Your Fit Trip (food) and Fittest Travel (fitness) provide travelers with wellness tips and information.

\section{Healthy hotels go mainstream.}

As wellness travel becomes more mainstream, many hotels are incorporating wellness into their design, amenities, services, and programming. Wellness features may include bedding and lighting that promote better sleep; windows and shades that block out light and noise; in-room fitness equipment and videos; healthy snacks, minibars, and menus at restaurants; or on-site spas and gyms.

- In conjunction with industry experts such as the Joffrey Ballet and Nora Tobin, Marriott has created a variety of new health and wellness offerings, including in-room fitness programming, immersive wellness retreats, healthy food, and outdoor fitness options. Since pioneering its iconic Heavenly ${ }^{\circledast}$ Bed concept in 1999, Westin has expanded to a fully integrated health and wellness strategy that addresses six pillars of wellbeing for guests (eat, sleep, move, feel, work, and play well), supported by a new $\$ 30$ million "Let's Rise" global brand campaign that communicates Westin's commitment to guests' wellbeing. Hilton has introduced its "Five Feet to Fitness" program, which provides over 11 different pieces of fitness equipment in guest rooms. Six Senses is highlighting "Eat and Sleep with Six Senses" to allow guests to focus on sleep quality and healthy eating. Accor has launched specialized wellness programs across its luxury brands; for example, the Pullman brand offers a "Sleep, Food, Sport, + Spa" program across its hotels and is piloting "Dreem," a neuroscience-based active sleep technology.

- Partnerships and acquisitions have allowed some larger hotel brands to quickly enhance their health and wellness offerings. Major hotel brands are partnering with a diverse array of fitness companies such as Technogym, Reebok, and Peloton to reach more wellness-minded consumers. Marriott, Four Seasons, Wyndham, and MGM have benefitted from the expertise of companies such as Delos (Stay Well ${ }^{\mathrm{TM}}$ ), to design guest rooms that provide extensive wellness amenities and services for travelers. Hyatt acquired both Miraval and Exhale to create strategic partnerships with existing wellness and fitness leaders. AccorHotels is also partnering with Banyan Tree to increase its wellness offerings.

- An emerging trend in hotels is the adoption of design principles such as wellness architecture, biophilic design, and sustainability elements into entire design of the property. For example, 1 Hotels has been a leader in implementing biophilic, healthy, and sustainable design features throughout its properties, aiming to stimulate guests' five senses and activate public spaces. 
A recent study by Terrapin Bright Green found that biophilic design in hotels has a strong impact on guest experience; for example, in the six Manhattan hotels they studied, $36 \%$ of guests actively or passively used hotel lobbies with biophilic design, while only $25 \%$ of guests spent time in conventional hotel lobbies..$^{10}$ In the future, we expect to see more evolution, differentiation, and experimentation in these areas.

\section{Engineering new wellness travel experiences.}

Consumers are increasingly viewing vacations as an opportunity to experience wellness in new ways, and tourism-related businesses from cruise lines to tour operators and event organizers are engineering diverse new wellness travel experiences.

- Cruise lines have not only brought sumptuous spas and workout spaces on board, but many are now showcasing other aspects of health and wellness including healthy food, relaxation, meditation, and wellness-themed excursions. In Asia, Chinese travelers have driven the rise of health and wellness offerings on several cruise lines. The Genting Dream, part of the Dream Cruises line in Asia, has a 4,000 square-meter spa with all of the latest Western and Asian spa treatments, in addition to a first-rate gym, fitness studio, and yoga and Pilates classes. Star Clippers has introduced complimentary yoga, meditation, and fitness classes on some of its cruises. In addition to high-tech gym equipment, Silver Sea cruises provides complimentary massages and wellness-themed classes including cooking and fitness. Many cruise ships are adding new therapies onboard, such as acupuncture and minimally-invasive beauty treatments that are typically offered at medical spas (e.g., botox and fillers).

- A number of cruise lines are partnering with wellness industry experts and service providers to raise the quality and sophistication of their wellness offerings, or to create wellnessthemed voyages. Lindblad Expeditions has formed a partnership with Exhale, while Seabourn is collaborating with Dr. Andrew Weil, an expert in integrative medicine, to launch wellness cruises. Holland America is working with $O$ (the Oprah Magazine) to offer mediation and healthy lifestyle programming on some of its cruises, and Windstar cruises now has James Beard Award nominee chefs creating its menus. MSC cruises, which highlights its partnerships with Technogym, has developed a comprehensive wellness program that includes a pre-cruise wellness assessment. In 2017, MSC also partnered with Weight Watchers to launch the first "Weight Watchers Rejuvenation Vacation at Sea" cruise. The first entirely health and wellnessthemed cruise line, Blue World Voyages, is slated to launch in 2019.

- Meanwhile, tour operators and event organizers are helping travelers to find their desired wellness travel experiences. Virtuoso (a high-end network of travel companies) has a wellness travel community that provides wellness travelers everything they need to create a tailored wellness vacation. In Africa, longstanding safari operators like Micato Safaris, as well as newer tour operators like Satori Africa (the first Africa-based wellness travel company), are combining wellness offerings such as yoga, meditation, massage, trail running, and healthy/ local cuisine with traditional safari activities. In North America, Wanderlust festivals with yoga and meditation instructors, musicians, and chefs, have drawn over 100,000 wellness enthusiasts to take part in wellness related activities in popular travel destinations.

10 Terrapin Bright Green (2017). Human Spaces 2.0: Biophilic Design in Hospitality. https://www.terrapinbrightgreen.com/report/human-spaces-2-O/. 


\section{Wellness products and brands travel with their customers.}

As wellness routines become a daily lifestyle for many consumers, products and brands are following their customers on their travels to help them continue these routines wherever they go.

- To allow its loyal cycling customers to continue to train when traveling, Peloton has partnered with Westin and some other Marriott brands to offer its bikes in hotel guest rooms and gyms. Equinox, known for its luxury gyms in major U.S. metropolitan areas, has created its own hospitality brand and will open its first hotel in New York City's Hudson Yards development in 2019. It has announced plans to build as many as 75 fitness-centric hotels in the world.

- Some retail and product companies are projecting their customer values and expanding their product brands into wellness travel experiences. Lululemon and Free People, both athleisure retailers, have created wellness retreats for their customers. ClassPass, which offers fitness subscription packages that permit customers to take a variety of studio classes, has just announced its first Getaways break in the Hamptons, New York, and it plans to roll out more short trips to other vacation destinations soon.

\section{A new nexus of travel, work, and wellness.}

For those who want longer time to experience a country than the standard vacation, several innovative companies have combined coworking and travel with wellness:

- Roam, Outsite, The Remote Experience, WY_CO, CoWoLi, Nomad House, and Unsettled are coliving and coworking enterprises that allow people to experience other countries and cultures while working and living with like-minded individuals. These companies typically offer private accommodations with shared living spaces, working spaces, and other community amenities, in addition to the opportunity to experience a city or region for a week, a month, or more. Many also provide on-site wellness/fitness amenities, yoga classes, meditation, and other community events. WeWork, which started with coworking and coliving properties and recently branched into fitness with Rise by We, has quietly entered the hospitality space with short term rental rooms/studios in New York City.

- Some coworking travel groups, such as Behere and Hera Hub, cater exclusively to women, helping them to maintain their health and wellness routines while safely exploring new cities and settings across the globe. Behere gives clients access to local gym and fitness studios, while Hera Hub has created spa-inspired environments within its shared spaces.

Clearly, the rise of wellness tourism is enticing new entrants into the market, as well as new forms of competition and partnerships. The integration of business areas along a continuum from hospitality to wellness and healthy lifestyles will continue to gather momentum. We expect more experimentation in different types of integration within this continuum in the future, as different players in the travel, hospitality, spa, fitness, and retail worlds identify what drives their core customers and seek out new ways to distinguish themselves from competitors in this evolving landscape. 


\section{Wellness tourism brings wide-ranging opportunities and benefits to destinations and their people.}

\section{Destination marketing becomes more authentic and place-based.}

At the national and regional levels, destination marketing for wellness tourism has both expanded and evolved in recent years. When GWI first measured wellness tourism in 2013, we counted 65 countries that were actively marketing some form of wellness tourism at the national level; that number has expanded to more than 100 countries in 2018 (see Appendix $A$ ). National governments and tourism ministries are rapidly catching on to the growing consumer interest in and enormous potential of this sector. Even more importantly, the nature and focus of wellness tourism marketing and development in the public sector is evolving to become more targeted and authentic, as understanding of what it is evolves and as traveler desires grow more sophisticated.

- When GWI first studied this sector five years ago, most destination marketing for wellness tourism was relatively generic (i.e., focused on spas) or tended to conflate wellness with medical tourism. Today, marketing approaches are more nuanced and more distinct from medical tourism, as countries start to link their wellness tourism offerings with their own natural and cultural assets. Thermal/mineral springs have seen the biggest growth in marketing and development focus. Most countries with longstanding hot spring bathing traditions (across Europe, Latin America, and Asia) are reinvigorating and investing in these assets and more actively marketing them as a key wellness tourism opportunity; meanwhile, countries with undeveloped geothermal assets are now seeking investments to create new high-value wellness tourism offerings (e.g., Kenya, Rwanda, Ethiopia, Saudi Arabia, Cambodia, India).

- A small but growing number of destinations are developing a truly authentic and place-based wellness tourism product and brand. The state of Kerala, India, was an early pioneer in this regard by branding itself as the "Land of Ayurveda" over two decades ago, successfully building a high-value wellness tourism offering to combat mass tourism and reduce seasonality. Today, neighboring countries Sri Lanka, Nepal, and Bhutan each promote unique, culturally-rooted wellness tourism experiences that link wellness with yoga, Ayurveda, meditation, spirituality, pilgrimage, indigenous medicine, faith healing, and happiness. On the other side of the world, Costa Rica is now building upon the uniquely Costa Rican "Pura Vida" concept to build a "Wellness Pura Vida" tourism campaign, which will develop seven areas of the country for wellness tourism around their unique natural and cultural features. In the United States, the city of Beverly Hills - long known for its five-star, high-end offerings - has launched the "City of Wellth" tourism campaign to redefine luxury as less about materialism and more about health, purpose, and happiness. 


\section{Wellness tourism becomes integrated with regional and community development.}

As public sector understanding of wellness tourism evolves, some regions no longer see it as an isolated niche tourism offering for a small segment of wealthy tourists, but rather as an opportunity to bring wide-ranging benefits to local economies and populations. In some places, wellness tourism development is starting to be integrated with local and regional urban planning, economic development, and community development initiatives:

- A few regions and metropolitan areas are connecting wellness tourism with broader development of a wellness industry cluster that can grow local business and employment opportunities. For example, Austria's Tirol region was an early pioneer in marketing wellness tourism over two decades ago, launching an Alpine wellness concept and developing wellness hotels that would combat the seasonality of its mainstay ski tourism. In the early-2000s, the region expanded on this success by creating the "Cluster Wellness Tirol" initiative to cultivate other economic opportunities and innovation around wellness. Today, over 100 wellnessrelated businesses in the region are part of this cluster network, ranging from telemedicine, to food production and nutrition, to spa equipment and technology, to workplace wellness, and much more. In the United States, the Lake Nona master-planned community near Orlando, Florida, started out as an industry cluster initiative to attract world-class biomedical, health, and human performance-focused companies. The region is building on this success to create wellness lifestyle real estate and amenities for both residents and visitors. Wellness tourism amenities include a hotel with Delos Stay Well ${ }^{T M}$ rooms, a planned integrated wellness/ performance/fitness facility and institute, and a planned performance resort and spa with a wellness-focused design.

- Some regions are developing their wellness tourism assets and amenities not as standalone offerings for tourists, but in a manner that will simultaneously benefit local residents alongside tourists. For example, as part of its "Ibiza is Wellness" rebranding campaign, Ibiza, Spain, has created an online map and directory of local businesses, facilities, and services across 16 categories of wellness. This effort aims to support local residents in accessing local healthy lifestyle services, while also cultivating a healthy, holistic, and sustainable tourism product that builds on the island's natural and cultural assets and combats seasonality and low-value mass tourism. Costa Rica's "Wellness Pura Vida" strategy (currently under development) has as one of its aims to engage local communities in the planning process and to use wellness tourism development as a catalyst for social and economic growth in seven regions across the country. Rochester, Minnesota's 20-year, $\$ 5.6$ billion Destination Medical Center initiative builds on the world-class reputation of the Mayo Clinic and its massive medical tourism industry (3 million+ visitors per year). Plans include a "heart of the city" urban district where hospitality intersects with healthcare, with healthy design and extensive wellness lifestyle and leisure amenities that will benefit the thousands of Mayo Clinic employees who live and work in the community, alongside the visitors to the clinic and their families. 


\section{In the future, the wellness of travel will increasingly link to the wellness of the place.}

As more consumers adopt wellness as a dominant value, they will increasingly filter their travel experiences through a holistic wellness lens. Analysts have taken note of the rising traveler interest in authenticity - that is, things rooted in local culture, traditions, history, and/or natural environment. When a recent Expedia survey asked Millennial travelers from China, Brazil, United States, and United Kingdom about their travel preferences, $60-78 \%$ of respondents agreed or strongly agreed that "When I travel, the most important thing for me is to experience the authentic culture of the place."11

Wellness travelers will continue to seek out and expect healthy rooms, food, amenities, and programming, but they are also increasingly interested in how people live and if people are well cared for in the places that they visit. That is one reason why a high-end resort hotel such as The Breakers Palm Beach (U.S.) would place their employee wellness at the center of their brand and their guest experience. Serenbe, a healthy/sustainable residential development outside of Atlanta, Georgia, has become a popular tourism destination based on its overall wellness design and the culture of its residential community. Recognizing that the wellness of a place is the DNA of its authentic wellness offering, more destinations, regions (such as Wellness Valley in Romagna, Italy and the state of Colorado in the United States), and countries (such as Costa Rica and Bhutan) are prioritizing the wellbeing of their residents and their environment to create their own unique wellness value proposition and brand.

"Expedia and Future Foundation (2016). Millennial Traveller Report: Why Millennials will shape the next 20 years of travel. 


\section{From "Me" to "We:" from consuming to contributing.}

In a holistic wellness framework, being well and doing good are closely connected; we cannot be truly well if our communities and the environment around us are not well. Research from the rapidly expanding fields of happiness, compassion, and altruism suggests that we are more likely to attain a deeper and lasting sense of peace and wellbeing by focusing on others, through helping, giving, and forming deeper connections. Some hospitality leaders are already taking note. For example, as a result of consumer research that supports this emerging consumer value, Westin Hotels \& Resorts has organized and sponsored activities that allow guests to give back to the places they are visiting, such as plogging (a Swedish fitness craze that combines picking up litter while jogging) or pairing beach clean-ups with paddleboarding activities. Pushing its core wellness concept further into the idea of contribution, Westin also launched its ThreadForward program to upcycle used hotel bed linens into pajamas for children in need.

In recent years, wellness travel has also been evolving from a focus on being experiential to being transformative. Much of this transformation is still centering on "Me" - as in, how "l" will evolve or grow through "my" travel experience. However, GWI predicts that a "We" perspective will grow as our quest for wellbeing continues to evolve, and wellness travel will see a shift from a consumptive to a contribution mindset. Future wellness travelers will increasingly link personal transformation with the connections they make during travel and their impacts on the people and the places that they touch, so that wellness travel will become a more meaningful two-way exchange between the travelers and the destination, instead of a one-sided consumptive and commercial transaction. This consumer evolution, along with the development of wellness tourism, can play an important role in mitigating the negative impacts of over-tourism in some popular destinations and regions.

As we look into the future, we see an escalation of consumer adoption and understanding of wellness as a holistic and dominant lifestyle value. How the tourism and hospitality industry will enable the realization of these values and lifestyles and capture these opportunities will determine its growth path and success in the future. 


\section{REGIONAL HIGHLIGHTS}

\section{Wellness Tourism by Region, 2017}

Combined Inbound/International and Domestic Wellness Tourism Trips and Expenditures

\section{North America}

\$241.7b Expenditures

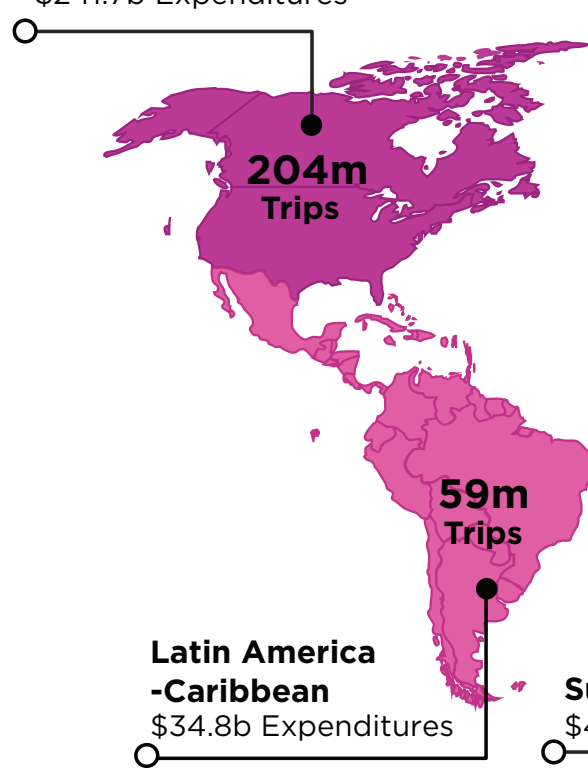

Europe Asia-Pacific

$\$ 210.8 \mathrm{~b}$ Expenditures $\$ 136.7 \mathrm{~b}$ Expenditures

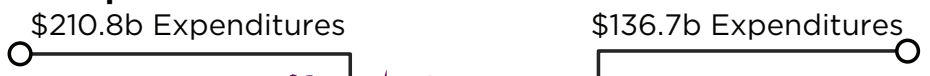

Sub-Saharan Africa

$\$ 4.8 \mathrm{~b}$ Expenditures
Middle East-North Africa

$\$ 10.7 \mathrm{~b}$ Expenditures
Arrivals/Trips

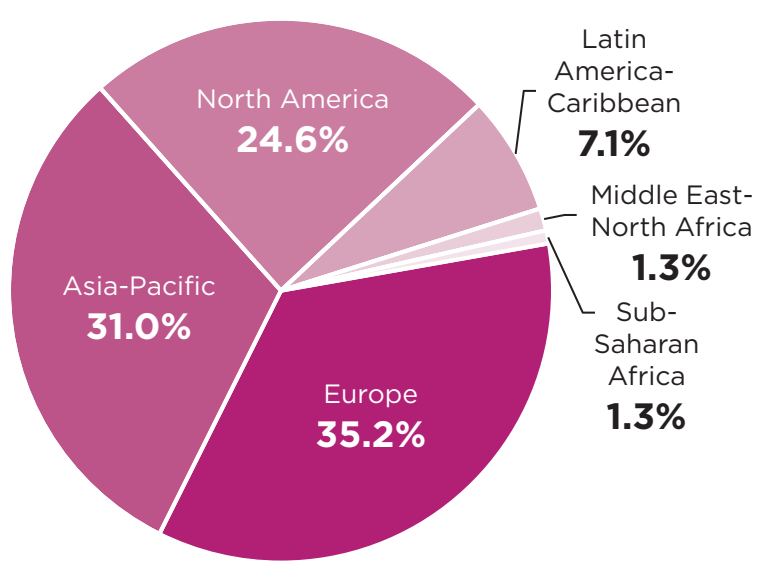

Receipts/Expenditures

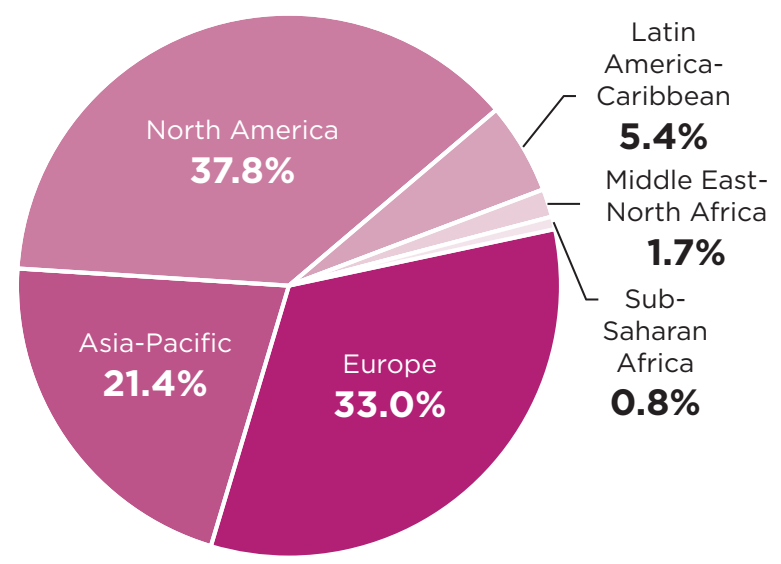


42 | Global Wellness Institute 


\section{Asia-Pacific Wellness Tourism Highlights (2017)}

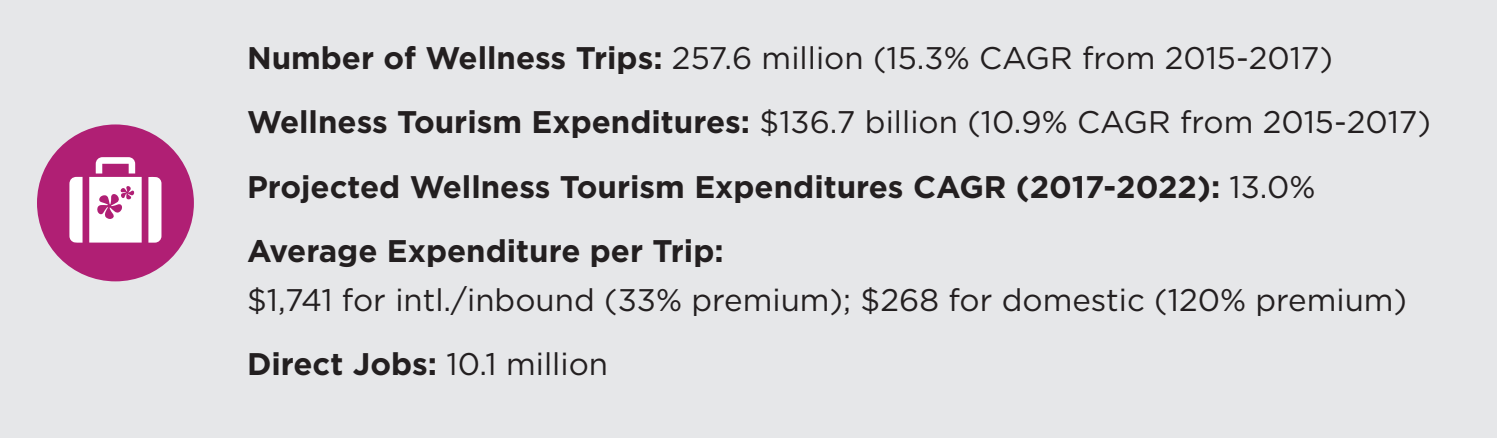

Top Ten Wellness Tourism Markets in Asia-Pacific, 2017

\begin{tabular}{l|r|r|r|r} 
& \multicolumn{3}{c|}{$\begin{array}{c}\text { Number of Arrivals/Trips } \\
\text { (thousands) }\end{array}$} & $\begin{array}{r}\text { Receipts/Expenditures } \\
\text { (US } \$ \text { millions) }\end{array}$ \\
\cline { 2 - 5 } & Inbound/Intl. & \multicolumn{1}{c}{ Domestic } & Total & $\mathbf{\$ 3 1 , 7 0 5 . 9}$ \\
\hline China & $7,724.3$ & $62,442.2$ & $\mathbf{7 0 , 1 6 6 . 5}$ & $\mathbf{\$ 2 2 , 4 6 6 . 1}$ \\
\hline Japan & $1,585.5$ & $38,900.0$ & $\mathbf{4 0 , 4 8 5 . 5}$ & $\mathbf{\$ 1 6 , 2 9 9 . 7}$ \\
\hline India & $4,542.4$ & $51,426.3$ & $\mathbf{5 5 , 9 6 8 . 6}$ & $\mathbf{\$ 1 2 , 0 1 8 . 4}$ \\
\hline Thailand & $5,691.9$ & $6,764.1$ & $\mathbf{1 2 , 4 5 6 . 0}$ & $\mathbf{\$ 1 0 , 5 2 0 . 9}$ \\
\hline Australia & 876.2 & $9,122.1$ & $\mathbf{9 , 9 9 8 . 3}$ & $\mathbf{\$ 7 , 1 8 6 . 6}$ \\
\hline South Korea & $1,709.8$ & $17,908.6$ & $\mathbf{1 9 , 6 1 8 . 3}$ & $\mathbf{\$ 6 , 9 2 8 . 5}$ \\
\hline Indonesia & $5,183.5$ & $3,151.7$ & $\mathbf{8 , 3 3 5 . 2}$ & $\mathbf{\$ 5 , 0 1 9 . 2}$ \\
\hline Malaysia & $3,331.7$ & $4,956.1$ & $\mathbf{8 , 2 8 7 . 8}$ & $\mathbf{\$ 4 , 0 0 1 . 1}$ \\
\hline Vietnam & $3,149.5$ & $6,465.8$ & $\mathbf{9 , 6 1 5 . 3}$ & $\mathbf{\$ 3 , 0 3 6 . 0}$ \\
\hline New Zealand & 341.0 & $2,736.5$ & $\mathbf{3 , 0 7 7 . 5}$ &
\end{tabular}

Note: These figures include both primary and secondary wellness trips. Expenditures data combine both international/inbound and domestic wellness tourism spending. Source: Estimates by the Global Wellness Institute, based upon tourism industry data from Euromonitor International

\section{Wellness Tourism Spending Premiums in the Top Ten Markets, 2017}

\begin{tabular}{|c|c|c|c|c|}
\hline & \multicolumn{2}{|c|}{$\begin{array}{l}\text { Average Spending per } \\
\text { INBOUND/INTERNATIONAL Trip }\end{array}$} & \multicolumn{2}{|c|}{$\begin{array}{l}\text { Average Spending per } \\
\text { DOMESTIC Trip }\end{array}$} \\
\hline & Wellness Trip & Average Trip & Wellness Trip & Average Trip \\
\hline China & $\$ 2,226$ & $\$ 1,417$ & $\$ 232$ & $\$ 146$ \\
\hline Japan & $\$ 2,192$ & $\$ 1,436$ & $\$ 488$ & $\$ 307$ \\
\hline India & $\$ 2,937$ & $\$ 1,941$ & $\$ 58$ & $\$ 36$ \\
\hline Thailand & $\$ 1,885$ & $\$ 1,206$ & $\$ 191$ & $\$ 120$ \\
\hline Australia & $\$ 2,992$ & $\$ 2,490$ & $\$ 866$ & $\$ 487$ \\
\hline South Korea & $\$ 2,054$ & $\$ 1,307$ & $\$ 205$ & $\$ 126$ \\
\hline Indonesia & $\$ 1,184$ & $\$ 793$ & $\$ 251$ & $\$ 115$ \\
\hline Malaysia & $\$ 1,109$ & $\$ 717$ & $\$ 267$ & $\$ 102$ \\
\hline Vietnam & $\$ 959$ & $\$ 634$ & $\$ 152$ & $\$ 97$ \\
\hline New Zealand & $\$ 2,758$ & $\$ 2,115$ & $\$ 766$ & $\$ 478$ \\
\hline
\end{tabular}

Note: These figures include both primary and secondary wellness trips. Source: Estimates by the Global Wellness Institute, based upon tourism industry data from Euromonitor International 


\section{Asia-Pacific Wellness Tourism Developments}

- Wellness tourism continues its rapid growth trajectory in the Asia-Pacific region, as more stressed-out people look to travel for respite and rejuvenation. To meet the growing wellness sophistication of Asian travelers, wellness travel offerings have expanded tremendously in breadth and depth, moving far beyond typical offerings such as detox, weight loss, spa treatments in a gazebo, and yoga on the beach. Across Asian destinations, there is tremendous increase in demand for all types of wellness modalities and experiences - from sound therapy to tai chi, and from meditation to spiritual guidance. Many travelers are interested in what a specific place has to offer, creating opportunities for destinations to dig into their own traditions, healing modalities, natural settings, and local ingredients to create a differentiated experience. With the alarming rise of air pollution across major metropolitan cities in China, India, and other Asian countries, some travelers are even traveling in search of healthier air, planning "lung-cleansing" and "smog-escape" wellness trips.

- Although less than half of the nations in the Asia-Pacific region promote wellness on their national tourism websites, this number has grown by more than $60 \%$ over the last five years (from 13 to 21 countries). Many of the countries that do market wellness tourism are also actively engaged in supporting the development of their nation's wellness offerings, often centered around thermal tourism sites. Some countries are promoting other aspects of their wellness sectors, such as beauty and traditional bathhouses in South Korea; healthy eating in Vietnam; meditation, Ayurveda, and yoga in Sri Lanka and India; and spirituality, meditation, and healing in Nepal and Bhutan. Several countries, including Sri Lanka, Bhutan, Malaysia, China, the Philippines and India, provide economic incentives to companies investing in wellness-related developments. For example, India, through its Market Development Assistance Scheme, supports new and redevelopment projects in the wellness tourism sector.

- India and other destinations in South Asia and the Himalayan region are capitalizing on the rising global interest in yoga, meditation, and Ayurvedic health to promote wellness tourism. In 2016, India set up a National Medical \& Wellness Tourism Promotion board to provide policy advice on these sectors. Measures to support wellness tourism include guidelines for quality and training, financial assistance, and investment promotion for wellness centers catering to tourists. Sri Lanka aggressively promotes wellness tourism with an Ayurvedic flavor, in conjunction with its wildlife, history, nature, and cultural offerings, and the country has seen a tremendous rise in investment and arrivals. Bhutan's distinct focus on low-volume, high-spend tourism (requirement of $\$ 200-250$ spending per day) aligns well with its growing wellness tourism industry, which has received massive investment that turns its various assets - nature, hot springs, antiquity, culture, spiritual heritage, and happiness - into specially curated healing journeys for guests.

- The Chinese wellness tourism sector, while enormous, mostly caters to its domestic travelers. The interest and appetite for wellness travel continue to rise among Chinese consumers, many of whom are rediscovering their wellness heritage and healing systems - from Traditional Chinese Medicine (TCM) and herbal medicine, to qigong, meditation, and martial arts. In recent years China has placed increased attention on developing its health and wellness industry, marketing to both domestic and international tourists the variety of health and wellness services offered across the country, especially those derived from TCM. Since the first Chinese Wellness Tourism Conference was held in 2016, a number of health and wellness conferences 
have emerged, including the Wellness China Expo, to promote wellness tourism products, investment, and financing.

- Some countries are leveraging their advanced medical industries and wellness sectors to cross-promote wellness and medical tourism, such as Malaysia, Singapore, South Korea, Thailand, and Philippines. Their strengths in both segments allow them to tap into overlapping opportunities, such as: stressed out executives who want a medical checkup, detox, meditation, and life coaching while on vacation; patients recovering from minor procedures (and their families) looking for a healing setting; as well as travelers seeking TCM, Ayurveda, Tibetan, and other integrative medicine and related wellness modalities to address chronic heath or mental wellness issues.

- Australia is both a major source and destination for wellness travelers. Australians are enthusiastic and sophisticated wellness consumers, and the diversity, vast size, and resources of the country create many opportunities to combine wellness with outdoor, nature, adventure, cultural, culinary, and other travel interests. Already home to a number of well-known wellness resorts and hot springs, Australia now also hosts a growing number of festivals and events that focus on wellness. The potential for wellness tourism has caught the government's attention. Tourism Australia has named wellness as one of five key niches for regional tourism development and is now actively promoting private investment in this sector.

- A relatively recent development in Asia-Pacific is the integration of wellness and wellness tourism into large-scale urban planning and economic development projects. For example, Malaysia's large-scale Medini Iskander development combines wellness-driven urban living and tourism facilities with advanced health services, medical tourism, and smart-city infrastructure and design. South Korea's Jeju Island project is expanding from its traditional medical tourism focus to add holistic and wellness amenities and services for tourists, as well as resort-style residential living with wellness-inspired design and amenities that capitalize on the island's natural beauty and environment.

\section{Spas}

- Asia-Pacific remains the region with the highest number of spas and the fastest growth, with the hotel/resort spa category leading in new investments and openings. Much of the growth is driven by demand from enthusiastic wellness travelers. Whether primary or secondary, wellness travelers seek a wide range of wellness experiences and options at their destination, while also expecting more personalization. Luxury urban hotels and resort hotels have been best able to adapt their facilities and offerings to meet these demands, and numerous luxury hotels have opened with sumptuous spas in diverse markets stretching from China to Vietnam to the Maldives.

- $\quad$ There is a marked increase among Asian hotels and resorts advertising their spas and wellness packages, and also developing offerings to meet the fast-growing demand for retreats along a full range of wellness themes/interests - yoga, meditation, detox, fitness/boot camp, personal transformation, surfing, etc. More spas are promoting traditional Asian wellness modalities and programming, from Ayurvedic treatments to TCM, from chi gong to yoga and meditation, and from Tibetan medicine to Balinese healing. In countries such as Sri Lanka and India, a growing number of hotel/resort spas and traditional Ayurvedic resorts are transforming themselves into 
destination spas and wellness retreats that provide a holistic package of services, experiences, or journeys. The Carnoustie Group, known for its Ayurveda and wellness resorts in India, has announced plans to develop luxury wellness centers throughout China.

- The underlying demand for the Asian spa industry is driven by growing consumer interest in living healthier and more fulfilled lives, against the rise of chronic disease, stress levels, mental imbalance, and unhappiness. It is increasingly common for consumers to turn to body work to relieve stress and chronic pain, and to seek treatments that help maintain vitality and good health. Interest in yoga, meditation, and mind-body practices is on the rise across the region. In many Asian metropolises, spas have turned into urban sanctuaries where guests seek much more than just a facial or massage, but a full range of holistic wellness experiences. The need to inject wellness into ever busier lives has given rise to half-day and one-day urban retreat programs that combine a range of modalities (meditation, yoga, coaching/spiritual guidance, body work, hydrotherapy, sound healing, energy treatments, etc.). The Four Seasons in Hong Kong, for example, has created a "Masters of Wellness" program that allows guests to learn from top-notch visiting healers and wellness experts in various therapies and treatments.

- Asia has some of the fastest growing beauty markets in the world, and the spa industry reflects this consumer interest. Cosmoprof Asia, the premier beauty and spa event of Asia, grows every year in size and scope. Asian spas, focused on the beauty aspect of wellness, have expanded their services to meet a growing demand for cosmetic enhancements. Consumers from Korea to China to India are sophisticated in what they seek and expect results in their spa and beauty treatments. Less stringent industry regulation sometimes allows the region's spa industry to offer technology-enhanced treatments that may not be available in North America and Europe.

\section{Thermal/Mineral Springs}

- With its vast thermal resources and bathing traditions dating back more than a thousand years, Asia is home to the largest thermal/mineral springs markets in the world. Countries are recognizing the potential of springs for wellness tourism and economic development, and a growing number of destinations (including Japan, Taiwan, New Zealand, Australia, Vietnam, and Laos) are highlighting their hot springs attractions to international visitors.

- The Chinese hot spring sector, while enormous, mainly caters to domestic visitors. The industry comprises the remnants of historic Soviet-style sanatoria, rustic day-use hot springs/ traditional bathhouses, and privately-owned and operated hot springs resorts and towns focused on recreation and family holidays. In order to raise standards and industry quality, China has established a national hot spring committee and regulations related to water quality, safety management, and the rating of "hot springs towns." Over the past five years, the industry has experienced strong growth, changing business models, and increased private investment, encouraged by rising consumer interest in healthy lifestyles and wellness tourism on the one hand, and government support for preventive health on the other hand. There are opportunities to upgrade existing facilities to world-class standards, and to integrate TCM with European-style hydro/balneotherapy to create Chinese-style hot spring wellness resorts. Some resorts also see potential for packaging employer-sponsored hot springs wellness holidays, developed as part of companies' employee wellness programs, which can create additional revenue for the sector (especially in the low seasons). 
- While Japan's hot spring inns are gaining in popularity among international tourists, most of these properties continue to operate in their traditional style, without facility upgrades or modernization of offerings to cater to a rising clientele of international wellness tourists. Recently, the industry has received substantial new investments in preparation for a visitor surge for the 2020 Tokyo Olympics. These include new high-end bathing facilities and hotels/ resorts with onsen in the center of Tokyo, and several large hotel brands such as InterContinental and Marriott opening new properties with their own private and communal hot springs.

- Elsewhere in East Asia, South Korea and Taiwan also have active hot springs sectors and traditions, evolving out of historical Japanese cultural influence. In recent years, Taiwan's hot springs sector has benefitted from aggressive tourism promotion to attract international visitors, families, wellness tourists, and even the MICE market. The sector is also actively linking hot springs to other types of tourism and interests. Taiwan hosts an annual Hot Spring \& Fine Cuisine Festival, and a healthy hot spring cuisine concept has emerged focusing on locallysourced fresh fish and vegetables. Hiking to one of Taiwan's more than 100 wild/undeveloped hot springs has also become a popular niche wellness tourism activity.

- Australia and New Zealand are leveraging their thermal resources aggressively for tourism promotion. The Peninsula Hot Springs in Australia is undergoing a significant expansion that will add overnight accommodations, new hot pools, ice cave/plunge pools, a group sauna area, an amphitheater, a "Food Bowl" that will promote organic produce, and expanded wellness programming. It is also working to create an official hot springs region near its location in Victoria. New Zealand is developing the city of Rotorua as a wellness destination focusing on its healing hot springs and mineral baths. The government is co-investing with private investors in a new hot spring facility (total investment US\$21.5m) on the lakefront, with the aim of developing a world-class spa, a thermal, and wellness tourism district with linkages to the local Maori culture. Other thermal springs around the country (e.g., Te Aroha and Okoroire) are seeking investments to upgrade facilities and create new destinations for luxury and short-break tourism.

- South and Southeast Asian countries also have considerable thermal resources but are generally at earlier stages of development. In recent years, governments that have designated hot spring areas for tourism development include Thailand (Klong Thom as a pilot "spa city"), Cambodia (Kampong Speu province), and Laos (Hiem district hot springs in Huaphan province). India has hundreds of hot springs, many of which are located near temples with religious significance. In 2016, the State of Uttarakhand tourism department announced plans to develop the region as a thermal wellness destination, with world-class facilities to be built across five thermal sites (including spa complexes, golf courses, yoga and meditation centers, etc.). In Bhutan and Nepal, thermal springs traditionally have been used for medical and therapeutic purposes (rather than recreation), and they are therefore tied to the indigenous healing systems and spiritual heritage and remain rustic and undeveloped. There is an emerging interest in Nepal to further develop these resources into wellness tourism destinations by tying thermal bathing with yoga, Ayurveda, and even shamanism. 
48 | Global Wellness Institute 


\section{Europe Wellness Tourism Highlights (2017)}

Number of Wellness Trips: 291.8 million (8.1\% CAGR from 2015-2017)

Wellness Tourism Expenditures: $\$ 210.8$ billion (4.4\% CAGR from 2015-2017)

Projected Wellness Tourism Expenditures CAGR (2017-2022): 5.5\%

Average Expenditure per Trip:

$\$ 1,209$ for intl./inbound (65\% premium); $\$ 594$ for domestic (105\% premium)

Direct Jobs: 3.2 million

Top Ten Wellness Tourism Markets in Europe, 2017

\begin{tabular}{l|r|r|r|r} 
& \multicolumn{3}{c|}{$\begin{array}{c}\text { Number of Arrivals/Trips } \\
\text { (thousands) }\end{array}$} & $\begin{array}{c}\text { Receipts/Expenditures } \\
\text { (US } \$ \text { millions) }\end{array}$ \\
\cline { 2 - 5 } & Inbound/Intl. & \multicolumn{1}{c}{ Domestic } & Total & $\mathbf{\$ 6 5 , 7 4 6 . 3}$ \\
\hline Germany & $6,197.3$ & $59,855.8$ & $\mathbf{6 6 , 0 5 3 . 1}$ & $\mathbf{\$ 3 0 , 7 1 4 . 6}$ \\
\hline France & $6,840.3$ & $25,573.4$ & $\mathbf{3 2 , 4 1 3 . 7}$ & $\mathbf{\$ 1 6 , 5 0 9 . 8}$ \\
\hline Austria & $7,000.8$ & $9,848.6$ & $\mathbf{1 6 , 8 4 9 . 3}$ & $\mathbf{\$ 1 3 , 4 7 8 . 1}$ \\
\hline United Kingdom & $3,613.1$ & $19,579.1$ & $\mathbf{2 3 , 1 9 2 . 2}$ & $\mathbf{\$ 1 3 , 4 2 8 . 4}$ \\
\hline Italy & $2,530.5$ & $10,574.0$ & $\mathbf{1 3 , 1 0 4 . 5}$ & $\mathbf{\$ 1 2 , 5 7 1 . 3}$ \\
\hline Switzerland & $4,070.6$ & $5,670.6$ & $\mathbf{9 , 7 4 1 . 2}$ & $\mathbf{\$ 9 , 8 8 5 . 6}$ \\
\hline Spain & $4,109.4$ & $14,735.7$ & $\mathbf{1 8 , 8 4 5 . 1}$ & $\mathbf{\$ 4 , 3 8 7 . 7}$ \\
\hline Turkey & $3,119.0$ & $5,947.1$ & $\mathbf{9 , 0 6 6 . 1}$ & $\mathbf{\$ 3 , 9 9 7 . 4}$ \\
\hline Russia & $2,093.6$ & $13,733.0$ & $\mathbf{1 5 , 8 2 6 . 6}$ & $\mathbf{\$ 3 , 4 0 5 . 2}$ \\
\hline Portugal & $1,552.9$ & $3,010.0$ & $\mathbf{4 , 5 6 2 . 9}$ &
\end{tabular}

Note: These figures include both primary and secondary wellness trips. Expenditures data combine both international/inbound and domestic wellness tourism spending. Source: Estimates by the Global Wellness Institute, based upon tourism industry data from Euromonitor International

\section{Wellness Tourism Spending Premiums in the Top Ten Markets, 2017}

\begin{tabular}{|c|c|c|c|c|}
\hline & \multicolumn{2}{|c|}{$\begin{array}{l}\text { Average Spending per } \\
\text { INBOUND/INTERNATIONAL Trip }\end{array}$} & \multicolumn{2}{|c|}{$\begin{array}{l}\text { Average Spending per } \\
\text { DOMESTIC Trip }\end{array}$} \\
\hline & Wellness Trip & Average Trip & Wellness Trip & Average Trip \\
\hline Germany & $\$ 1,901$ & $\$ 1,180$ & $\$ 902$ & $\$ 536$ \\
\hline France & $\$ 1,166$ & $\$ 759$ & $\$ 889$ & $\$ 554$ \\
\hline Austria & $\$ 1,189$ & $\$ 780$ & $\$ 831$ & $\$ 524$ \\
\hline United Kingdom & $\$ 1,535$ & $\$ 883$ & $\$ 405$ & $\$ 229$ \\
\hline Italy & $\$ 1,325$ & $\$ 907$ & $\$ 953$ & $\$ 642$ \\
\hline Switzerland & $\$ 2,070$ & $\$ 1,227$ & $\$ 731$ & $\$ 457$ \\
\hline Spain & $\$ 1,547$ & $\$ 1,004$ & $\$ 240$ & $\$ 148$ \\
\hline Turkey & $\$ 891$ & $\$ 537$ & $\$ 271$ & $\$ 159$ \\
\hline Russia & $\$ 384$ & $\$ 201$ & $\$ 233$ & $\$ 123$ \\
\hline Portugal & $\$ 1,101$ & $\$ 710$ & $\$ 563$ & $\$ 357$ \\
\hline
\end{tabular}

Note: These figures include both primary and secondary wellness trips. Source: Estimates by the Global Wellness Institute, based upon tourism industry data from Euromonitor International 


\section{Europe Wellness Tourism Developments}

- Wellness tourism has deep roots in Europe. For centuries, people have traveled within the region to take advantage of hot springs, alpine air, sea breezes, slow food, and idyllic landscapes, in order to escape from everyday life and pursue recreation and healing. Europeans are sophisticated wellness consumers, based on longstanding cultural and historical traditions across the region, and this influences their propensity for wellness travel. In a Eurobarometer survey of 30,000 Europeans across 33 countries, 13\% indicated that wellness/spa/health treatments were their primary or secondary motivation for going on holiday in 2015 (and the share of trips for which wellness was a primary motivation has doubled, from 3\% in 2010 to $6 \%$ in 2015). In several countries, the propensity for primary-motivation wellness trips is very high, including Iceland (19\% of survey respondents), Sweden (17\%), Hungary (16\%), Portugal and Slovakia (15\%), and Czech Republic (10\%).12

- Europe's wellness tourism industry continues to leverage its historic wellness assets, while upgrading its infrastructure (spas, wellness hotels, health resorts, etc.) and service offerings to attract the modern consumer. Throughout the region, governments and destinations are looking to wellness tourism to diversify their tourism sector, carve out a unique niche, reduce seasonality, combat over-tourism in some cases, and bring more benefits to their local communities and small businesses. For example, Russia's tourism plan for 2020 emphasizes the importance of enhancing spa and wellness sector quality and offerings to attract domestic and international wellness tourists. Italy recently launched Terme d'Italia, a project aimed at stimulating demand for spas and wellness resorts in eight regions. Azerbaijan, a relative newcomer that has received attention from the National Geographic Traveler Awards, is highlighting its thermal wealth and the unique quality of its mud to elevate its wellness tourism standing.

- A majority of the countries in Europe promote some form of wellness on their national tourism websites, with many highlighting their well-developed and historic thermal resources and spas. A smaller, but still considerable, number of countries also focus on developing this sector as part of their national tourism development/marketing strategies. Ten nations, including Slovenia and Montenegro have national initiatives designed to encourage investment in wellness sectors. Finland, for example, seeks to use public-private partnerships to enhance its wellness tourism offerings. Similarly, Croatia hopes to create a spa tourism zone around one of its leading thermal spas, providing financial incentives for wellness tourism projects in this area.

\footnotetext{
12 1) European Commission (2016). Preferences of Europeans towards Tourism. Flash Eurobarometer Report No. 432. 2) European Commission (2011). Survey on the attitudes of Europeans towards tourism. Flash Eurobarometer Report No. 328. Both available at: https://ec.europa.eu/growth/tools-databases/vto/ eurobarometer.
} 
- In Central and Eastern Europe, wellness tourism is intrinsically linked to thermal resources and an extensive network of historic health resorts and sanatoria, where guests stay for doctorsupervised, water-based medical treatments, financed wholly or partially by national insurance systems. Many of these sanatoriums are now undergoing renovations, modernization, and wellness menu enhancements (mostly with private investment) in order to attract a younger clientele who are seeking wellness rather than medical treatments, and who are more likely to spend on room upgrades, add-on services, and a higher quality experience.

- The quest for differentiation and authenticity has led many industry players to refocus on their own traditions and wellness modalities in designing destinations and crafting guest experiences. Some look to their bathing traditions; for example, Finnish saunas, Austrian sauna aufguss, and Russia banya all offer distinctive experiences that combine wellness with rituals, community, fun, and entertainment, within a specific cultural context. With Scandinavians consistently ranking as the happiest people in the world, there is also surging interest in Nordic lifestyle concepts such as hygge ("cozy" for the Danish and Norwegians) and lagom ("balanced" or "just right" for the Swedish), which can be incorporated into facility design, guest experiences, wellness offerings, and marketing/promotion.

- Wellness trips and retreats that are built around a specific wellness activity are on the rise, from boot camps to meditation and silence retreats. There is more demand to combine activities in nature with wellness modalities, such as hiking to a scenic location for meditation, or yoga and tai chi in an outdoor setting. Short-haul, weekend getaways continue to grow - not only for couples and girlfriends, but increasingly for families (including multi-generations) - and destinations are modifying their amenities and programming to accommodate this trend.

\section{Spas}

- Across the region, the spa market has been growing at a steady pace alongside stable economic growth and rising consumer interest in services and activities that align with their wellness lifestyle. Spa offerings are proliferating to provide novelty, diversity, and choices to customers. Some spas are expanding along a full range of holistic health and preventive services that extend to nutritional advice, sleep therapy, sound therapy, gut microbe analysis, energy healing, and so forth. Others are adopting wellness and healing modalities from different traditions and cultures: Finnish saunas, Japanese onsens, Turkish hammams, Traditional Chinese Medicine, and Ayurveda are no longer confined to their country or region of origin, or to niche spas. At the same time, establishments that provide a single, specialized wellness service/treatment also continue to grow, from beauty treatments, massage, and reflexology, to reiki, flotation tanks, cryotherapy, salt caves, etc., competing with similar offerings at conventional full-service day spas and hotel/resort spas.

- Spas are also responding to a rising need for mental wellness and stress reduction, along with growing interest in igniting and supporting behavioral change that will lead to a more healthful, balanced, and fulfilled life for guests outside of the spa. To complement body/energy work, many spas are beginning to offer more personalized and tailored services, such as nutritional assessments, individual counseling/advice, holistic personal wellness plans, coaching, etc. Overall, there is a gradual shift and expansion in offerings, as more spas recognize that they are no longer operating within the confines of the spa sector but competing in a much broader and quickly evolving landscape of the wellness industry. 
- Consumer adoption and understanding of wellness is quickly evolving, and many spas are undergoing redesign/refurbishments of their facilities and offerings, reflecting emerging needs and preferences, such as: the desire for community (e.g., creating club-like settings and atmospheres, or group programs and classes that facilitate connections among guests); intergenerational wellness experiences (e.g., "better-aging" modalities; kids/teen spa treatments, classes, and activities); water for healing (e.g., hydrotherapy, watsu, therapeutic thermal/mineral spring bathing and treatments); and using nature to enhance our sense of wellbeing (e.g., forest bathing; use of natural, organic, and local ingredients; biophilic design of facilities).

\section{Thermal/Mineral Springs}

- Thermal and mineral springs have been a part of wellness rituals in many European countries for centuries, and they are intrinsically linked to the strong bathing culture and tradition across the continent. Natural therapies related to water are as extensive as they are varied: balneotherapy, thalassotherapy, mud, salts, algae, etc.

- European countries that have a large sector of sanatoria-style health resorts catering to government-funded patients are looking to upgrade, privatize, and diversify many of these establishments. Investments are being made in thermal resorts and spas all over Europe, some in major expansions of well-established assets - for example, the addition of a subterranean spa, a Retreat Lagoon, hotel, and restaurant at the renowned Blue Lagoon in Iceland. Some investments aim to introduce cross-cultural bathing experience, such as introducing Japanesestyle onsens or Turkish baths to European bathers at existing or new thermal resorts. Many facilities receive new investments to add spa and complementary wellness services, facilities, and programming that will appear to a broader range of guests, such as health food restaurants, beauty treatments, fitness studios, and mind-body classes.

- With the rise of wellness and wellness tourism, thermal/mineral springs across Europe are viewed as a vital resource for tourism and economic development. Many new investments and marketing initiatives have been launched in recent years, from "the Year of Healthy Waters" promotion in Slovenia, to a Spain-Portugal partnership to jointly promote thermal establishments along their border. "Roman Thermal Spas of Europe" is a multi-country (Greece, Germany, Hungary, Portugal, France, and Bulgaria) partnership to develop and promote thermal tourism packages involving spas and health resorts with a Roman origin. Greece and Turkey, among other countries, have placed hot springs at the center of their tourism promotion themes, seeking investments to modernize and upgrade thermal offerings. 


\section{North America Wellness Tourism Highlights (2017)}

Number of Wellness Trips: 204.1 million (4.6\% CAGR from 2015-2017)

Wellness Tourism Expenditures: $\$ 241.7$ billion (5.8\% CAGR from 2015-2017)

Projected Wellness Tourism Expenditures CAGR (2017-2022): 5.2\%

Average Expenditure per Trip:

$\$ 3,285$ for intl./inbound (44\% premium); $\$ 1,058$ for domestic ( $57 \%$ premium)

Direct Jobs: 2.2 million

\section{Wellness Tourism Markets in North America, 2017}

\begin{tabular}{l|r|r|r|r} 
& \multicolumn{3}{c|}{$\begin{array}{c}\text { Number of Arrivals/Trips } \\
\text { (thousands) }\end{array}$} & $\begin{array}{c}\text { Receipts/Expenditures } \\
\text { (US\$ millions) }\end{array}$ \\
\cline { 2 - 4 } & Inbound/Intl. & \multicolumn{1}{c|}{ Domestic } & \multicolumn{1}{c}{ Total } & \$226,017.7 \\
\hline United States & $9,360.2$ & $167,179.1$ & $\mathbf{1 7 6 , 5 3 9 . 3}$ & $\mathbf{\$ 1 5 , 6 5 2 . 6}$ \\
\hline Canada & $2,207.8$ & $25,318.2$ & $\mathbf{2 7 , 5 2 6 . 0}$ & \\
\hline
\end{tabular}

Note: These figures include both primary and secondary wellness trips. Expenditures data combine both international/inbound and domestic wellness tourism spending. Source: Estimates by the Global Wellness Institute, based upon tourism industry data from Euromonitor International

\section{Wellness Tourism Spending Premiums in North American Markets, 2017}

\begin{tabular}{l|r|r|r|r} 
& \multicolumn{2}{c|}{$\begin{array}{c}\text { Average Spending per } \\
\text { INBOUND/INTERNATIONAL Trip }\end{array}$} & \multicolumn{2}{c}{$\begin{array}{c}\text { Average Spending per } \\
\text { DOMESTIC Trip }\end{array}$} \\
\cline { 2 - 5 } & Wellness Trip & \multicolumn{1}{c}{ Average Trip } & Wellness Trip & \multicolumn{1}{c}{ Average Trip } \\
\hline United States & $\$ 3,812$ & $\$ 2,689$ & $\$ 1,139$ & $\$ 716$ \\
\hline Canada & $\$ 1,052$ & $\$ 731$ & $\$ 527$ & $\$ 291$ \\
\hline
\end{tabular}

Note: These figures include both primary and secondary wellness trips. Source: Estimates by the Global Wellness Institute, based upon tourism industry data from Euromonitor International 


\section{North America Wellness Tourism Developments}

- Over one-third of the states in the United States now promote some form of wellness tourism on their official state tourism marketing website (by comparison, only eight states were marketing the sector in 2013). These are primarily concentrated in the western United States and typically highlight their natural hot springs and/or spas. A few states also emphasize a broader, more holistic approach to wellness; for example, New Mexico highlights its Native American-inspired traditions and treatments, while Maine markets meditation and yoga amidst its natural scenery. For Canada, six out of its eleven provinces actively promote wellness to tourists. While hot spring bathing figures prominently, some of the major tourist destinations, such as Ontario and British Colombia, also focus on spas and general wellness offerings. While state, provincial, and local tourism boards are starting to take notice of the growth in this sector, most of the wellness tourism developments, investments, and marketing campaigns in North America continue to be driven by private businesses.

- The rise of wellness travel is driving new positioning and promotion strategies in North America's hospitality industry. Industry leaders recognize the growing demand for wellness, not just at destination getaways but also in urban locations. Companies such as Canyon Ranch and Six Senses are expanding from their base of destination resorts into major U.S. metropolitan areas (e.g., Six Senses announced that their first North American property will be a luxury urban hotel adjacent to Manhattan's popular High Line). Luxury brands such as Four Seasons, Ritz-Carlton, and Mandarin Oriental have created wellness programs and health and fitness offerings that rival the top destination spa resorts. Mandarin Oriental hotels, for example, have on-site wellness professionals who offer customized Pilates, yoga, meditation, and tai chi classes. Meanwhile, numerous brands are rolling out new wellness initiatives to appeal to the growing number of business and leisure travelers who value healthy food, fitness, and mindbody balance. Leisure hotels aggressively market wellness weekends and rejuvenation retreats, and they promote their wellness offerings and environments as distinguishing characteristics. Business hotels address the time constraints of their guests by providing options such as shorter massages or in-room fitness equipment. Hilton, for example, launched "Five Feet to Fitness," which provides more than 11 different equipment and accessory options to guests in premium fitness rooms (which cost $\$ 45$ more than a standard room).

- Many hotel chains have developed partnerships with recognized wellness industry leaders to increase flexibility and offer expanded services/programming to guests. These partnerships can range from streaming content (e.g., Pilates, yoga, meditation) to providing interactive fitness equipment (e.g., Peloton). Examples of partnerships between major brands include: Shangri-La and Lululemon; Mandarin Oriental Hotels and the Mayo Clinic; Park Hyatt Hotels and MNDFL Meditation; Fairmont Hotels with Reebok and Technogym; and Wyndham Hotels and Resorts with Stay Well ${ }^{\mathrm{TM}}$ /Delos. For urban hotels where space is more challenging, some brands have formed partnerships with local boutique exercise studios, massage therapists, and spas to package offerings close to their properties.

- Airports and airlines continue to step up their wellness amenities to target secondary wellness travelers (i.e., those who want to maintain wellness during travel). Airport spas - in small kiosks and stores within terminals, as well as in airline first-class lounges - have proliferated in North American airports. Offerings can range from saunas, massages, manicures, pedicures, 
and haircuts to oxygen therapy, cryotherapy, guided meditation, and VR-assisted relaxation. While airline lounges are generally reserved for first- and business-class passengers or club members, many airlines sell spa access for a daily or half-day fee. Wellness services are also extended in other ways. American Express partners with Exhale to offer spa services at airport lounges. Delta has employee-only spas at several airports. Canyon Ranch is partnering with Singapore Airlines to step-up wellness amenities for passengers on ultra-long-haul flights. Additional airport wellness offerings on the rise include: "silent airports," yoga rooms, intransit fitness clubs, therapy dogs, napping pods and suites, treadmill desks, and designated terminal walking circuits.

\section{Spas}

- The spa industry has enjoyed steady growth in North America, driven by a steady economy and rising consumer spending on all things related to wellness. Growth has been led by hotel/ resort spas as well as medical spas. A 2017 ISPA survey reported that $42 \%$ of hotel/resort sector respondents cite "wellness, health and fitness" as the top trend affecting the spa industry. ${ }^{13}$ Luxury branded hotels (e.g., Four Seasons, Fairmont, Ritz-Carlton, etc.) increasingly use their spas and wellness programs as a marketing tool for hotel guests and to generate revenue from non-guest customers. Some hotels have begun charging a general resort fee whether guests use the wellness amenities or not.

- Medical spas are enjoying rising demand, reflecting increased consumer interest in self-care, maintenance, anti-aging, and beauty. While the majority of customers are women between the ages of 35-54, there is also rising interest from men and under-35 customers. According to the American Med Spa Association, in recent years there is a pronounced increase in demand for less invasive treatments such as injectables, chemical peels, and non-surgical skin tightening, in addition to body sculpting and tattoo removal. Many medical spas are investing in a more spa-like and less clinical/medical environments and atmospheres for their customers. Capitalizing on rising demand and the success of single service models such as Drybar (for blowouts), Alchemy 43 has attracted seed funding to launch a series of locations that focus on Botox and fillers in a spa/salon-like setting in major cities.

- Franchises such as Massage Envy, Elements Massage, Massage Heights, and Hand \& Stone continued to grow from 2015-2017, particularly in the suburbs and secondary city markets, but at a slower rate as compared to the previous two years. This leveling of growth is probably attributed to a maturing market, cost pressures, and aggressive discounting and competition from small, single-service establishments (e.g., reflexology centers, Thai massage clinics, etc.). GWI estimates that there were about 2,500 franchised spas in the United States in 2017, up from about 1,500 locations just five years earlier in 2012. ${ }^{14}$

\footnotetext{
${ }_{13}$ International SPA Association (2017). 2017 U.S. Spa Industry Study. Lexington, KY: International SPA Association.

${ }^{14}$ Global Wellness Institute analysis of data from Entrepreneur.com. 
- Zeel, a pioneer in the model of massage-on-demand, has expanded to more than 75 U.S. cities, and has launched a new platform that places licensed massage therapists on-demand at hundreds of spas, salons, and hotel partners, to help manage staffing and demand surges. Meanwhile, Soothe - a newcomer to massage-on-demand - recently raised \$31 million in new capital to fund expansion in the U.S. market and to launch new services in the UK and Australia. Similar on-demand and app-based services are also proliferating in the salon and beauty sector, with the growth of companies such as Glamsquad, BeGlammed, TheGlamApp, and BeautyLynk.

\section{Thermal/Mineral Springs}

- The majority of thermal/mineral springs are located in the Western and Southwestern United States and Western Canada, and these establishments tend to be fairly rustic bathing- and swimming-focused facilities. The thermal/mineral springs sector is quite underdeveloped in North America as compared to other wellness sectors, mainly because North Americans have not developed the type of bathing culture prevalent in much of Europe and East Asia. But that is changing, with a rising interest in and visitation to springs due to a confluence of consumer values and lifestyle preferences. Overall, more people are looking to nature and its power to calm and rejuvenate. Across North America and especially in Canada, consumers are discovering the healing powers of water, from Nordic spa circuits to hydrotherapy. Finally, the rise of loneliness has created awareness of the value of "third places" - social environments outside of home and work, where people can find community with one another. These trends, and the accessibility and affordability of visiting hot springs, are expected to drive the growth of the springs sector (and other wellness sectors) over the next decade.

- Business owners and investors are taking note of these trends and are renovating, expanding, and reopening historic hot springs facilities in many locations across the United States. Multimillion dollar expansions continue at California's iconic Two Bunch Palms and Glen Ivy Hot Springs. Several new facilities and reopenings of shuttered properties are slated over the next few years in Arizona, Wyoming, Montana, and California, while longer-term thermal spring redevelopment projects are in the works from California to Texas to South Dakota. 


\section{Latin America-Caribbean Wellness Tourism Highlights (2017)}

Number of Wellness Trips: 59.1 million (12.4\% CAGR from 2015-2017)

Wellness Tourism Expenditures: $\$ 34.8$ billion (7.0\% CAGR from 2015-2017)

(101)

Projected Wellness Tourism Expenditures CAGR (2017-2022): 9.5\%

Average Expenditure per Trip:

$\$ 1,067$ for intl./inbound (31\% premium); $\$ 380$ for domestic (26\% premium)

Direct Jobs: 1.4 million

Top Ten Wellness Tourism Markets in Latin America-Caribbean, 2017

\begin{tabular}{|c|c|c|c|c|}
\hline & \multicolumn{3}{|c|}{$\begin{array}{c}\text { Number of Arrivals/Trips } \\
\text { (thousands) }\end{array}$} & \multirow{2}{*}{$\begin{array}{l}\text { Receipts/Expenditures } \\
\text { (US\$ millions) }\end{array}$} \\
\hline & Inbound/Intl. & Domestic & Total & \\
\hline Mexico & $9,282.9$ & $9,368.8$ & $18,651.7$ & $\$ 12,845.0$ \\
\hline Brazil & 180.1 & $10,344.3$ & $10,524.4$ & $\$ 4,068.9$ \\
\hline Chile & $1,139.5$ & $6,790.0$ & $7,929.6$ & $\$ 2,223.5$ \\
\hline Argentina & 339.2 & $3,983.1$ & $4,322.4$ & $\$ 2,112.4$ \\
\hline Dominican Rep. & 828.3 & 186.4 & $1,014.7$ & $\$ 1,352.6$ \\
\hline Costa Rica & 791.3 & 208.1 & 999.4 & $\$ 1,350.0$ \\
\hline Peru & 297.4 & $1,987.1$ & $2,284.5$ & $\$ 1,262.9$ \\
\hline Ecuador & 571.2 & 439.7 & $1,010.9$ & $\$ 1,059.6$ \\
\hline Colombia & 160.5 & $1,744.6$ & $1,905.1$ & $\$ 984.9$ \\
\hline Jamaica & 539.2 & 120.9 & 660.1 & $\$ 739.0$ \\
\hline
\end{tabular}

Note: These figures include both primary and secondary wellness trips. Expenditures data combine both international/inbound and domestic wellness tourism spending. Source: Estimates by the Global Wellness Institute, based upon tourism industry data from Euromonitor International

\section{Wellness Tourism Spending Premiums in the Top Ten Markets, 2017}

\begin{tabular}{|c|c|c|c|c|}
\hline & \multicolumn{2}{|c|}{$\begin{array}{c}\text { Average Spending per } \\
\text { INBOUND/INTERNATIONAL Trip }\end{array}$} & \multicolumn{2}{|c|}{$\begin{array}{l}\text { Average Spending per } \\
\text { DOMESTIC Trip }\end{array}$} \\
\hline & Wellness Trip & Average Trip & Wellness Trip & Average Trip \\
\hline Mexico & $\$ 801$ & $\$ 493$ & $\$ 577$ & $\$ 450$ \\
\hline Brazil & $\$ 1,572$ & $\$ 1,188$ & $\$ 366$ & $\$ 243$ \\
\hline Chile & $\$ 734$ & $\$ 456$ & $\$ 204$ & $\$ 152$ \\
\hline Argentina & $\$ 1,257$ & $\$ 1,044$ & $\$ 423$ & $\$ 243$ \\
\hline Dominican Rep. & $\$ 1,543$ & $\$ 1,016$ & $\$ 400$ & $\$ 243$ \\
\hline Costa Rica & $\$ 1,678$ & $\$ 1,065$ & $\$ 107$ & $\$ 54$ \\
\hline Peru & $\$ 1,423$ & $\$ 852$ & $\$ 422$ & $\$ 317$ \\
\hline Ecuador & $\$ 1,423$ & $\$ 915$ & $\$ 561$ & $\$ 475$ \\
\hline Colombia & $\$ 1,350$ & $\$ 1,071$ & $\$ 440$ & $\$ 241$ \\
\hline Jamaica & $\$ 1,313$ & $\$ 912$ & $\$ 255$ & $\$ 214$ \\
\hline
\end{tabular}

Note: These figures include both primary and secondary wellness trips. Source: Estimates by the Global Wellness Institute, based upon tourism industry data from Euromonitor International 


\section{Latin America-Caribbean Wellness Tourism Developments}

- There is strong momentum to develop wellness tourism in Latin America and the Caribbean based on the region's diverse natural and cultural assets, alongside the motivations of key visitor segments: rest and relaxation; experiencing nature, biodiversity, adventure, active vacations, and ecotourism; and beauty and medical tourism. Many countries are discovering the potential of promoting thermal/mineral springs in conjunction with wellness tourism. Overall, we observe destinations adopting different strategies and positioning based on their unique assets and advantages. Caribbean tourism and destination marketing organizations are working to promote the region as a wellness destination by adopting spa facility standards, training personnel, and creating a wellness tourism identity. Nonetheless, the promotion of wellness tourism in the region will continue to be affected by various natural and human-made events and issues, such as hurricanes, earthquakes, safety, and travel warnings.

- Over half of the governments in the Latin America-Caribbean region actively market their wellness tourism offerings on their national visitor websites. Interest in wellness tourism among national tourism ministries and promotion boards has grown rapidly, given that only six countries in the region were promoting the sector just five years ago. The marketing focus varies greatly - from thermal springs to spas and wellness resorts - oftentimes tying into unique local geographic or cultural features. About 10 percent of the countries (e.g., Guatemala and Jamaica) have prioritized their wellness tourism sectors for support and development, and several nations (e.g., Colombia and Dominica) have identified wellness sector projects for investment promotion.

- To appeal to visitors who are already familiar with spas and R\&R offerings, many destinations (e.g., Mexico and several Caribbean countries) are upgrading their spas and reorienting their programming and positioning from luxury and pampering to active lifestyle and holistic wellness. These initiatives include building new wellness resorts/retreats, as well as developing rigorous programs and offerings of holistic wellness that focus on prevention and human performance, integrative medicine, and indigenous healing modalities.

- In countries with advanced medical and esthetic markets, the promotion of wellness tourism often builds off of strengths in beauty enhancement treatments (e.g., Argentina, Brazil), strong medicine and surgery sectors (e.g., Mexico, Cuba, Colombia), and the therapeutic properties of thermal/mineral waters (e.g., Ecuador). These nations' clinics and hospitals are partnering with resorts and hotels to create facilities that have the same attributes as U.S. medical spas.

- Countries such as Costa Rica and Belize are well-established eco-tourism destinations that have pioneered concepts such as jungle/eco-spas. Visitors who are interested in nature and biodiversity are already taking advantage of offerings such as coffee scrubs and volcanic mud wraps, or doing yoga and meditation retreats against a backdrop of pristine nature and diverse wildlife. Costa Rica has the ambition of branding its country as not only a wellness destination, but as a country of wellness, with special attention to the wellbeing of the people and the protection of its natural environment and cultural heritage. It has recently expanded its national promotional slogan from "Pura Vida" to "Wellness Pura Vida," and it is working on a long-term strategy to develop seven areas of the country around their unique wellness tourism assets. 


\section{Spas}

- The spa market in Latin American and the Caribbean is robust, reflecting strong tourism arrivals, steady economic growth, and rising interest in wellness among both residents and visitors. Hotel and resort developments have been especially strong in popular destinations (e.g., Mexico, Costa Rica, Colombia, Brazil, Belize, St. Kitts, etc.), and spas are nearly ubiquitous, as guests have come to expect spa services in resorts and city hotels alike. Many resort hotels are transforming their spas and expanding their offerings to meet the growing demand for more holistic wellness services, therapies, and programming that target prevention rather than pampering (e.g., hydrotherapy, circuit training, tai chi, meditation, etc.). Some are drawing inspiration from indigenous healing modalities (e.g., Mexican sweat lodges or temazcals) to create new experiences for guests interested in authenticity and local cultures.

- The region's spa sector has a strong association with beauty and slimming. Beyond spas catering to tourists, there is a robust market for esthetic and body treatments for a growing middle class, marked by the arrival of chains/franchises and the proliferation of massage clinics and esthetic salons in major urban areas (especially in Mexico and Brazil). Product companies are leveraging the region's biodiversity and local ingredients to create treatments tailored to specific health, wellness, beauty, and anti-aging needs. In particular, Jamaica, Nicaragua, Costa Rica, and Mexico are encouraging the promotion of locally made skincare products and native-based treatments in their spa industry.

\section{Thermal/Mineral Springs}

- Latin America and the Caribbean hosts extensive thermal/mineral water resources that extend from the Sierra Madre mountains in Central America to the Guaraní Aquifer in the Southern Cone. The region's rich natural offerings (biodiversity, beaches/coastlines, jungles and forests, wildlife, etc.), combined with its history and culture, offers tremendous opportunities for differentiation and unique positioning. However, today most facilities are traditional/rustic bathing and swimming establishments (e.g., balnearios and baños termales) or modern/ themed waterparks primarily used by residents and regional tourists for recreation. Countries in the region are in various stages of development to exploit new opportunities in this sector.

- Brazil has the largest and most developed thermal tourism sector in the region, with several major spa towns/regions hosting dozens of large-scale recreational resorts and waterparks. There are many major investments and new projects in the pipeline. In the Olimpia region, the $\$ 29$ million Hot Beach waterpark and resort opened in 2017. The Foz de Ignaçu region is investing heavily in its facilities, including development of the new Foz de Ignaçu Blue Park (the world's largest artificial thermal beach when completed, and inspired by Orlando theme parks) and a \$242 million expansion of its flagship Itaipuland thermal park (adding 2,500 timeshare apartments and an entertainment/hospitality complex). Other major developments include the Gramado Termas Resort (Brazil's first indoor thermal waterpark, with timeshare apartments), as well as new ancillary attractions in the Rio Quente Hot Park (rafting, archery, zipline, and a 1,200-person concert/event center). 
- Nicaragua, Ecuador, and Colombia have recently begun to explore and develop their natural springs, through site surveys and inventories, feasibility studies, and private-public partnerships. Other countries such as Jamaica and Mexico have made aggressive investments to upgrade hospitality infrastructure and complementary wellness services around the springs in order to target international tourists. In Argentina, where thermal springs are promoted by many provinces but lacking in basic tourism infrastructure, the government is conducting assessments to determine how to standardize and improve quality and services. The Uruguayan government has made the thermal sector a major tourism development priority, investing in a cluster of six hot springs on its western coast and opening a new 4-star resort, Salinas del Almiron in 2016. Costa Rica, with its well-developed eco/nature tourism clientele, is working to heighten the quality and diversity of its offerings with new investments in hot spring parks and hotels.

- Some countries focus on the therapeutic benefits of thermal springs as a healthcare and medical tourism resource. The Chilean government, for example, subsidizes older citizens to visit hot springs for rest and recuperation. Guatemala has many medical thermal spas and medical centers that offer rehabilitation, nutrition services as well as yoga. Its tourism promotion emphasizes the use of hot spring and mineral treatments in combination with the latest medical technology. Similarly, Cuba emphasizes the medicinal properties of its historic thermal/mineral springs and baths as it promotes itself as a medical travel destination. 


\section{Middle East-North Africa Wellness Tourism Highlights (2017)}

Number of Wellness Trips: 11.0 million (13.4\% CAGR from 2015-2017)

Wellness Tourism Expenditures: $\$ 10.7$ billion (13.3\% CAGR from 2015-2017)

Projected Wellness Tourism Expenditures CAGR (2017-2022): 11.8\%

Average Expenditure per Trip:

$\$ 1,305$ for intl./inbound (44\% premium); $\$ 599$ for domestic (65\% premium)

Direct Jobs: 0.3 million

Top Ten Wellness Tourism Markets in Middle East-North Africa, 2017

\begin{tabular}{l|r|r|r|r} 
& \multicolumn{3}{c|}{$\begin{array}{c}\text { Number of Arrivals/Trips } \\
\text { (thousands) }\end{array}$} & $\begin{array}{c}\text { Receipts/Expenditures } \\
\text { (US\$ millions) }\end{array}$ \\
\cline { 2 - 5 } & Inbound/Intl. & Domestic & Total & $\mathbf{\$ 3 , 7 5 0 . 0}$ \\
\hline UAE & $1,191.2$ & 652.7 & $\mathbf{1 , 8 4 3 . 9}$ & $\mathbf{\$ 1 , 7 1 7 . 8}$ \\
\hline Morocco & $1,320.1$ & $1,473.4$ & $\mathbf{2 , 7 9 3 . 6}$ & $\mathbf{\$ 1 , 1 3 1 . 3}$ \\
\hline Israel & 319.1 & 625.7 & $\mathbf{9 4 4 . 8}$ & $\mathbf{\$ 6 0 4 . 3}$ \\
\hline Jordan & 306.9 & 157.4 & $\mathbf{4 6 4 . 3}$ & $\mathbf{\$ 5 6 3 . 8}$ \\
\hline Bahrain & 271.1 & 57.1 & $\mathbf{3 2 8 . 2}$ & $\mathbf{\$ 4 9 2 . 2}$ \\
\hline Saudi Arabia & 119.9 & 538.6 & $\mathbf{6 5 8 . 5}$ & $\mathbf{\$ 4 7 3 . 5}$ \\
\hline Oman & 211.9 & 168.7 & $\mathbf{3 8 0 . 6}$ & $\mathbf{\$ 4 2 7 . 3}$ \\
\hline Egypt & 635.5 & 588.0 & $\mathbf{1 , 2 2 3 . 4}$ & $\mathbf{\$ 3 8 8 . 5}$ \\
\hline Iran & 272.3 & 328.1 & $\mathbf{6 0 0 . 4}$ & $\mathbf{\$ 3 7 1 3 . 8}$ \\
\hline Tunisia & 397.1 & 180.2 & $\mathbf{5 7 7 . 3}$ & \\
\hline
\end{tabular}

Note: These figures include both primary and secondary wellness trips. Expenditures data combine both international/inbound and domestic wellness tourism spending. Source: Estimates by the Global Wellness Institute, based upon tourism industry data from Euromonitor International

\section{Wellness Tourism Spending Premiums in the Top Ten Markets, 2017}

\begin{tabular}{|c|c|c|c|c|}
\hline & \multicolumn{2}{|c|}{$\begin{array}{c}\text { Average Spending per } \\
\text { INBOUND/INTERNATIONAL Trip }\end{array}$} & \multicolumn{2}{|c|}{$\begin{array}{l}\text { Average Spending per } \\
\text { DOMESTIC Trip }\end{array}$} \\
\hline & Wellness Trip & Average Trip & Wellness Trip & Average Trip \\
\hline UAE & $\$ 2,046$ & $\$ 1,451$ & $\$ 2,011$ & $\$ 1,284$ \\
\hline Morocco & $\$ 956$ & $\$ 636$ & $\$ 309$ & $\$ 197$ \\
\hline Israel & $\$ 2,453$ & $\$ 1,621$ & $\$ 557$ & $\$ 354$ \\
\hline Jordan & $\$ 1,701$ & $\$ 1,138$ & $\$ 523$ & $\$ 334$ \\
\hline Bahrain & $\$ 1,821$ & $\$ 919$ & $\$ 1,229$ & $\$ 784$ \\
\hline Saudi Arabia & $\$ 940$ & $\$ 626$ & $\$ 705$ & $\$ 443$ \\
\hline Oman & $\$ 1,904$ & $\$ 1,217$ & $\$ 416$ & $\$ 265$ \\
\hline Egypt & $\$ 601$ & $\$ 398$ & $\$ 78$ & $\$ 50$ \\
\hline Iran & $\$ 1,168$ & $\$ 785$ & $\$ 215$ & $\$ 137$ \\
\hline Tunisia & $\$ 623$ & $\$ 255$ & $\$ 367$ & $\$ 241$ \\
\hline
\end{tabular}

Note: These figures include both primary and secondary wellness trips. Source: Estimates by the Global Wellness Institute, based upon tourism industry data from Euromonitor International 


\section{Middle East-North Africa Wellness Tourism Developments}

- Several Middle East and North Africa region countries prominently promote wellness tourism on their national tourism websites, but many focus exclusively on spas (e.g., Dubai, Abu Dhabi, Qatar, Morocco, and Egypt). Tunisia and Algeria tend to highlight their traditional thermal offerings, while Jordan promotes a diverse wellness tourism experience that extends from natural healing around the Dead Sea, to spas and meditation tourism. Israel has leveraged the therapeutic properties of the Dead Sea for wellness tourism as well as promoting skincare/ cosmetic products. However, thousands of sinkholes have closed down beaches, damaged resorts, and halted developments, highlighting the conflict between fragile natural resources and the tourism and economic development that depends on them.

- Many regions within Egypt are historically famous for therapeutic tourism anchored on unique natural features, e.g., the black sands of the Safaga/Red Sea region, the sand baths and hot springs in the Siwa Oasis, and sulfur springs in Helwan. These regions currently receive local and regional tourists, and their offerings tend to be European-style natural resourcebased therapies that occupy the grey area between wellness and medical tourism. National and regional government authorities (including Ministries of Environment and Health) have recently started to redevelop and promote these regions, and they are seeking investments to build new therapeutic and wellness resorts.

- While wellness tourism in the Gulf region continues to be dominated by secondary wellness travelers - those who have come to expect extensive spa and fitness facilities in both city and resort hotels when they travel - the region is starting to develop offerings that cater to primary wellness travelers. The Gulf's first holistic wellness retreat/destination spa opened at the Retreat Palm Dubai in 2017, and the integrative Zalal Wellness Destination Retreat is currently under construction in Qatar. The healthy hotel concept is also growing in the region. The Al Shaqab healthy/active lifestyle concept hotel opened in Qatar's Education City in 2016. In Dubai, Smartotels is launching its FORM Hotel concept in 2018, focused on wellbeing, lifestyle, and technology-driven and socially-responsible design.

- Several Gulf country governments (e.g., Bahrain, Kuwait, Saudi Arabia) are looking to tourism for economic diversification strategy and investing in large-scale resort spa developments. They often use "health tourism" as an umbrella term to capture both wellness tourism and medical tourism, which they are also targeting. Some countries are spending billions of dollars to build large-scale mixed-use projects that combine residential, tourism/hospitality, commercial, and health/medical components, aiming to promote tourism and economic development while encouraging healthy lifestyles among the local population. Most of these projects include green/sustainable building, outdoor and fitness amenities, world-class medical services, alternative/complementary wellness services, and other offerings for residents and visitors. Examples include the Dubai Healthcare City/WorldCare Wellness Village in UAE; the Dilmunia Island project in Bahrain; the Kuwait Silk City project, and the Qatar Foundation Stadium and Health \& Wellness Precinct/Education City project. 


\section{Spas}

- This region has long had a reputation for leisure, shopping, and beach tourism, and the spa sector may be finally catching up with its highly developed hospitality industry. Hotels continue to be built at a rapid pace, and spas are now seen as integral/central part of hotels from the mid-price ranges and up. Some hotels leverage the region's hammam tradition to create a more culturally authentic experience. The UAE and Qatar have benefitted from significant investments in new hotels and resort properties in preparation for Expo 2020 and the FIFA World Cup 2022. A number of high-end spas have been planned or opened recently in new hotels and resorts, and as part of entertainment/retail complexes in Doha and UAE. Across the Middle East and North Africa, a rising consumer preference for healthy lifestyles has increased demand for wellness services, especially in spa and fitness. Saudi Arabia is often regarded as a high-potential market with its rapidly growing population, rising incomes, and a growing chronic disease epidemic.

- Spas in the region have long been associated with beauty and pampering. The UAE continues to be the region's largest spa market, with its cosmopolitan residents increasingly adopting health and wellness lifestyles that include spa-going, fitness, and healthy eating. The market serves a diverse customer base, including middle/professional-class expatriates, wealthy Emiratis, and European tourists who expect high quality services. Increasing demand for spa/wellness services and programming has driven growth in hotel and resort spas, as well as international brands, chains, and franchises, enhancing treatment offerings at a variety of price points. Competition is especially tough in the day spa market, where new entrants and aggressive promotion and discounting have created intense price pressures for many businesses. 


\section{Thermal/Mineral Springs}

- Tunisia and Algeria have the region's most established thermal bathing and thalassotherapy sectors, rooted in the French tradition of "thermalisme." In recent years, many formerly medical-oriented thermal centers have been adding complementary spa treatments, recreational options, lodging, and other offerings to attract wellness tourists. Governments in both countries have long supported the therapeutic and medical use of thermal/mineral/sea waters, and both countries have national tourism strategies that leverage thermal resources for diversification and growth. Several major projects are underway throughout Tunisia, where there are plans to privatize some of the historic thermal centers and build 54 new ones by 2020. There are many new developments in Algeria, where 70 springs have been granted to private investors, 13 new private facilities have opened, and \$100 million is being invested to modernize eight publicly-owned thermal centers and 40 traditional thermal hammams. Both countries are also raising quality standards through workforce training (Algeria) and new ISO certification for thalassotherapy facilities (Tunisia).

- Meanwhile, several countries that do not have an established hot springs industry or tradition are recognizing the value of these natural resources for tourism development. For example, Oman is now promoting its natural springs on its national tourism website. Saudi Arabia is promoting investment in hot springs to establish therapeutic, recreational, and wellness resorts that will attract domestic and regional tourists for both wellness and medical tourism. Even Iraq has recently reopened its historic Hammam al-Alil, a historic hot springs facility that used to receive thousands of wellness and medical tourism visitors prior to the war. 


\section{Sub-Saharan Africa Wellness Tourism Highlights (2017)}

Number of Wellness Trips: 6.5 million (10.1\% CAGR from 2015-2017)

(101)

Wellness Tourism Expenditures: $\$ 4.8$ billion (7.0\% CAGR from 2015-2017)

Projected Wellness Tourism Expenditures CAGR (2017-2022): 11.1\%

Average Expenditure per Trip:

$\$ 1,215$ for intl./inbound (63\% premium); $\$ 194$ for domestic (126\% premium)

Direct Jobs: 0.5 million

Top Ten Wellness Tourism Markets in Sub-Saharan Africa, 2017

\begin{tabular}{l|r|r|r|r} 
& \multicolumn{3}{c|}{$\begin{array}{c}\text { Number of Arrivals/Trips } \\
\text { (thousands) }\end{array}$} & \multicolumn{1}{c}{$\begin{array}{c}\text { Receipts/Expenditures } \\
\text { (US\$ millions) }\end{array}$} \\
\cline { 2 - 5 } & Inbound/Intl. & \multicolumn{1}{c}{ Domestic } & \multicolumn{1}{c}{ Total } & $\mathbf{\$ 2 , 2 5 0 . 3}$ \\
\hline South Africa & $1,466.9$ & $2,555.7$ & $\mathbf{4 , 0 2 2 . 6}$ & $\mathbf{\$ 4 1 2 . 3}$ \\
\hline Kenya & 212.6 & 57.0 & $\mathbf{2 6 9 . 6}$ & $\mathbf{\$ 3 1 5 . 1}$ \\
\hline Mauritius & 184.1 & 1.8 & $\mathbf{1 8 6 . 0}$ & $\mathbf{\$ 3 0 2 . 7}$ \\
\hline Tanzania & 169.2 & 43.7 & $\mathbf{2 1 2 . 9}$ & $\mathbf{\$ 2 8 2 . 8}$ \\
\hline Seychelles & 105.3 & 4.3 & $\mathbf{1 0 9 . 7}$ & $\mathbf{\$ 1 4 6 . 6}$ \\
\hline Uganda & 143.7 & 39.1 & $\mathbf{1 8 2 . 8}$ & $\mathbf{\$ 1 3 4 . 0}$ \\
\hline Nigeria & 101.7 & 24.9 & $\mathbf{1 2 6 . 6}$ & $\mathbf{\$ 1 2 0 . 5}$ \\
\hline Madagascar & 59.1 & 16.0 & $\mathbf{7 5 . 1}$ & $\mathbf{\$ 1 1 7 . 8}$ \\
\hline Zimbabwe & 136.1 & 51.0 & $\mathbf{1 8 7 . 2}$ & $\mathbf{\$ 1 1 5 . 0}$ \\
\hline Botswana & 197.0 & 71.7 & $\mathbf{2 6 8 . 7}$ & \\
\hline
\end{tabular}

Note: These figures include both primary and secondary wellness trips. Expenditures data combine both international/inbound and domestic wellness tourism spending. Source: Estimates by the Global Wellness Institute, based upon tourism industry data from Euromonitor International

\section{Wellness Tourism Spending Premiums in the Top Ten Markets, 2017}

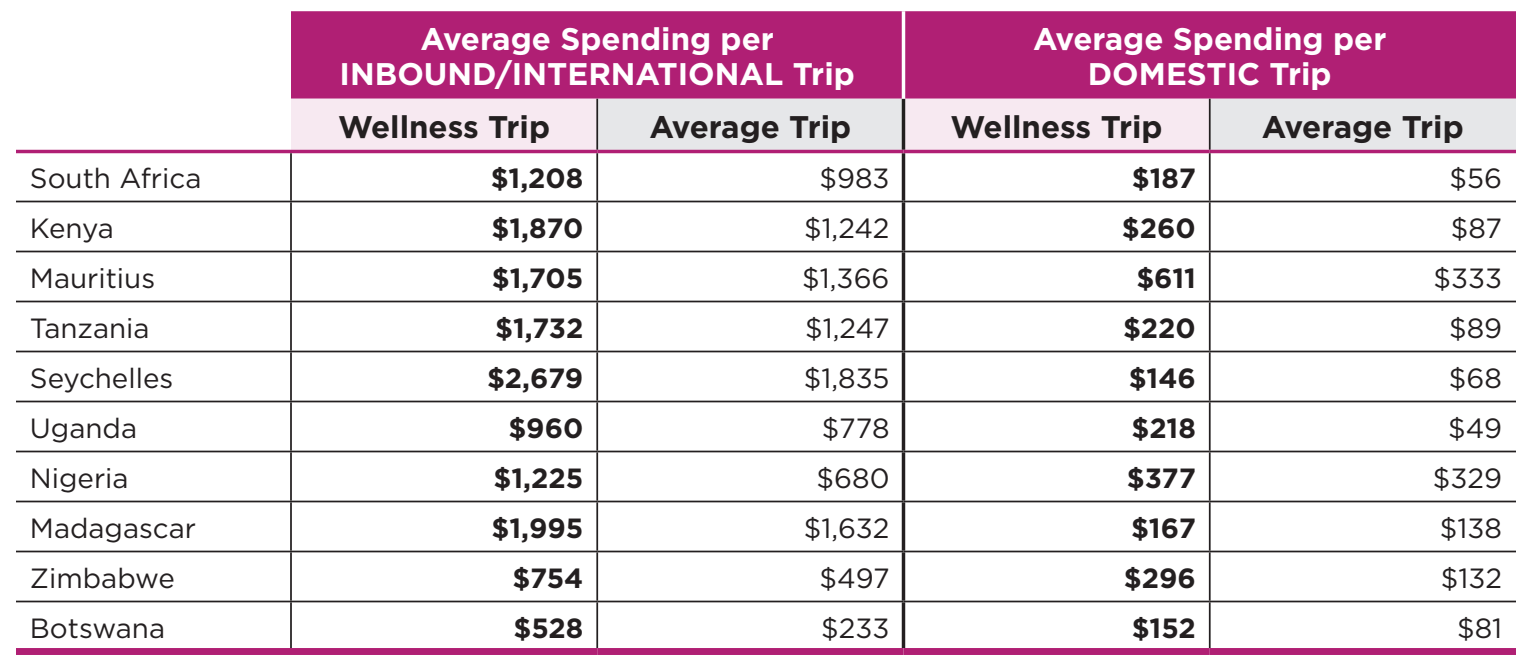

Note: These figures include both primary and secondary wellness trips. Source: Estimates by the Global Wellness Institute, based upon tourism industry data from Euromonitor International 


\section{Sub-Saharan Africa Wellness Tourism Developments}

- Several African countries are actively promoting wellness tourism, including Mauritius, Namibia, South Africa, and Tanzania, primarily focusing on spa offerings to diversify from the traditional safari or beach tourism for international visitors. By comparison, no countries in Africa were promoting wellness tourism when GWI first started studying this sector in 2013. While "spafari" - high-end safari lodges that offer spas services - has been around for a while, many destinations have moved from a spa/pampering focus to holistic wellness, adding offerings such as "mindfulness safaris," "yoga in the wilderness," and "body treatments in the bush," and incorporating local ingredients and treatments/therapies rooted in African traditions.

- All across Africa, from island resort destinations (e.g., Seychelles, Mauritius, Madagascar) to the Southern and Eastern African nations strong in the safari/wildlife/ecotourism niche, destinations are adding wellness offerings to their product mix. We have also seen tremendous growth in the number of wellness retreats and yoga retreats in Africa, combining wellness with complementary travel interests in the eco, adventure, spiritual, and cultural categories. The natural beauty and wilderness across this vast continent create unique opportunities, such as stargazing in Namibia, meditation among wildlife in Zambia, and long uninterrupted beach walks in Mozambique.

- Overall, wellness tourism has the potential to offer enormous economic, social, conservation, and branding benefits to the African continent. Tourism has long been an ambassador industry for any country or region. With its focus on holistic health, healing, and authentic experiences, wellness tourism highlights and promotes a country's strengths that are rooted in nature, culture, heritage, and traditions. These are strong counters to the negative images often promoted in the media about Africa (e.g., underdevelopment, disease, political instability, etc.). Because indigenous culture and the environment are so important in this niche market, wellness tourism can increase the motivations among government, businesses, and communities to protect wildlife, natural resources, and local culture and promote environmental sustainability. As a continent, Africa consists of dozens of countries, each with unique cultures and traditions in wellness. With wellness experiences increasingly linked to the wellness of the place, wellness tourists are more aware of and interested in what each destination has to offer, the local people, and their communities. Therefore, it will be important in Africa to ensure that wellness tourism development is aligned with the development needs of local communities and brings benefits in all aspects (economic, social, environmental, etc.). 


\section{Spas}

- Many countries in Sub-Saharan Africa have well-established spa industries (e.g., South Africa, Nigeria, Kenya, Mauritius, etc.) but in most countries, spa clients are expats or wealthy/uppermiddle-class consumers who have traveled internationally and have been exposed to spas elsewhere. While this is changing, the perception of spa as a luxury service for the wealthy can narrow the market growth opportunities. Other forces that may hold back the industry include the lack of standards/regulations and skilled workforce.

- In the past, spa offerings/products/menus have been relatively homogenous and based on western spa models. In recent years, there is increasing interest in and demand for uniquely African wellness treatments and healing traditions. Offerings from calabash massage to the izinyawo foot cleanse to drumming meditation and healing are increasingly appearing in spas across the region. There is also rising demand for homegrown products and brands, especially herbal blends and natural and organic beauty/skin care products that are rooted in local ingredients and traditions. Many African ingredients (e.g., argan oil, shea butter, rooibos, etc.) have already found their way into mainstream beauty/skin products around the world. There is also more awareness of the need to cater to different skin types. With consumer interest pushing the global beauty/skincare industry toward natural and new botanical ingredients, the continent's rich cultural heritage and biodiversity offers exciting opportunities.

\section{Thermal/Mineral Springs}

- Many countries in Sub-Saharan Africa are rich in thermal waters, but the thermal/mineral bathing sector remains primitive and underdeveloped across the region. South Africa is the only country with a significant thermal/mineral springs industry. Its hot spring resorts tend to focus on recreation and leisure (rather than health and wellness offerings), and most offer relatively rustic accommodations (e.g., camping, cabins, and self-catering chalets). These almost exclusively serve the domestic market. A number of historic hot springs resorts in South Africa, dating from the early 20th century, have fallen into disuse and disrepair, and efforts to renovate and revitalize these facilities have been limited and small in scale. Meanwhile, Namibia recently made significant investments in modernizing its two major hot springs resorts (Gross Barmen in 2014 and Ai-Ais in 2017), and Madagascar has renovated and reopened its historic Hotel Thermal Ranomafana.

- Kenya and Rwanda, both of which have robust and high-growth tourism industries, are now looking to tap their undeveloped thermal water resources to boost wellness tourism. Thermal/ mineral waters can help diversify their tourism offerings and can appeal to wealthy, safariseeking international visitors as well the growing market of intra-regional African travelers. Rwanda is currently seeking investment to develop its first hot springs-based wellness and eco resorts (at Gihaya Island and Rubavu). Kenya recently opened the KenGen Olkaria Geothermal Spa, the continent's largest thermal bathing facility, modeled after Iceland's Blue Lagoon. 
68 | Global Wellness Institute 


\section{APPENDIX A: COUNTRIES CURRENTLY PROMOTING WELLNESS TOURISM}

This list is current as of August 2018.

\section{Asia-Pacific}

\begin{tabular}{|c|c|c|c|}
\hline & $\begin{array}{c}\text { National/Official } \\
\text { Tourism Website } \\
\text { Promotes Wellness } \\
\text { Tourism }\end{array}$ & $\begin{array}{l}\text { National Tourism } \\
\text { Strategy Addresses } \\
\text { Wellness Tourism }\end{array}$ & $\begin{array}{l}\text { Wellness Tourism Is } \\
\text { a Target for National } \\
\text { Investment Promotion }\end{array}$ \\
\hline Australia & Yes & No & No \\
\hline Bhutan & Yes & Yes & Yes \\
\hline Cambodia & Yes & No & No \\
\hline China & No & Yes & Yes \\
\hline Fiji & Yes & No & Yes \\
\hline $\begin{array}{l}\text { French } \\
\text { Polynesia }\end{array}$ & Yes & No & No \\
\hline Guam & Yes & No & No \\
\hline India & Yes & Yes & Yes \\
\hline Indonesia & Yes & No & No \\
\hline Japan & Yes & No & No \\
\hline Laos & Yes & No & No \\
\hline Malaysia & Yes & Yes & Yes \\
\hline Maldives & Yes & Yes & Yes \\
\hline Nepal & Yes & No & No \\
\hline New Caledonia & Yes & No & No \\
\hline New Zealand & Yes & No & Yes \\
\hline Philippines & Yes & Yes & Yes \\
\hline Samoa & Yes & No & No \\
\hline South Korea & Yes & Yes & No \\
\hline Sri Lanka & yes & No & No \\
\hline Taiwan & Yes & No & Yes \\
\hline Thailand & No & Yes & No \\
\hline Vietnam & Yes & Yes & No \\
\hline
\end{tabular}




\section{Europe}

\begin{tabular}{|c|c|c|c|}
\hline & $\begin{array}{c}\text { National/Official } \\
\text { Tourism Website } \\
\text { Promotes Wellness } \\
\text { Tourism }\end{array}$ & $\begin{array}{l}\text { National Tourism } \\
\text { Strategy Addresses } \\
\text { Wellness Tourism }\end{array}$ & $\begin{array}{l}\text { Wellness Tourism Is } \\
\text { a Target for National } \\
\text { Investment Promotion }\end{array}$ \\
\hline Andorra & Yes & Yes & No \\
\hline Armenia & Yes & Yes & No \\
\hline Austria & Yes & No & No \\
\hline Azerbaijan & No & Yes & Yes \\
\hline $\begin{array}{l}\text { Bosnia } \\
\text { Herzegovina }\end{array}$ & Yes & No & No \\
\hline Bulgaria & Yes & Yes & Yes \\
\hline Croatia & Yes & Yes & Yes \\
\hline Cyprus & Yes & No & No \\
\hline Czech Republic & Yes & Yes & No \\
\hline Denmark & Yes & No & No \\
\hline Estonia & Yes & Yes & Yes \\
\hline Finland & Yes & Yes & Yes \\
\hline France & Yes & Yes & $\mathrm{Np}$ \\
\hline Georgia & Yes & Yes & Yes \\
\hline Germany & Yes & No & No \\
\hline Greece & Yes & No & No \\
\hline Hungary & Yes & Yes & Yes \\
\hline Iceland & Yes & No & No \\
\hline Ireland & Yes & No & No \\
\hline Italy & Yes & No & No \\
\hline Kazakhstan & Yes & Yes & No \\
\hline Kyrgyzstan & Yes & No & No \\
\hline Latvia & Yes & Yes & No \\
\hline Lithuania & Yes & Yes & Yes \\
\hline Luxembourg & Yes & No & No \\
\hline Malta & Yes & No & No \\
\hline Monaco & Yes & No & No \\
\hline Montenegro & Yes & Yes & Yes \\
\hline Netherlands & Yes & No & No \\
\hline Norway & Yes & No & No \\
\hline Poland & Yes & Yes & Yes \\
\hline Portugal & Yes & No & No \\
\hline Romania & Yes & Yes & Yes \\
\hline Serbia & Yes & Yes & Yes \\
\hline Slovakia & Yes & Yes & Yes \\
\hline Slovenia & Yes & Yes & Yes \\
\hline
\end{tabular}




\begin{tabular}{l|l|l|l}
\hline Spain & Yes & No & No \\
\hline Sweden & Yes & No & No \\
\hline Switzerland & Yes & Yes & Yes \\
\hline Turkey & Yes & No & Yes \\
\hline Turkmenistan & Yes & No & No \\
\hline
\end{tabular}

\section{North America}

\begin{tabular}{|c|c|c|c|}
\hline & $\begin{array}{c}\text { National/Official } \\
\text { Tourism Website } \\
\text { Promotes Wellness } \\
\text { Tourism }\end{array}$ & $\begin{array}{l}\text { National Tourism } \\
\text { Strategy Addresses } \\
\text { Wellness Tourism }\end{array}$ & $\begin{array}{l}\text { Wellness Tourism Is } \\
\text { a Target for National } \\
\text { Investment Promotion }\end{array}$ \\
\hline \multicolumn{4}{|c|}{ United States (state-level) } \\
\hline Arizona & Yes & & \\
\hline Arkansas & Yes & & \\
\hline Colorado & Yes & & \\
\hline Connecticut & Yes & & \\
\hline Florida & Yes & & \\
\hline Hawaii & Yes & & \\
\hline Idaho & Yes & & \\
\hline Indiana & Yes & & \\
\hline Maine & Yes & & \\
\hline Michigan & Yes & & \\
\hline Nevada & Yes & & \\
\hline New Mexico & Yes & & \\
\hline Utah & Yes & & \\
\hline Vermont & Yes & & \\
\hline Virginia & Yes & & \\
\hline Washington & Yes & & \\
\hline West Virginia & Yes & & \\
\hline Wyoming & Yes & & \\
\hline \multicolumn{4}{|c|}{ Canada (provincial-level) } \\
\hline Alberta & Yes & & \\
\hline $\begin{array}{l}\text { British } \\
\text { Columbia }\end{array}$ & Yes & & \\
\hline Manitoba & Yes & & \\
\hline Ontario & Yes & & \\
\hline Saskatchewan & Yes & & \\
\hline Yukon & Yes & & \\
\hline
\end{tabular}




\section{Latin America-Caribbean}

\begin{tabular}{|c|c|c|c|}
\hline & $\begin{array}{c}\text { National/Official } \\
\text { Tourism Website } \\
\text { Promotes Wellness } \\
\text { Tourism }\end{array}$ & $\begin{array}{l}\text { National Tourism } \\
\text { Strategy Addresses } \\
\text { Wellness Tourism }\end{array}$ & $\begin{array}{l}\text { Wellness Tourism Is } \\
\text { a Target for National } \\
\text { Investment Promotion }\end{array}$ \\
\hline Anguilla & Yes & No & No \\
\hline Argentina & Yes & Yes & No \\
\hline Aruba & Yes & No & No \\
\hline Bahamas & Yes & Yes & No \\
\hline Barbados & Yes & No & No \\
\hline Bermuda & Yes & No & No \\
\hline Chile & Yes & No & No \\
\hline Colombia & Yes & No & Yes \\
\hline Costa Rica & Yes & No & Yes \\
\hline Cuba & Yes & Yes & No \\
\hline Curacao & Yes & No & No \\
\hline Dominica & Yes & Yes & Yes \\
\hline Ecuador & Yes & Yes & No \\
\hline Grenada & Yes & No & No \\
\hline Guadeloupe & Yes & No & No \\
\hline Guatemala & Yes & Yes & Yes \\
\hline Jamaica & Yes & Yes & Yes \\
\hline Mexico & Yes & No & No \\
\hline Nicaragua & Yes & Yes & No \\
\hline Peru & Yes & No & No \\
\hline St. Kitts \& Nevis & Yes & No & No \\
\hline St. Lucia & Yes & No & No \\
\hline $\begin{array}{l}\text { St. Martin / Sint } \\
\text { Maarten }\end{array}$ & Yes & No & No \\
\hline $\begin{array}{l}\text { Turks \& Caicos } \\
\text { Islands }\end{array}$ & Yes & No & No \\
\hline Uruguay & Yes & Yes & Yes \\
\hline
\end{tabular}




\section{Middle East-North Africa}

\begin{tabular}{l|c|c|c} 
& $\begin{array}{c}\text { National/Official } \\
\text { Tourism Website } \\
\text { Promotes Wellness } \\
\text { Tourism }\end{array}$ & $\begin{array}{c}\text { National Tourism } \\
\text { Strategy Addresses } \\
\text { Wellness Tourism }\end{array}$ & $\begin{array}{c}\text { Wellness Tourism Is } \\
\text { a Target for National } \\
\text { Investment Promotion }\end{array}$ \\
\hline Algeria & Yes & No & Yes \\
\hline Egypt & Yes & Yes & Yes \\
\hline Iran & No & No & No \\
\hline Israel & Yes & Yes & No \\
\hline Jordan & Yes & No & Yes \\
\hline Kuwait & Yes & Yes & Yes \\
\hline Morocco & Yes & Yes & Yes \\
\hline Oman & Yes & No & Yes \\
\hline Qatar & Yes & No & No \\
\hline Saudi Arabia & No & No & No \\
\hline Tunisia & Yes & No & \\
\hline United Arab Emirates & Yes & & Yes \\
\hline Abu Dhabi & Yes & &
\end{tabular}

\section{Sub-Saharan Africa}

\begin{tabular}{l|c|c|c} 
& $\begin{array}{c}\text { National/Official } \\
\text { Tourism Website } \\
\text { Promotes Wellness } \\
\text { Tourism }\end{array}$ & $\begin{array}{c}\text { National Tourism } \\
\text { Strategy Addresses } \\
\text { Wellness Tourism }\end{array}$ & $\begin{array}{c}\text { Wellness Tourism Is } \\
\text { a Target for National } \\
\text { Investment Promotion }\end{array}$ \\
\hline Ethiopia & No & Yes & Yes \\
\hline Ghana & No & Yes & No \\
\hline Kenya & No & Yes & No \\
\hline Mauritius & Yes & No & Yes \\
\hline Namibia & Yes & No & Yes \\
\hline Rwanda & No & No & No \\
\hline South Africa & Yes & No & No \\
\hline Tanzania & Yes & & \\
\hline & & &
\end{tabular}


74 | Global Wellness Institute 
The authors are indebted to the many industry leaders and experts who shared their time, expertise, data, and research to inform the global wellness economy data and insights:

Adriana Azuara, CEO, All4Spas, Mexico

Brian Badura, Director, Global Public Relations \& Strategic Initiatives, Seabourn Cruise Line, United States

Anna Bjurstam, Vice President of Spa \& Wellness, Six Senses Hotels Resorts Spas; Partner, Raison D’Etre, Sweden

Rocco Bova, General Manager, Chable Resort \& Spa, Mexico

Alexia Brue, Co-Founder and CEO, Well+Good, United States

Eduardo Carstens Chalita, Director, Marketing \& Sales, Groupo Megaterra, Mexico

Jorge Alfonso Carstens Chalita, Director, Marketing \& Sales, Groupo Megaterra, Mexico

Dorcas Cheung, Head of Trade Marketing, Annabelle Asia Company, Hong Kong

Jon Canarick, Managing Director, North Castle Partners, United States

Randall Corcoran, Director, Onboard Revenue, Holland America Group, United States

Des Cummings Jr., Executive Vice President, Florida Hospital, United States

Tony de Leede, Founder, Gwinganna Lifestyle Retreat, Australia

Katherine Droga, Founder, Droga \& Co., Australia

Susie Ellis, Chairman and CEO, Global Wellness Summit, United States

Sallie Fraenkel, President, Mind Body Spirit Network, United States

CG Funk, Speaker and Consultant, Beauty, Spa and Wellness, United States

Melisse Gelula, Co-Founder and Chief Content Officer, Well+Good, United States

Wendy Gelfound, Area Director of Marketing, Hospitality Division, The Howard Hughes Corporation, United States

Andrew Gibson, Chairman, Wellness Tourism Association; formerly Vice President for Wellbeing, Luxury Brands, AccorHotels, UAE

Adam Glickman, Principal, Parallax Hospitality, United States

Charlie Hartwell, Operating Partner, Bridge Builders Collaborative, United States

Mark Hennebry, Director at CP Holdings; Vice Chairman, Danubius Hotel Group, United Kingdom 
Ed Hoganson, Chief Financial Officer and Treasury, Hospitality Investors Trust, United States

David Humphrey, Chairman of the Board, Massage Heights, United States

C.K. (Chee Kwong) Low, Managing Director, HerbaLine, Malaysia

Kim Matheson Chedrick, Senior Vice President, WTS International, United States

Tomonori Maruyama, Chief Researcher \& Manager at the Research Institute, Mitsui Knowledge Industry Co., Ltd., Japan

Beth McGroarty, Director of Research and Public Relations, Global Wellness Summit, United States

Wendy Nierel-Bosalavage, President, LIVunLtd, United States

Stephanie Rest, Consultant, Caribbean Wellness \& Education, United States

Katie Roberts, Senior Director of Global Consumer Public Relations, Marriott International, United States

Melissa Rodriguez, Senior Research Manager, IHRSA, United States

Ricardo Rose, Certified Personal Trainer, Equinox and Everybody Fights, United States

Zev Suissa, Chief Innovation Officer, Strategic Partnerships, eMindful, United States

Liz Terry, CEO, Leisure Media \& CLADglobal, United Kingdom

Tom Waller, Senior Vice President of Whitespace, Lululemon, Canada

Jeff Wang, Chairman, Chongqing Hakone Hot Springs\& Thermalism Industry, China

Josef Woodman, CEO, Patients Beyond Borders, United States

Vivien Yeung, General Manager, Venture at Lululemon, Canada 


\section{INDUSTRY RESEARCH SPONSORS}

\section{Platinum Level}

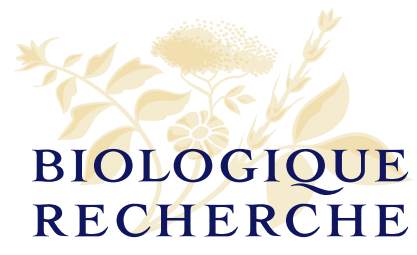

PARIS

\section{BIOLOGIQUE RECHERCHE}

For over 35 years Biologique Recherche's unique methodology has built a strong reputation for astounding effectiveness based on a clinical approach to skincare, delivering immediate and long lasting results. Combined with highly customized protocols and meticulous procedures which recondition the epidermis, Biologique Recherche's extensive range of skincare products are highly concentrated in botanical, marine and biological active ingredients that are cold formulated in its own laboratory in France. Biologique Recherche is the partner of choice in over 70 countries for exclusive medical spas and day spas in addition to the world's premiere luxury hotel spas. Visit Biologique Recherche at www.biologiquerecherche.com.

\section{CANYONRANCH.}

\section{CANYON RANCH}

Canyon Ranch ${ }^{\oplus}$ has been a trailblazer and an industry-leading proponent of the wellness lifestyle and real estate living for nearly 40 years, operating the world's most celebrated collection of lifeenhancement properties. Canyon Ranch has wellness destinations in Tucson, Arizona and Lenox, Massachusetts. In addition, Canyon Ranch operates the world's largest day spa at The Venetian ${ }^{\circledast}$ \& The Palazzo ${ }^{\oplus}$ hotels in Las Vegas, Nevada and 22 Canyon Ranch at Sea ${ }^{\oplus}$ wellness facilities onboard luxury cruise ships: Cunard Cruise Line, Oceania ${ }^{\oplus}$ Cruises, Regent Seven Seas Cruises ${ }^{\circledast}$, and on Celebrity Cruises ${ }^{\oplus}$. Canyon Ranch is a 13-time winner of Travel + Leisure's Best Spa Award, an 11-time recipient of the Condé Nast Traveler Best Destination Spa Award, is honored by Town \& Country as one of the 'Best Luxury Spas in the World' in their 2017 Spa Awards and is recognized as the 'Best Wellness Program' by Virtuoso's 'Best of the Best’ 2017 awards. Visit Canyon Ranch at www.canyonranch.com.

\section{Gold Level}

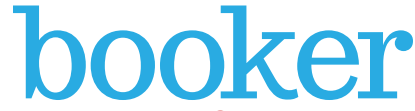

by $O$ MINDBODY.

\section{BOOKER BY MINDBODY}

Booker by MINDBODY is transforming the way beauty and wellness services are managed by local businesses and discovered by consumers. Booker replaces everything from manual methods to disconnected software, and unifies the essential components of running a service business into a single web-based platform, accessible from any device. Booker was acquired by MINDBODY, the leading technology platform for the fitness, beauty and wellness 
services industries, in April 2018. Together, Booker and MINDBODY also enable beauty and wellness businesses to sell their services online, through their website and a network of partner sites and apps, creating a seamless online booking experience for consumers. For more information on Booker, visit www.booker.com, and for more on how MINDBODY is helping people lead healthier, happier lives by connecting the world to wellness, visit www.mindbodyonline.com.

\section{HYDRAFACIAL}

hydrafacial

The HydraFacial Company is revolutionizing skin health for aesthetic professionals and their clients. Innovating for over 20 years, we have 54 patents issued/pending and numerous awards including New Beauty's Best, 4 years running. We are loved around the world, found in over 10,000 locations throughout 80 countries. The HydraFacial is a 3-step, 30-minute treatment that cleanses, extracts, and hydrates while quenching skin with vital nutrients like antioxidants, peptides, and hyaluronic acid. The amazing results are both instant and long-lasting, improving the appearance of fine lines, enlarged pores, congested skin, and dark spots. For more information, visit HydraFacial at www.HydraFacial.com.

Silver Level $\underset{\text { Feel welcome }}{\operatorname{ACCOR} \text { HOTS }}$

\section{bodyholiday.} Saint Lucia

\section{ACCORHOTELS}

AccorHotels is a world-leading travel \& lifestyle group offering unique experiences in more than 4,500 hotels, resorts and residences across 100 different countries. With an unrivaled portfolio of internationally renowned brands, including luxury offerings such as Raffles, Fairmont and Sofitel, AccorHotels seeks to create meaningful connections between its guests, hotel colleagues, brands, destinations and communities in which it operates. Relying on its global team of more than 250,000 dedicated staff, AccorHotels is committed to fulfilling its primary mission: to make every guest Feel Welcome. For more information or to make a reservation, please visit accorhotels.group or accorhotels.com.

\section{BODYHOLIDAY}

BodyHoliday in Saint Lucia is not only a great beach vacation but it has been famed for its unique approach to health and wellbeing. The experience is a combination of the very best of a vacation combining individual tailored classes in fitness, nutrition, lifestyle and overall wellness. It is designed to be the most relaxing, rejuvenating beach vacation in the world. BodyHoliday makes a promise, "Give us your body for a week and we'll give you back your mind". It offers a range of personalized treatment, therapies while taking advantage of the most comprehensive activity and exercise schedules. What makes it 


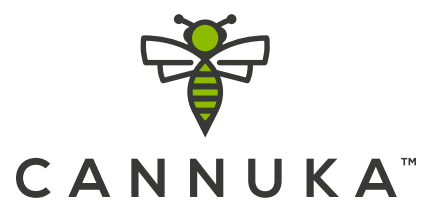

HERBALIFE NUTRITION Making the World Healthier and Happier
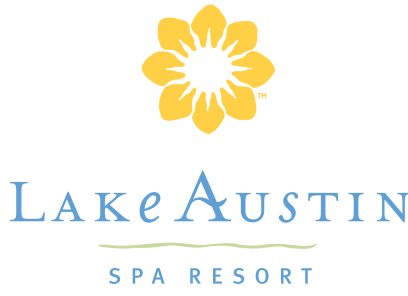

great is that you can do as much or as little as you like; enjoy an active fun filled vacation or choose to lie back and do nothing at all! Visit BodyHoliday at www.thebodyholiday.com.

\section{CANNUKA}

Cannuka is a medically inspired natural skincare line that combines two powerful ingredients; cannabis CBD and Manuka honey. Together, the unique healing properties of cannabis CBD and Manuka honey provide a daily skin therapy that both calms and heals skin - for your face, lips, cuticles, elbows, and anywhere else there's dryness or inflammation. In fact, it's the natural, potent anti-inflammatory characteristics of the ingredients that make it so effective. Inflammation is the one constant in skin problems, and Cannuka is specifically designed to help reduce inflammation and soothe skin. Visit Cannuka at www.cannuka.com.

\section{HERBALIFE NUTRITION}

Herbalife Nutrition is a global nutrition company whose purpose is to make the world healthier and happier. We have been on a mission for nutrition - changing people's lives with great nutrition products \& programs - since 1980. Together with our Herbalife Nutrition independent distributors, we are committed to providing solutions to the worldwide problems of poor nutrition and obesity, an aging population, skyrocketing public healthcare costs and a rise in entrepreneurs of all ages. We offer high-quality, sciencebacked products, one-on-one coaching with an Herbalife Nutrition independent distributor, and a supportive community approach that inspires customers to embrace a healthier, more active lifestyle. Visit Herbalife Nutrition at www.herbalife.com.

\section{LAKE AUSTIN SPA RESORT}

The award-winning 40-room luxury wellness resort in Austin, Texas has been at the forefront of organic gardening and healthy cuisine for 20 years. Today, a luxe water taxi transports guests to the idyllic lakeside destination to enjoy science backed wellness classes on the water, Culinary Experience weeks and cooking classes, hiking, yoga and more than 130 weekly classes. Over 100 unique and healing services are offered at the resort's 25,000-square foot LakeHouse Spa. Sublime interiors with original art and antiques, coupled with breathtaking interactions in nature and Conscientious Cuisine prepared by Executive Chef Stéphane Beaucamp create an immersive wellness experience for guests seeking respite and retreat. Visit Lake Austin Spa Resort at www.lakeaustin.com. 


\section{M/RAVAL。 - exhale}

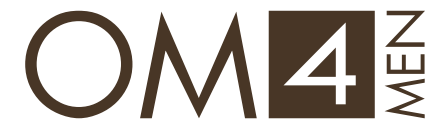

PRECISION SKIN SOLUTIONS 4 MEN
MIRAVAL AND EXHALE

Hyatt's wellness brands are Miraval and exhale. Miraval is a global leader in wellness resorts and spas. Opened in 1995 Miraval Arizona pioneered the destination wellness spa resort category with its comprehensive program of activities, experiences, and personal treatments. Miraval's core is mindfulness, and its motto "life is better when in balance" guides each visit. Activities include fitness, meditation, yoga, well-being, equine, hiking, biking, and metaphysical exploration. Miraval Life in Balance Spa opened in April 2016 at Monarch Beach Resort in Dana Point, CA, and in November 2017 at Park Hyatt St. Kitts Christophe Harbour. Additionally, Miraval will unveil two new properties including Miraval Austin in Fall 2018 and Miraval in the Berkshires in 2019. With 24 locations worldwide, exhale offers a combination of cardio, barre, and yoga classes along with healing spa therapies, providing a sanctuary for people to escape the day-to-day and take time to be well. Visit Miraval Group at www. miravalresorts.com and exhale at www.exhalespa.com.

\section{OM4 ORGANIC MALE}

OM4 Organic Male is the first skin type and condition-specific professional men's line to launch in the US. On the leading edge of performance-based, green science organics, OM4 globally sources clinically-advanced, socially-responsible ingredients to target the unique biological skin differences and concerns of men. The brand mantra: 4 PRODUCTS | 4 STEPS | 4 MINUTES | 4 MEN. Color coded by skin type with each step numbered, OM4 is intuitively designed to be fast, easy and effective. OM4's core business is to help partners: (1) grasp the psychology of selling to men, and (2) capture a greater percentage of the fastest growing market in spa. Visit OM4 Organic Male at www.om4men.com.

\section{PERFORMANCE HEALTH' \\ Feel Good Live Great ${ }^{\text {tw }}$}

\section{PERFORMANCE HEALTH}

Headquartered in Akron, Ohio, Performance Health is a leading designer, manufacturer and marketer of branded massage, spa, rehabilitation, and wellness products sold into a variety of U.S. clinical markets, leading national retailers and in over one hundred countries through a multi-national network of distribution partners. The Company's product offering includes an innovative line of marketleading topical analgesics, professional massage products and a broad range of rehabilitation and wellness products. Performance Health markets its diverse product offering under the well-known and highly recognized TheraBand ${ }^{\circledast}$, Biofreeze ${ }^{\circledR}$, Cramer $^{\circledast}$, Bon Vital' ${ }^{\circledR}$, Thera $^{\circ}$ Pearl $^{\circledR}$ and Perform ${ }^{\circledR}$ brand names.Visit Performance Health at www.performancehealth.com. 


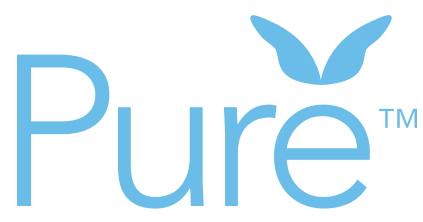

PURE

Founded in 2003 PURE is the global leading provider of healthy indoor spaces. With locations serving 15 international markets, PURE has partnered with industry leaders in hospitality, maritime, fitness, scholastic, office and residential applications. PURE's patented seven step Wellness program purifies every surface and air particle, providing environments that exceed industry standards by more than $50 \%$. Whether you're traveling for business, cruising for pleasure, providing the healthiest work or fitness environment, PURE's wellness environments are a sanctuary of peace, health and tranquility. Every surface is allergy friendly, and the air is as pure as an ocean breeze. You can feel fresher, breathe deeper, and live better. Currently over 2.5 million people per month experience PURE Wellness spaces. Winner of the innovation award from the School of Hospitality Management at Cornell, and the coveted Parent Tested Parent Approved seal of approval award, PURE is evolving quickly as the number one name in indoor environmental quality and wellness. Visit PURE at WwW. purespaces.com.

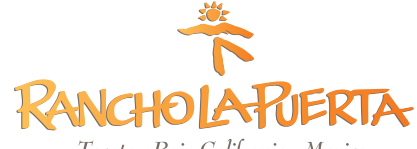

Tecate - Baja California $\cdot$ Mexico

\section{RANCHO LA PUERTA}

Each week guests at Rancho La Puerta Fitness Resort and Spa in Tecate, Baja California, Mexico, renew their minds, bodies, and spirits on a journey to true wellness. Founded in 1940, The Ranch pioneered the concept of a true destination spa, for both its guests and employees. Over 440 employees and their families are part of the Employee Wellness Program, which provides daily fitness classes, complimentary medical services, and healthy living workshops on topics such as chronic disease prevention and nutrition. The Ranch is dedicated to ensuring that both guests and employees live long, healthy, active, and inspired lives. Visit Rancho La Puerta at www. rancholapuerta.com.

\section{serenbe}

\section{SERENBE}

Serenbe is the leading global wellness community focused on all aspects of a well-lived life. Featuring a range of homes, an organic farm, a wellness center, Swim Club, arts and cultural programing, multiple restaurants and boutiques plus over 15 miles of nature trails, all set within hundreds of acres of preserved land. Serenbe is a biophilic model for building community with nature first and wellbeing at its core. Walk out your back door into nature and out your front door for a world-class meal; the best reason to live here is the life here. Visit Serenbe at www.serenbe.com. 


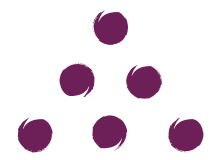

SIX SENSES

HOTELS RESORTS SPAS

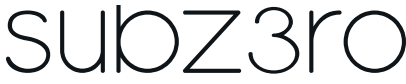

recovery beautify energize

\section{SIX SENSES}

Six Senses Hotels Resorts Spas are discovered in some of the world's most beautiful places. They are synonymous with a unique style authentic, personal and sustainable, and in harmony with individual surroundings; local, yet in tune with the wider world. They are intimate, offering an emotionally intelligent approach to anticipative service, which supports delightful and unexpected surprises. Crafted guest experiences stimulate, energize and revitalize the human spirit, spa and wellness programming is all pervasive. All aspects of Six Senses' operations, including the Evason brand, embrace these values, which define the brand and the enduring Six Senses mission: To help people reconnect with themselves, others and the world around them. Visit Six Senses at www.sixsenses.com.

\section{SUBZ3RO}

Founded in 2016, the subz3ro experience takes the spa concept on a new dimension where ground-breaking and innovative cold therapy treatments are taking the wellness sector by storm. Recently recognized as Top Luxury Spa Mexico and Global Leader in Cryotherapy, subz3ro specializes in cryostimulation - a form of Cold Therapy, which safely reduces the skin's surface temperature below zero, reducing the body's chronic inflammation and improving overall wellness. Although often considered a recovery treatment for elite athletes, subz3ro's success has been its focus on leveraging cryostimulation as an alternative to invasive treatments such as BOTOX $^{\circledR}$ and PRP, reducing cellulite and spider veins to rejuvenate and enhance the appearance and feel of the skin. Visit subz3ro at www.subz3ro.mx.

\section{UNIVERSAL COMPANIES}

For more than 30 years, over 30,000 spa professionals in 47 countries have trusted Universal Companies to be their single-source supplier, providing thousands of products to help them manage and grow their businesses. Located in beautiful and historic Abingdon, Virginia, we distribute furniture, fixtures, equipment, implements, supplies, and spa apparel to customers from the largest spa to the independent practitioner. Universal Companies also offers professional skin and body products, retail items, and merchandising tools, and provides spas with innovative consulting services, educational materials, and training options. For more information about Universal Companies, please call 800-558-5571 or visit www.universalcompanies.com. 


\section{WESTIN}

HOTELS \& RESORTS

\section{WESTIN HOTELS \& RESORTS}

Westin Hotels \& Resorts, a leader in wellness and hospitality for more than a decade, empowers guests and associates to take back control of their well-being while traveling through the brand's Six Pillars of Well-Being: Sleep Well, Eat Well, Move Well, Feel Well, Work Well and Play Well. At more than 220 hotels and resorts in nearly 40 countries and territories, guests can experience offerings that include the iconic Heavenly ${ }^{\circledast}$ Bed, RunWESTIN ${ }^{\top M}$, TRX $^{\circledR}$ Suspension Training equipment, Peloton and Westin Gear Lending with New Balance, among others. To learn more, visit www.westin.com. Stay connected to Westin: @ westin on Twitter and Instagram and facebook.com/Westin. 


WE ACKNOWLEDGE AND THANK OUR INDUSTRY RESEARCH SPONSORS

WHO MADE THIS REPORT POSSIBLE:

\author{
Biologique Recherche \\ Canyon Ranch \\ Booker by MINDBODY \\ HydraFacial \\ AccorHotels \\ BodyHoliday \\ Cannuka \\ Herbalife Nutrition \\ Lake Austin Spa Resort \\ Miraval and exhale \\ OM4 Organic Male \\ Performance Health \\ PURE \\ Rancho La Puerta \\ Serenbe \\ Six Senses \\ Subz3ro \\ Universal Companies \\ Westin Hotels \& Resorts
}

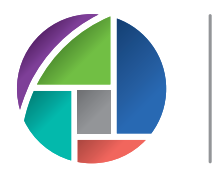

\title{
GLOBAL WELLNESS
}

INSTITUTE $^{\text {TM }}$

EMPOWERING WELLNESS WORLDWIDE

333 S.E. 2nd Avenue, Suite 2048

Miami, FL 33131, USA

www.globalwellnessinstitute.org 